SERVIÇO DE POS-GRADUAÇÃO DO ICMC-USP Data de Depósito......................

Assinatura:........marili duade

\title{
Implementação do Algoritmo \\ Paralelo para o Problema de Roteamento de Dados no Computador Paralelo IBM-SP2
}

Fábio Hernandes

Orientadora: Prof ${ }^{a}$. $\mathrm{Dr}^{\mathrm{a}}$. Cassilda Maria Ribeiro

Dissertação apresentada ao Instituto de Ciências Matemáticas e de Computação - USP, como parte dos requisitos para a obtenção do título de Mestre em Ciências - Área de Ciências de Computação e Matemática Computacional.

USP - São Carlos

Maio/1999 
Dedico esta dissertação aos meus pais, José e Maria. 


\section{AGRADECIMENTOS}

A DEUS pelo dom da vida, por me conceder saúde, por iluminar meu caminho e por me abençoar na realização de todos os meus deveres.

À minha família, aos meus pais José e Maria, aos meus irmãos André, Ricardo e Henrique, pelo incentivo, apoio, compreensão e carinho

À Cassilda pela orientação, disponibilidade e atenção, pela compreensão, respeito e paciência, pelo apoio, incentivo e amizade, que foram fundamentais para a realização deste trabalho.

Ao Fredson pela ajuda durante a fase de implementação deste projeto, principalmente na implementação em paralelo.

Ao Paulo (LaSDPC) e ao Rogério (CISC) pelas sugestões dadas durante a implementação em paralelo.

Aos amigos de república: Carlos Eduardo (Dudu) e Emerson pela amizade, incentivo, contribuição, paciência e pelas festas.

Aos meus amigos: Maju, Selma e Sílvio, pela grande amizade e incentivo, pelas longas noites de estudo durante a fase de curso das disciplinas, pelas festas e pela contribuição para a realização deste trabalho.

Aos amigos: Juliana, Lilian (Lidiane), Luciane, Ricardo, Sandra, Luciana, Luiz Fernando, José Geraldo, Denilson, Igor, Maristela, Marcelo, Alessandra e Vanessa, pelo incentivo e pelos momentos de descontração.

Ao pessoal do GOU "Sal \& Luz", pela amizade, conversas e conselhos que foram fundamentais em certos momentos.

Aos funcionários do instituto pela atenção, competência e disposição com que sempre me trataram.

A todos que de alguma forma participaram direta ou indiretamente para a realização deste trabalho.

Ao CNPq pelo apoio financeiro. 


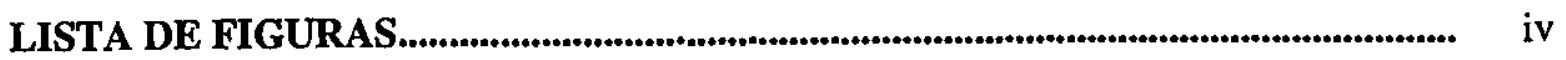

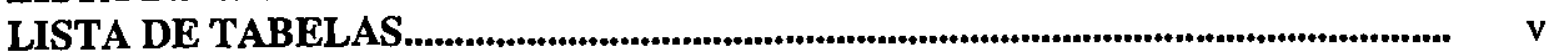

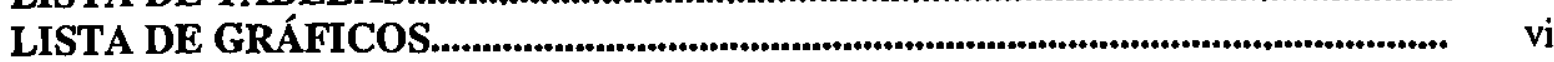

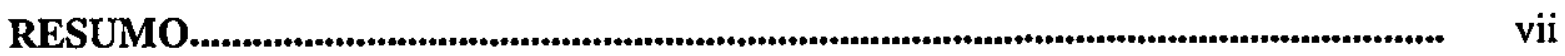

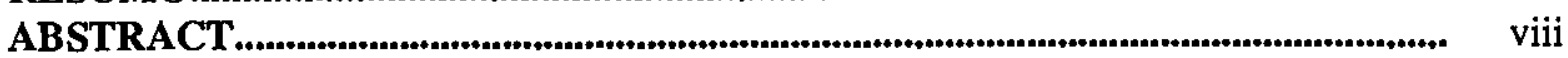

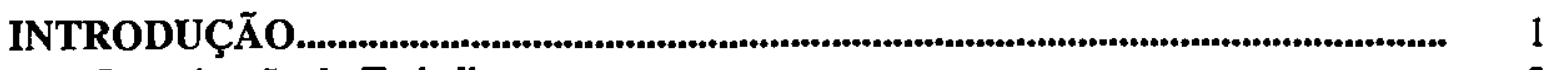

Organização do Trabalho............................................................................................ 2

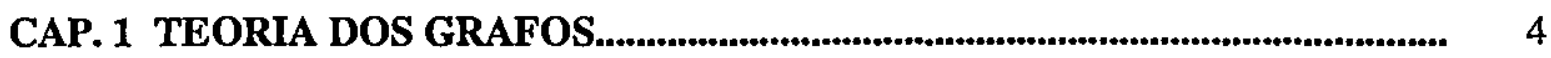

1.1 Histórico..................................................................................................... 4

1.2 Conceitos Preliminares............................................................................... 5

1.2.1 Definiçöes........................................................................................... 6

1.2.2 Matrizes Associadas a um Grafo.................................................... 13

1.2.3 Modelo de Redes em Grafos............................................................ 16

1.2.4 Proposiçóos................................................................................... 20

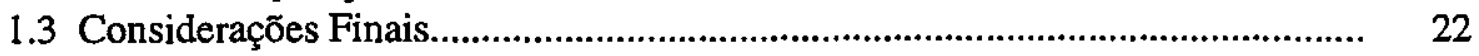

CAP. 2 PROBLEMAS DE FLUXOS E MULTIFLUXO..................................... 23

2.1 Modelo de Fluxo em Redes.......................................................................... 23

2.2 Problemas de Fluxos.................................................................................... 24

2.3 Problemas de Multifluxo................................................................................ 27

2.3.1 Formulação Matemática.................................................................. 27

2.3.2 Formulação Nó-Arco do Problema de Multifluxo................................. 28

2.3.3 Formulação Arco-Caminho do Problema de Multifluxo....................... 29

2.4 Considerações Finais................................................................................ $\quad 30$

CAP. 3 O PROBLEMA DE ROTEAMENTO DE DADOS................................... 31

3.1 Problema de Roteamento................................................................................ 32

3.1.1 Formulação do Problema para um Único Produto................................. 33

3.1.2 Generalização para Vários Produtos................................................. $\quad 35$

3.1.3 Restrições do Problema................................................................... $\quad 37$

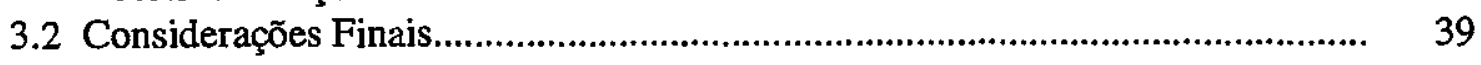

CAP. 4 ALGORITMO PARALELO PARA ROTEAMENTO DE DADOS.............. 41

4.1 Método de Relaxamento.................................................................................. 41

4.1.1 Decomposição do Problema............................................................... 42

4.1.2 Procedimentos do Método.............................................................. 44 
4.1.3 Algoritmo de Relaxamento (multifluxo).......................................... 46

4.2 Método Simplex Convexo............................................................................. 47

4.3 Consideraçōes Finais................................................................................. 54

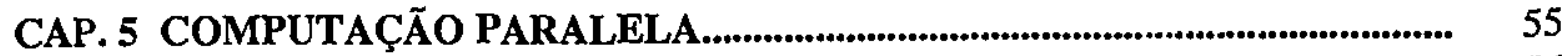

5.1 Histórico................................................................................................... 56

5.2 Motivações para o paralelismo................................................................... 56

5.3 Arquiteturas Paralelas................................................................................. 57

5.3.1 Classificação de Flynn................................................................... 57

5.3.2 Classificação de Duncan.................................................................... 60

5.4 Problemática do Cálculo Paralelo......................................................................... 62

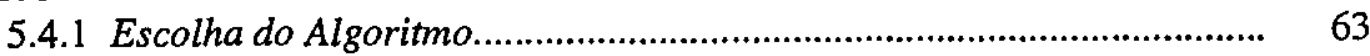

5.4.2 Divisão das Tarefas.......................................................................... 63

5.4.3 Atribuições das Tarefas aos Processadores........................................ 63

5.4.4 Sincronizaçāo das Tarefas............................................................... 64

5.4.5 Implementação do Algoritmo Paralelo................................................. 64

5.4.6 Estudo do Desempenho..................................................................... 64

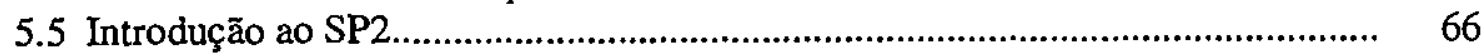

5.5.1 Arquitetura IBM Power.................................................................. 66

5.5.2 Hardware do SP2 .......................................................................... 66

5.5.3 Software do SP2 ........................................................................... 69

5.6 Considerações Finais..................................................................................... 69

CAP. 6 PVM - PARALLEL VIRTUAL MACHINE............................................... 71

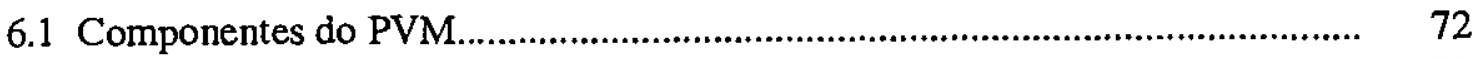

6.1.1 PVM Daemon (Pvmd).................................................................... 72

6.1.2 Biblioteca de Comunicação (Libpvm).............................................. 73

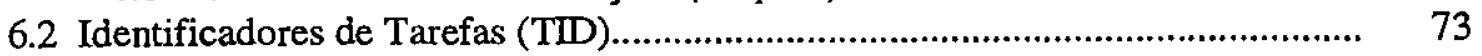

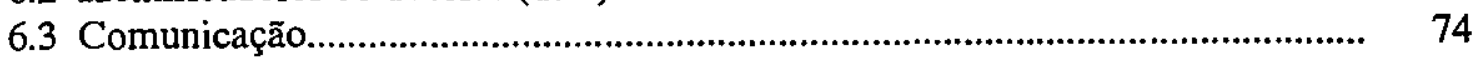

6.4 Utilização do Pvmd̉...................................................................................... $\quad 76$

6.4.1 Inicialização e Finalização............................................................. 76

6.4.2 Pvmd' - Shadow Pvmd................................................................... 77

6.4.3 Tolerância à Falhas.......................................................................... 77

6.4.4 Roteamento de Pacotes e Mensagens................................................ 78

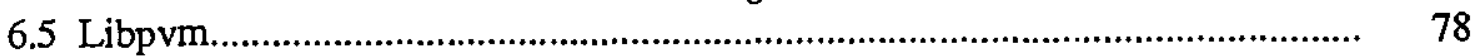

6.6 Protocolos de Comunicação........................................................................... 79

6.6.1 Pvmd-Pvmd..................................................................................... $\quad 79$

6.6.2 Pvmd-Tarefa e Tarefa-Tarefa......................................................... 79

6.7 Limitaçōes do PVM.................................................................................. 80

6.7.1 No Pvmd.................................................................................... 80

6.6.2 Na Libpvm............................................................................... 80

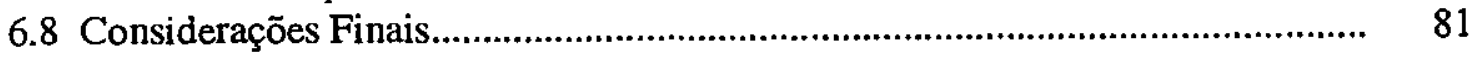

CAP. 7 IMPLEMENTAÇÃO E RESULTADOS COMPUTACIONAIS................... 82

7.1 Implementação........................................................................................ 82

7.1.1 Implementação do Método Simplex Convexo...................................... 83

7.1.2 Implementação em Paralelo................................................................ 86

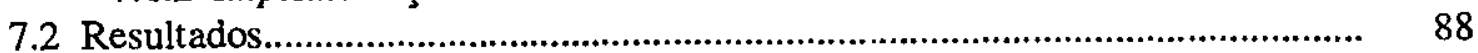


7.2.1 Diferença entre Seqüência de Orientação e Variáveis Duais............... 91

7.2.2 Desempenho das Redes......................................................................... 93

7.2.3 Comparações entre os Tempos Seqüencial e Paralelo.......................... 99

7.3 Consideraçōes Finais.................................................................................. 100

CONCLUSÕES........................................................................................................... 101

Conclusões Obtidas................................................................................................. 101

Contribuições deste Trabalho................................................................................. 102

Dificuldades Encontradas.................................................................................. 102

Sugestões de Propostas Futuras...................................................................... 103

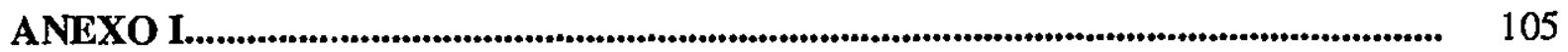

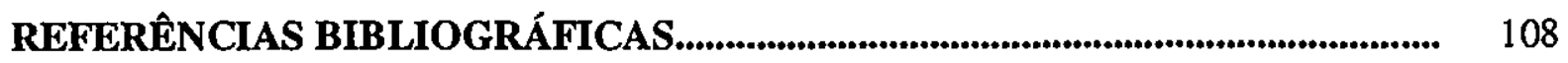

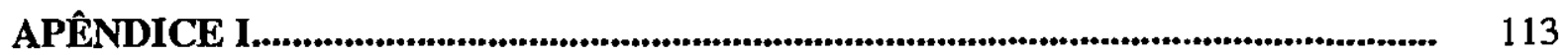

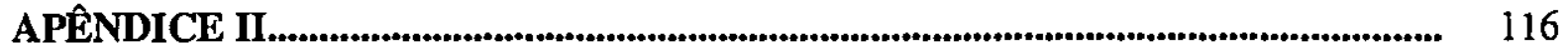


Figura 1.1 Pontes de Königsberg........................................................................ 5

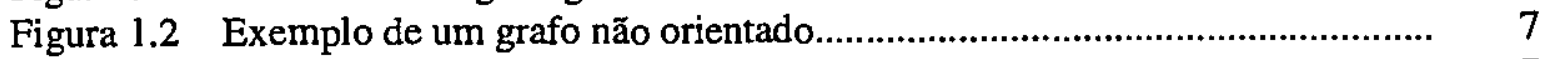

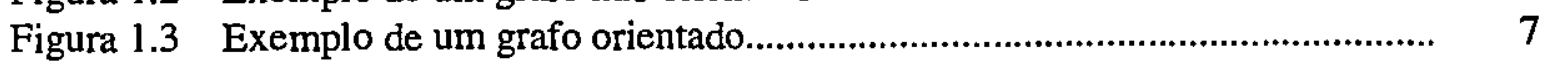

Figura 1.4 Exemplo de arcos adjacentes................................................................... 8

Figura 1.5 Exemplo de um grafo orientado para definir um caminho......................... 9

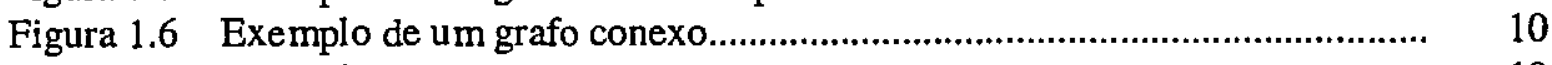

Figura 1.7 Exemplo de um grafo não conexo............................................................ 10

Figura 1.8 Exemplo de um grafo......................................................................... 11

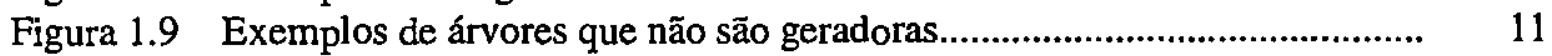

Figura 1.10 Exemplo de uma árvore geradora......................................................... 11

Figura 1.11 Exemplo de uma árvore geradora........................................................ 12

Figura 1.12 Exemplos de grafos que não são árvores................................................... 12

Figura 1.13 Exemplo de uma árvore enraizada........................................................... 13

Figura 1.14 Exemplo de um grafo de uma matriz de incidência nó-arco...................... 14

Figura 1.15 Exemplo de um grafo para uma matriz de adjacência................................ 16

Figura 5.1 Exemplo de arquitetura SISD................................................................. 58

Figura 5.2 Exemplo de arquitetura MISD.............................................................. 58

Figura 5.3 Exemplo de arquitetura SIMD................................................................. 59

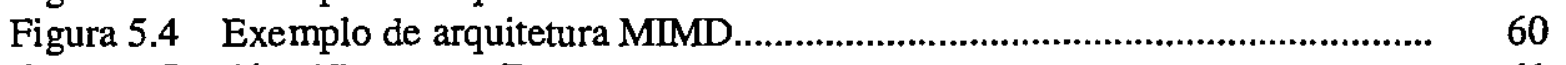

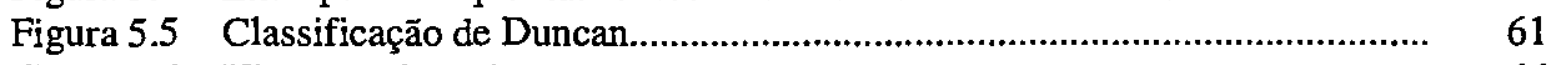

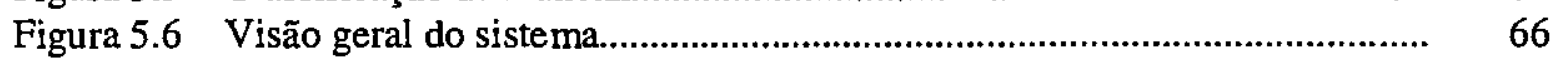

Figura 5.6 Identificador de tarefas genérico........................................................... 73

Figura 7.1 Esquema do programa paralelo................................................................. 88

Figura 7.1 Esquema do LoadLeveler...................................................................... 106 


\section{LISTA DE TABELAS}

Tabela 7.1 Descrições das redes testadas.................................................................. 89

Tabela 7.2 Valores das soluções iniciais e finais da rede............................................ 90

Tabela 7.3 Tempo de execução das redes (implementação seqüencial)...................... 92

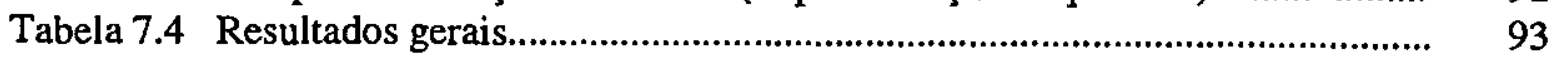




\section{LISTA DE GRÁFICOS}

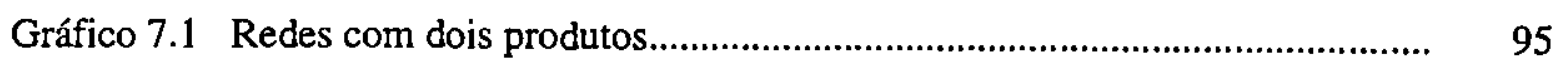

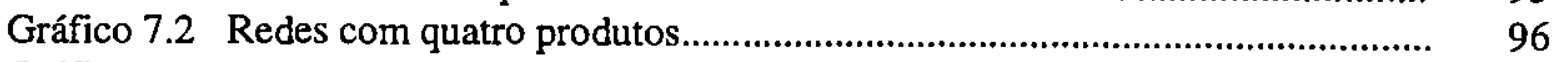

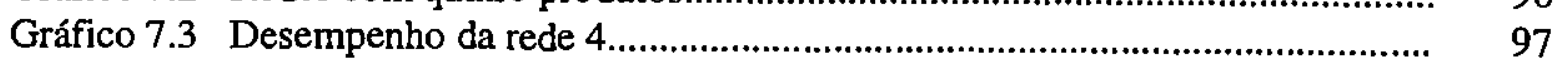

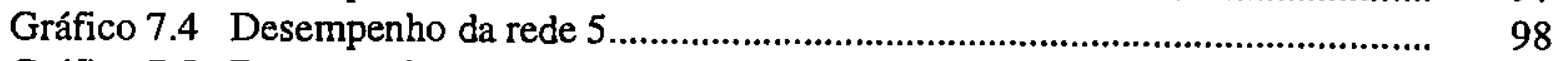

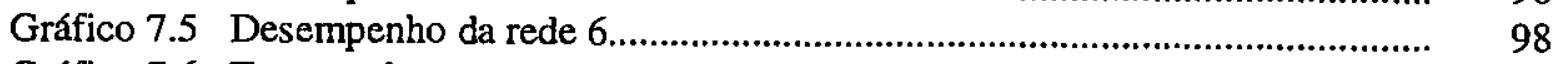

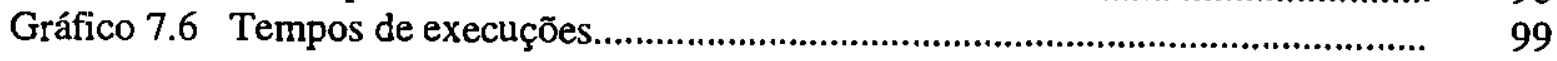




\section{RESUMO}

Nesta dissertação apresentamos e implementamos um método de relaxamento para resolver o problema de roteamento de dados em redes de comutação. Este problema pode ser formulado como um problema de muitifluxo, a critério convexo. $O$ algoritmo apresentado resolve iterativamente o problema de multifluxo, decompondo-o da forma mais independente possível em subproblemas de simples fluxo. Esta independência entre os cálculos permite que a resolução dos subproblemas seja simultânea; isto nos permitiu a implementação em paralelo. Os resultados do algoritmo paralelo foram usados para estabelecer uma comparação com o algoritmo sequiencial e assim analisar o speedup. A biblioteca paralela utilizada foi o PVM. 


\section{ABSTRACT}

In this thesis we present and implement a relaxation method for solving the routing problem in packet-switched communication networks. This problem can be formulated as a multicommodity flow problem, using the convex criterion. The algorithm presented here solves iteratively the multiflow problem, decomposing it in the most independent form possible, in subproblems of single flow commodities. That independence between the calculations allows that the resolution of the subproblems be simultaneous, this allowed us the implementation in parallel. The results of the parallel algorithm were used to establish a comparison with the sequencial algorithm and thus to analyse the speedup. The parallel library used was the PVM. 


\section{INTRODUÇÃO}

O problema de fluxo e multifluxo em redes tem numerosas aplicações práticas. Trata-se de uma área de pesquisa bastante fecunda devido, principalmente, ao interesse que representa o melhoramento da gestão das grandes redes de serviços, tais como: distribuição de água ou gás, planejamento de redes telefônicas e elétricas, controle de tráfego aéreo, roteamento de dados, geração de energia elétrica, alguns problemas de finanças, dentre outros. Com o desenvolvimento de novos meios de comunicação, este problema teve seu interesse aumentado, sobretudo na gestão de redes telefônicas e redes de informática (roteamento de dados). Em particular tratamos do problema de roteamento de dados.

A área dedicada ao desenvolvimento de algoritmos para resolução do problema de roteamento 6timo é intensa [AUT87; BER83; BER87; FRA73; GAL77; GOL97; MCB98; RIB92; ROC84; SCH76; SOK97; STE77; TAR97; TSA89; TSI86]. Schwartz e Cheung [SCH76], por exemplo, adaptaram o método do gradiente projetado para a resolução deste problema. Stem [STE77] propôs um método dual de descentralização dos cálculos utilizando um procedimento de relaxamento para cada no existente na rede. Mcbride [MCB98] descreve os recentes progressos sobre a redução do tempo computacional para resolver o problema de multifluxo com grande número de restrições.

Como Mcbride descreveu, o tempo computacional, em problemas de redes, é um dos principais fatores de estudo. Muitos pesquisadores trabalham para a redução deste fator [ARM97; ORL97], pois com esta redução o problema de roteamento de dados se tornará mais eficiente. 
O problema de roteamento de dados em rede de comutação, consiste em minimizar um critério de encaminhamento das mensagens. Um dos critérios mais utilizado é o tempo médio de atraso na transmissão das mesmas. O problema de roteamento de dados consiste entāe em encontrar, dentre os yários caminhos existentes, aquele que minimize o tempo médio de atraso. das mensagens que circulam através dos arcos da rede. Luvezute [LUV95] e Ribeiro [RIB98] propuseram um algoritmo primal de relaxamento para otimizar o problema de roteamento de dados, que resolve iterativamente o problema de multifluxo, decompondo-o da forma mais independente possível, em subproblemas de simples fluxo, sendo um subproblema para cada mensagem. Esta independência permite que a resolução dos subproblemas seja feita simultaneamente, admitindo-se assim uma implementação em paralelo.

O objetivo deste trabalho é proceder à implementação paralela do algoritmo primal de relaxamento para o problema de roteamento de dados, desenvolvido pelo grupo Descentralização, Hierarquização e Paralelismo (DHP) do Departamento de Ciências de Computação e Estatística da USP [LUV95; RIB98]. Para a minimização dos subproblemas de simples fluxo, adotamos o método Simplex Convexo apresentado por Kennington [KEN80]. Nesta implementação paralela utilizamos a biblioteca paralela PVM [BEG94] e executamos o algoritmo implementado no computador paralelo IBM-SP2.

Este projeto tem como aplicação prática o envio de mensagens, em uma rede mapeada, e é de grande valor pois une duas áreas de pesquisa em constante progresso, que são os problemas de fluxos e multifluxo e a computação paralela, que tem como principal objetivo a melhoria do desempenho computacional

\section{Organização do Trabalho}

Este trabalho está organizado em sete capítulos e uma conclusão, como descrito a seguir:

No primeiro capítulo apresentamos alguns conceitos básicos e resultados sobre teoria dos grafos, que são necessários à compreensão do trabalho.

No segundo capítulo comentamos sobre os principais problemas de fluxos e multifluxo encontrados na literatura.

No terceiro capítulo definimos o problema de roteamento de dados e apresentamos sua formulação como um problema de multifluxo não linear a critério convexo. 
No quarto capítulo apresentamos o algoritmo paralelo para o problema de roteamento de dados e o método Simplex Convexo utilizado para a minimização dos subproblemas.

No quinto capítulo comentamos sobre computação paralela e o computador paralelo IBM-SP2, utilizado durante a implementação.

No sexto capítulo falamos sobre a biblioteca PVM.

O sétimo capítulo é dedicado a apresentação das formas de implementação do algoritmo proposto, bem como à exposição e análise dos resultados obtidos.

Por fim apresentamos a conclusão geral e as perspectivas de futuros trabalhos. 


\section{CAPÍtULO 1}

\section{TEORIA DOS GRAFOS}

Neste capítulo descrevemos alguns conceitos básicos sobre a teoria dos grafos, redes e fluxos. Também apresentamos alguns resultados decorrentes e necessários para a compreensão do projeto. As demonstrações das proposições podem ser encontradas em Gondran [GON84], Kennington [KEN80], Sakarovitch [SAK84] e Szwarcfiter [SZW86].

\subsection{Histórico}

O assunto que se constituiu no marco inicial da teoria dos grafos é na realidade um problema algorítmico cuja solução resultou na elaboração de um algoritmo eficiente. Este problema conhecido como o Problema da Ponte Königsberg foi resolvido por Euler em 1736 e é apresentado a seguir: No Rio Pregel, na antiga Prussia, junto a cidade de Königsberg existiam duas ilhas ligadas por sete pontes. Estas ligações formavam quatro regiões distintas de terra, A, $\mathrm{B}, \mathrm{C}, \mathrm{D}$ conforme mostra a figura 1.1. O problema consiste em, partindo de uma, dessas regiões, determinar um trajeto pelas pontes segundo o qual se possa retornar à região de partida, após atravessar cada ponte somente uma vez. Euler mostrou que não existia tal trajeto, ao utilizar um modelo em grafos para uma generalização deste problema. Através desse modelo ele mostrou que o desejado trajeto existe somente quando em cada região ocorrer um número par de pontes. 
A solução encontrada por Euler é considerada como sendo o primeiro teorema em teoria dos grafos.

Em 1847, Kirchoff utilizou grafos nos seus estudos de circuitos elétricos. A partir daí, pouco a pouco, esta teoria começou a ser utilizada em áreas como química, economia, entre outras. Mas foi somente a partir de 1946 que a teoria dos grafos teve um grande desenvolvimento. Isto ocorreu devido a sua forte aplicação em problemas concretos de pesquisa operacional.
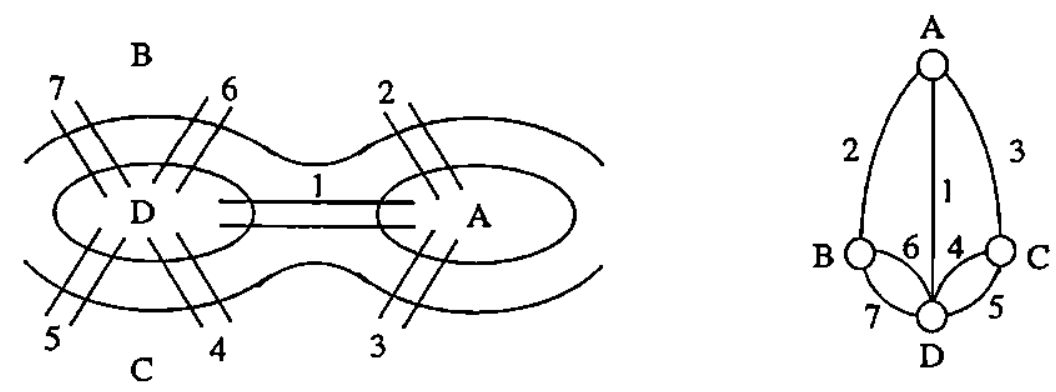

Figura 1.1 - Pontes de Königsberg.

\subsection{Conceitos Preliminares}

Os grafos permitem o modelamento de problemas práticos em otimização de redes (rodovias, elétricas, telefônicas, entre outras), ou de seqüenciamento de operações em uma fábrica.

Trata-se de uma ferramenta rica para a compreensão de uma situação concreta, para o seu modelamento e resolução.

Os conceitos que apresentamos são muito importantes para a compreensão do método Simplex Convexo que será visto no capítulo 4. 


\subsubsection{Definições}

Definição 1.1: Um grafo, denotado por $G=[N, L]$, é definido como um conjunto $N$ cujos elementos são chamados nós (ou vértices) e um conjunto $L$ cujos elementos $l \in L$ são pares ordenados de elementos de $N$ (nós), chamados $\operatorname{arcos}$ (ou arestas).

Seja $L$ o conjunto de arcos, ou arestas, denotado por: $L=\left\{l_{1}, l_{2}, \ldots, l_{L}\right\}$ e seja $N$ o conjunto dos nós, ou vértices, denotado por: $N=\{1,2, \ldots, N\}$. Podemos descrever cada arco $l_{j} \in L$ pelo par de nos $(i, k)$, que o define onde:

- $i$ é a origem do arco $l_{j}$;

- $k$ é o destino do arco $l_{j}$;

- $i$ é o predecessor do arco $l_{j}$;

- $i$ e $k$ são adjacentes.

Definição 1.2: Se os pares $(i, k) \in L$ forem ordenados, isto é $i$ é a origem do arco $l_{j}$ (também denotado por $O\left(l_{j}\right)$ ) e $k$ é o destino do arco $l_{j}\left(D\left(l_{j}\right)\right.$ ), o grafo é dito orientado. Caso contrário é dito não orientado.

Um grafo pode ser visualizado através da sua representação geométrica. Nesta representação os nós (vértices) correspondem a pontos distintos sobre o plano e os arcos (arestas) as linhas unindo os nós correspondentes. A seguir apresentamos dois exemplos, um grafo não orientado e um grafo orientado.

Exemplo 1.1: Grafo não orientado.

Sejam:

$$
\begin{aligned}
& N=\{1,2,3,4\} . \\
& L=\{(1,2),(1,3),(1,4),(2,1),(2,4),(3,1),(4,1),(4,2)\} .
\end{aligned}
$$

Então o grafo $G=[N, L]$ pode ser representado da seguinte maneira: 


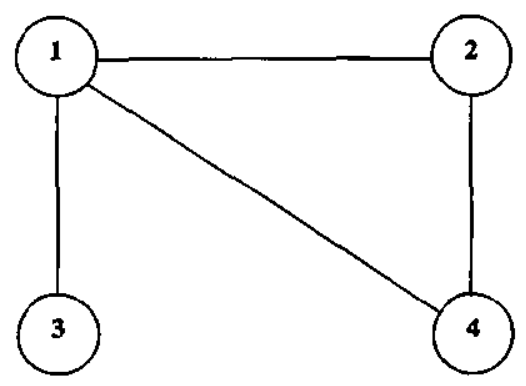

Figura 1.2 - Exemplo de um grafo não orientado.

Exemplo 1.2: Grafo orientado.

Seja o seguinte grafo:

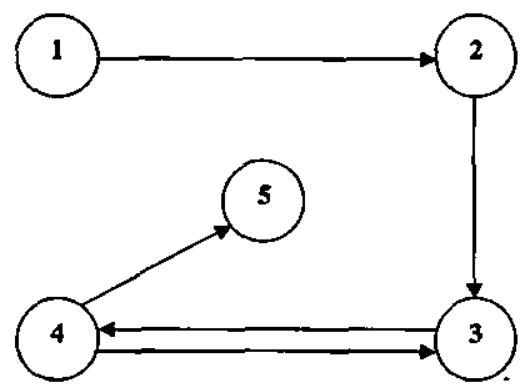

Figura 1.3 - Exemplo de um grafo orientado.

onde:

$$
\begin{aligned}
& N=\{1,2,3,4,5\} \\
& L=\{(1,2),(2,3),(3,4),(4,3),(4,5)\}
\end{aligned}
$$

Definição 1.3: Um arco (ou aresta) cujos extremos coincidem é chamado de laço.

Definição 1.4: Dois arcos (ou arestas) são chamados adjacentes se possuírem pelo menos um extremo em comum. 
Exemplo 1.3: Arcos adjacentes.

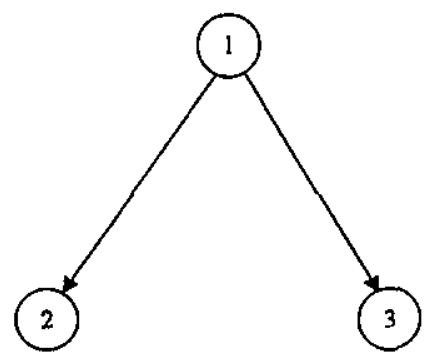

Figura 1.4 - Exemplo de arcos adjacentes.

Na figura acima os $\operatorname{arcos}(1,2),(1,3)$ são adjacentes.

Definição 1.5: Dizemos que $G$ é um grafo próprio se o número de nós $N$ é maior ou igual a 2 e o número de $\operatorname{arcos} L$ é maior ou igual a 1 .

Definição 1.6: Um p-grafo é um grafo com não mais que $p$ arcos $(i, j)$ entre quaisquer dois vértices $i$ e $j$. Em particular, um 1-grafo é um grafo com não mais que um arco $(i, j)$, para todo $i \mathrm{e} j$.

Definição 1.7: Um grafo $\hat{G}=[\hat{N}, \hat{L}]$ é chamado de subgrafo de $G$ se $\hat{N} \subset N$ e $\hat{L} \subset L$.

Definição 1.8: Dizemos que $\hat{G}$ é um subgrafo gerador de $G$ se $\hat{N}=N$.

Definição 1.9: Definimos um caminho em $G$ como sendo uma sequiência finita de nós e arcos, $P=\left\{n_{1}, l_{j 1}, n_{2}, l_{j 2}, \ldots, n_{k}, l_{j k}, n_{k+1}\right\}$, onde o número de arcos $k \in P \geq 1$ e para qualquer arco $l_{j i} \in P$ temos que, $l_{j i} \in\left\{\left(n_{i}, n_{i+1}\right),\left(n_{i+1}, n_{i}\right)\right\}$. 


\section{Exemplo 1.4:}

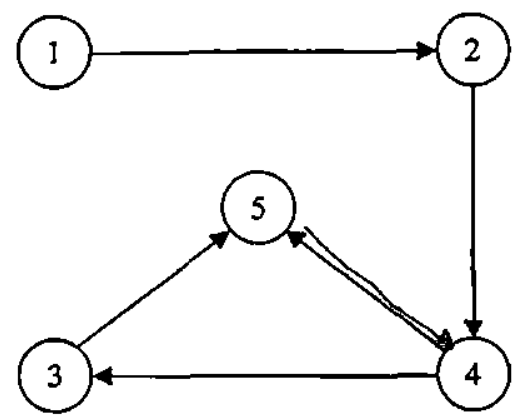

Figura 1.5 - Exemplo de um grafo orientado para definir um caminho.

Na figura 1.5 a seqüência $\{1,(1,2), 2,(2,4), 4,(4,3), 3,(3,5), 5\}$ define um caminho do nó $I$ ao no 5.

Definição 1.10: Um ciclo em $G$, é um caminho onde o nó inicial é igual ao nó final e os arcos são todos distintos.

\section{Exemplo 1.5:}

Na figura 1.5 , a seqüência $\{3,(3,5), 5,(5,4), 4,(4,3), 3\}$ define um ciclo.

Definição 1.11: O comprimento de um caminho, ou ciclo, é determinado pela quantidade de arcos existentes neste caminho ou ciclo.

Definição 1.12: Para toda seqüência, caminho ou ciclo de comprimento $q$, podemos definir a seqüência de orientação $O R_{i}(P)$, como sendo:

$$
O R_{i}(P)=\left\{\begin{array}{cl}
1, & \text { se } l_{i j}=\left(n_{i}, n_{i+1}\right) \\
-1, & \text { se } l_{i j}=\left(n_{i+1}, n_{i}\right)
\end{array} \quad \text { para } i=1, \ldots, q .\right.
$$

\section{Exemplo 1.6:}

A seqüência de orientação do ciclo citado no exemplo 1.5 é:

$$
O R_{i}=(1,-1,1)
$$


Definição 1.13: Um grafo $G=[N, L]$ é chamado acíclico se não conseguirmos formar ciclos com qualquer subseqüência composta com os elementos de $N$ e $L$.

Definição 1.14: Um grafo $G=[N, L]$ é chamado conexo se para todo par de vértices $i$ e $j$ que pertencem a $N$ existe pelo menos um caminho unindo-os.

\section{Exemplo 1.7:}

(1.7.1) Grafo conexo:

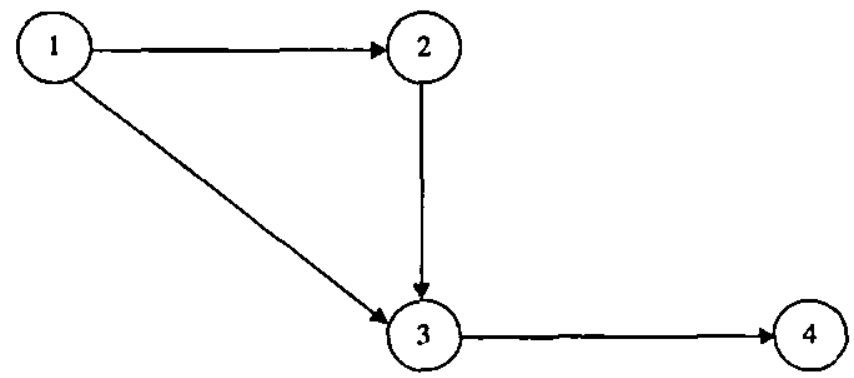

Figura 1.6 - Exemplo de um grafo conexo.

(1.7.2) Grafo não conexo ou desconexo:
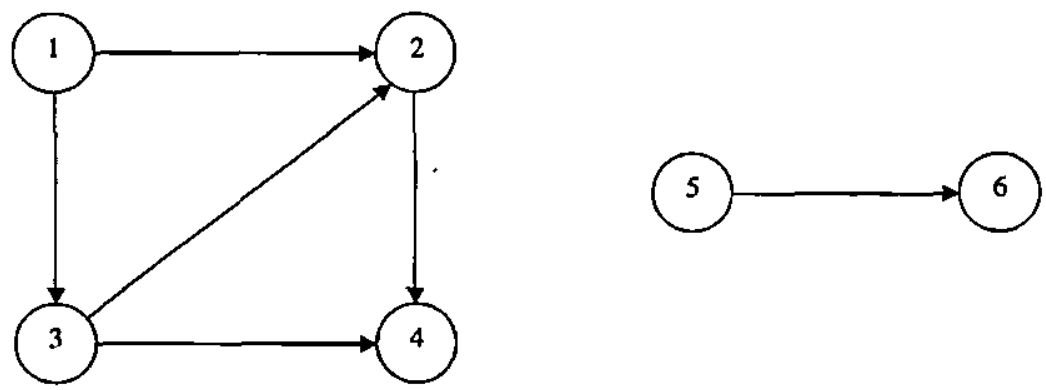

Figura 1.7 - Exemplo de um grafo não conexo.

Definição 1.15: Uma árvore $\tau$ é um grafo conexo e acíclico, ou seja, para todo par de nós $i$ e $j$ distintos de $N$, existe um único caminho ligando $i$ a $j$.

Definição 1.16: Seja $G=[N, L]$ um grafo conexo. O grafo $H=[N, V]$ é uma co-árvore de $G$, se e somente se, o grafo $\bar{H}=[N, L-V]$ é uma árvore de $G$. 
Definição 1.17: Uma árvore $\tau$, que é um subgrafo gerador de um grafo $G$, é chamado de árvore geradora de $G$.

\section{Exemplo 1.8:}

(1.8.1) Seja o grafo $G$ :

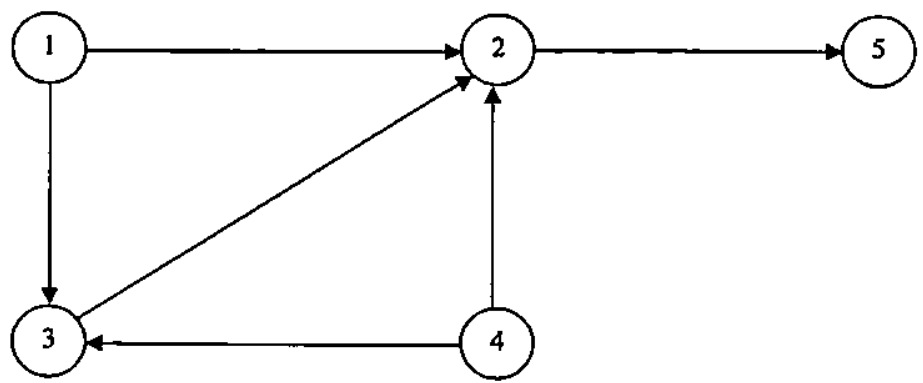

Figura 1.8 - Exemplo de um grafo.

(1.8.2) Subgrafos de $G$ que são árvores, mas não são árvores geradoras:
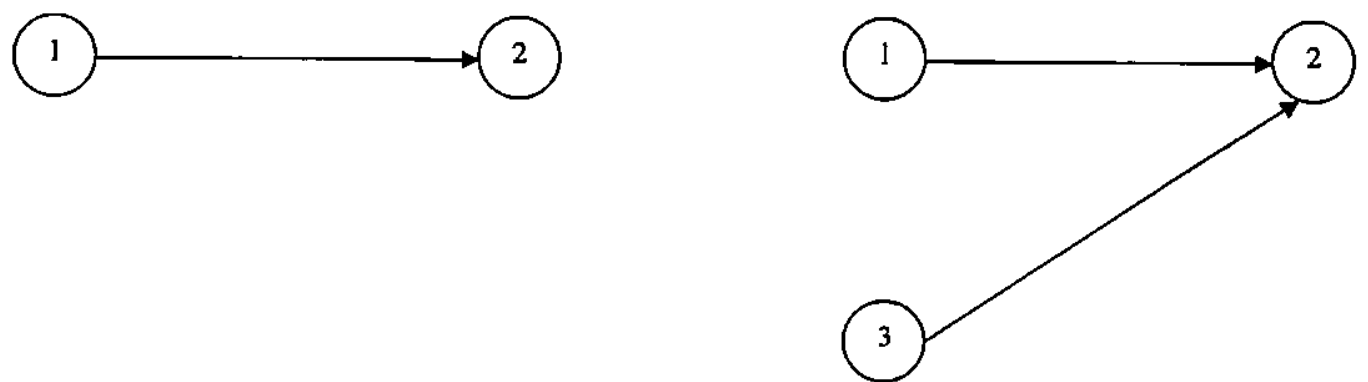

Figura1.9 - Exemplos de árvores que não são geradoras.

(1.8.3) Subgrafos de $G$ que são árvores geradoras:

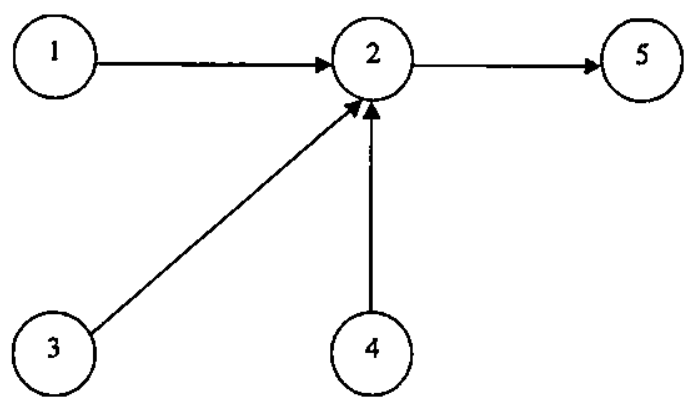

Figura 1.10 - Exemplo de uma árvore geradora. 


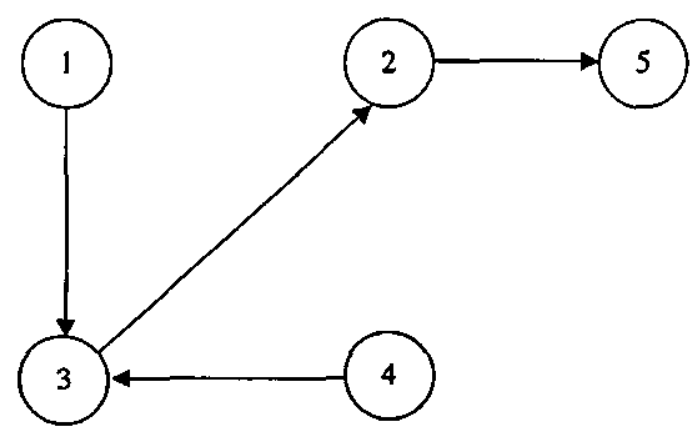

Figura 1.11 - Exemplo de uma árvore geradora.

(1.8.4) Subgrafos de $G$ que não são árvores:
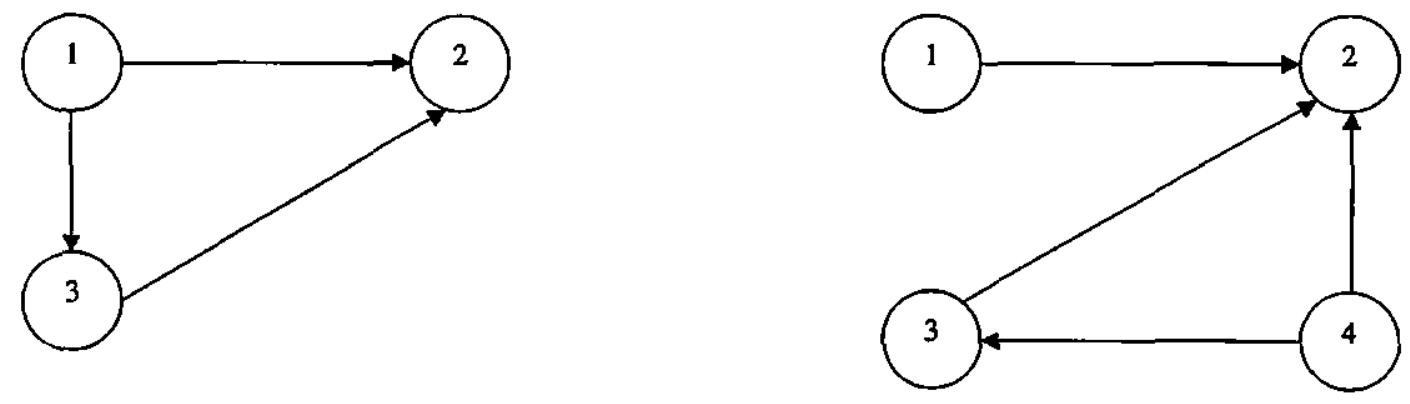

Figura 1.12 - Exemplos de grafos que não são árvores.

Definição 1.18: Definimos o grau do nó $i$ no grafo $G$, denotado por grau( $i)$, como sendo o número de arcos de $G$ incidentes em $i$.

Definição 1.19: Um nó de grau igual a um numa árvore $\tau$ é denominado de folha.

Definição 1.20: Uma árvore $\tau$ é denominada enraizada quando algum nó de $G$ é escolhido como especial. Este nó é então chamado de raiz. 
Exemplo 1.9 - Árvore enraizada:

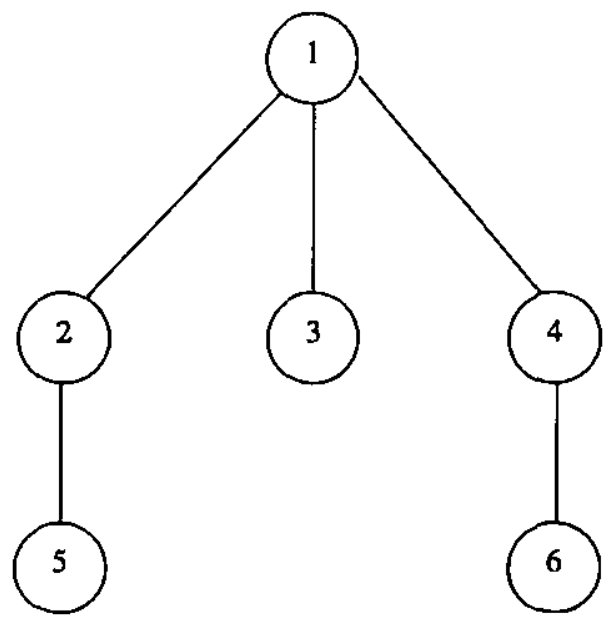

Figura 1.13 - Exemplo de uma árvore enraizada.

No caso da figura acima, considerou-se o nó I como sendo o raiz.

Definição 1.21: Chama-se nivel de um nó $i$, denotado por nível( $i)$, o comprimento do caminho da raiz $r$ ao nó $i$.

\subsubsection{Matrizes Associadas a um Grafo}

\section{- Matriz de Incidência Nó-Arco (Grafo Orientado)}

A matriz de incidência nó-arco de um grafo $G=[N, L]$ é uma matriz $A_{(N \times L)}$ com coeficientes 0,1 ou -1 , onde, cada coluna corresponde a um arco de $G$ e cada linha corresponde a um nó de $G$ e seus elementos são definidos como:

$$
a_{n l}=\left\{\begin{array}{cl}
1, & \text { se o arco } l \text { sai do nó } n \\
-1, & \text { se o arco } l \text { entra no nó } n \\
0, & \text { se o arco } l \text { não incide no nó } n
\end{array}\right.
$$

Uma característica desta matriz é o fato de suas colunas possuírem exatamente duas entradas, uma sendo +1 e outra -1 . 


\section{Exemplo 1.10:}

Seja a seguinte matriz de incidência nó arco:

$$
N_{1} N_{3}\left(\begin{array}{rrrrr}
L_{1} & L_{2} & L_{3} & L_{4} & L_{3} \\
N_{4} & 1 & 0 & 0 & 0 \\
-1 & 0 & 1 & -1 & 0 \\
0 & -1 & -1 & 0 & 1 \\
0 & 0 & 0 & 1 & -1
\end{array}\right)
$$

A partir da matriz acima, obtemos o seguinte grafo:

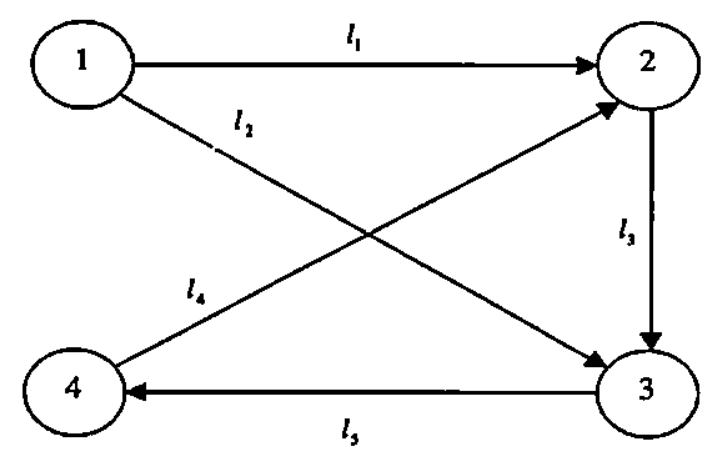

Figura 1.14 - Exemplo de um grafo de uma matriz de incidência nó-arco.

Definição 1.22: Uma matriz quadrada é dita unimodular se o seu determinante for 1 ou -1 .

Uma matriz retangular $A$ é chamada totalmente unimodular, se e somente se, todas as submatrizes quadradas não singulares de $A$ são unimodulares.

Proposição 1.1: A matriz de incidência nó-arco de um grafo $G=[N, L]$ é totalmente unimodular.

Proposição 1.2: Seja $A$ a matriz de incidência nó-arco para o grafo $G$ conexo, com $N$ nós, então o posto máximo de $A$ é $N$-1. 
- Matriz de Incidência Nó-Aresta (Grafo Não Orientado)

Seja $G=[N, L]$ um grafo não orientado, a matriz de incidencia nó-aresta de $G$ é uma matriz com coeficientes 0 ou 1 , onde cada linha corresponde a um vértice e cada coluna a uma aresta de $G$ e seus elementos são definidos como:

$$
a_{n I}= \begin{cases}1, & \text { se o arco } l \text { incide no nó } n \\ 0, & \text { se o arco } l \text { não incide no nó } n\end{cases}
$$

\section{Exemplo 1.11:}

Desconsiderando a orientação do grafo da figura 1.14 , a matriz de incidência nó-aresta é:

$$
\left(\begin{array}{lllll}
1 & 1 & 0 & 0 & 0 \\
1 & 0 & 1 & 1 & 0 \\
0 & 1 & 1 & 0 & 1 \\
0 & 0 & 0 & 1 & 1
\end{array}\right)
$$

Definição 1.23: Um grafo $G=[N, L]$ é chamado bipartido se o conjunto de nós pode ser particionado em dois sub-conjuntos $X_{1}$ e $X_{2}$, só que para cada aresta $(i, j) \in L$ :

$$
i \in X_{1} \rightarrow j \in X_{2} \text { ou } i \in X_{2} \rightarrow j \in X_{1}
$$

Proposição 1.3: A matriz de incidência nó-aresta de um grafo $G=[N, L]$ é totalmente unimodular, se e somente se, $G$ é um grafo bipartido.

\section{- Matriz de Adjacência ou Matriz de Incidência Nó-Nó}

Seja $G=[N, L]$ um grafo orientado que não contém arcos múltiplos, ou seja, não existem dois arcos ou mais, provenientes do mesmo nó $i$ para o nó $j$, comportando eventualmente laços, mas no máximo um por nó. A matriz de adjacência é uma matriz $A_{(N \times N)}$, com coeficientes 0 ou 1 , onde cada linha e cada coluna correspondem a um nó de $G$ e: 


$$
a_{i j}=\left\{\begin{array}{l}
1, \text { se existe o } \operatorname{arco}(i, j) \\
0, \text { se não existe o } \operatorname{arco}(i, j)
\end{array}\right.
$$

Exemplo 1.12: Seja o grafo:

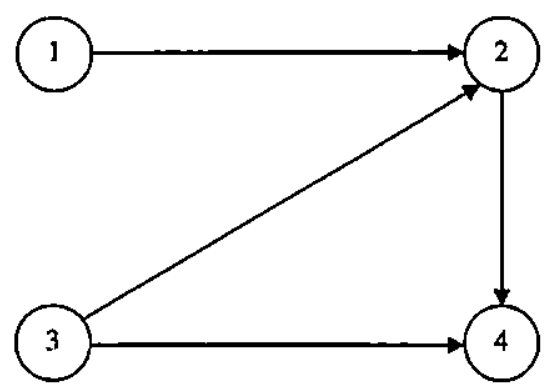

Figura 1.15 - Exemplo de um grafo para uma matriz de adjacência.

A matriz de adjacência é:

$$
\left(\begin{array}{llll}
0 & 1 & 0 & 0 \\
0 & 0 & 0 & 1 \\
0 & 1 & 0 & 1 \\
0 & 0 & 0 & 0
\end{array}\right)
$$

No caso do grafo ser não orientado, a matriz de adjacência de um grafo simples pode também ser definida considerando que para cada aresta $(i, j)$ há dois $\operatorname{arcos}(i, j)$ e $(j, i)$ correspondentes. Neste caso a matriz de adjacência é simétrica.

\subsubsection{Modelo de Redes em Grafos}

Uma rede é composta de arcos e nós. Os arcos podem ser entendidos como a direção ou o caminho para o transporte de produtos que circulam pela rede e os nós como a localização dos terminais conectados pelos arcos, ou podem também significar a origem ou destino do fluxo do produto que circula pela rede, ou simplesmente um nó de transição o qual o fluxo passa para poder atingir seu destino,

Seja uma rede com $N$ nós e $L$ arcos, onde esteja estabelecida uma ordem sobre os nós e arcos numa correspondência dos $N$ nós sobre os $L$ arcos, respectivamente. Pode-se representar a 
estrutura desta rede através da matriz $A_{(N \times L)}$ de incidência nó-arco, definida anteriormente. Esta matriz está também associada às restrições de conservação de fluxo em cada nó da rede, ou seja, o fluxo total que chega no nó deve ser igual ao fluxo total que deixa o nó. Porém, a matriz $A_{(N \times L)}$ de incidência nó-arco possui posto $N-1$, como citado na proposição 1.2. Assim, assumiremos a matriz de restrições associada a um produto $m$, como a matriz de incidência reduzida de uma linha, obtendo deste modo um conjunto linearmente independente de restrições, isto é: $A_{((N-1) \times L)}$. Neste caso específico, excluiremos a linha relativa ao nó destino do produto $m$ envolvido e o denotaremos por $D_{m}$.

Suponhamos que exista um único produto circulando pela rede, assumiremos que não existem arcos múltiplos na rede, isto é, não existem $\operatorname{arcos} l_{j}$ e $l_{k}$ tais que as colunas correspondentes da matriz de incidência nó-arco sejam idênticas. Além disso, se existirem dois arcos provenientes do mesmo nó $i$ para o nó $j$, um deles pode ser representado por dois outros $\operatorname{arcos}(i, k)$ e $(k, j)$, onde $k$ é um nó artificial acrescentado na rede.

Define-se o vetor $b_{(N \times 1)}$, como a demanda da rede, ou seja, a quantidade total de fluxo que entra e sai de todos os nós da rede. Especificamente, $b_{n}$ representa a quantidade de fluxo que entra no nó $n$ se $b_{n}>0$, ou a quantidade de fluxo que saj do nó $n$ se $b_{n}<0$.

Chama-se de $x_{l}$ o fluxo do produto considerado que circula através do arco $l$.

Assim, podemos equacionar as restrições de conservação como: $A x=b$, onde o vetor $b$ também se apresenta reduzido da coordenada $D_{m}$ correspondente à linha de retirada da matriz de incidência nó-arco, isto é: $b_{((N-1) \times 1)}$.

Diz-se que uma rede possui arcos capacitados, se existe um limitante superior para a quantidade de fluxo que circula por eles, a estes limitantes estão associadas as restrições de capacidade e também existem as restrições de não negatividade dos fluxos em todos os arcos, que devem ser consideradas.

Com isso, o modelo matemático para o problema de fluxo de custo mínimo para uma rede com um único produto pode ser escrito como: 


$$
\left\{\begin{array}{l}
\text { Minimizar } \sum_{l=1}^{L} c_{l} x_{l} \\
\text { sujeito a: } \\
A x=b \\
x_{l} \leq C_{l}, \quad l=1, \ldots, L \\
0 \leq x_{l}, \quad l=1, \ldots, L
\end{array}\right.
$$

onde:

$c_{l}$ : custo unitário para o fluxo no arco $l$.

$G$ : capacidade do arco $l, l=1,2, \ldots, L$.

$x_{l} \leq C_{l}$ : restrições de capacidade, $l=1,2, \ldots, L$.

$0 \leq x_{l}$ : restrições de não negatividade, $l=1,2, \ldots, L$.

Como a matriz $A$ de restrições é totalmente unimodular, para valores de $b$ inteiro, a soluçāo ótima do problema será sempre inteira, não importando os valores de $c$, desde que estes sejam reais.

Suponha que queiramos fazer circular pela rede diferentes produtos, isto é, ao invés de entrar na rede um único produto, entrarão diversos produtos de natureza diferentes. Na prática, isto significa que em cada arco os fluxos podem ser somados globalmente mas, precisamos especificar cada produto individualmente. Por exemplo, se quiséssemos transportar caixas de limões e de laranjas, neste caso, ao resolvermos o problema, precisamos especificar claramente quantas caixas de laranja e quantas caixas de limão estamos transportando em cada arco. Este problema é conhecido pelo nome de multifluxo ou problema de fluxo com vários produtos.

No problema de multifluxo, temos uma restrição de conservação de fluxo para cada nó e para cada produto, ou seja, temos uma matriz de incidência nó-arco para cada produto. Temos também, uma restrição de não negatividade para cada produto. As restrições de capacidade sāo aqui chamadas de restrições de acoplamento pois, para cada arco, elas amarram todos os produtos numa única restrição, ou seja:

Suponha que existam $M$ produtos circulando pela rede. Se denotarmos o fluxo do produto $m$ como $x^{m}$, então o fluxo total passando pelo arco $l$ pode ser denotado por:

$$
X_{l}=\sum_{m=1}^{M} x_{l}^{m}
$$


Assim a restrição de acoplamento será:

$$
X_{l}=\sum_{m=1}^{M} x_{l}^{m} \leq C_{l}
$$

* Deste modo, o modelo matemático para o problema de multifluxo em rede com custo mínimo, pode ser escrito como:

$$
\left\{\begin{array}{l}
\text { Minimizar } \sum_{l=1}^{L} c_{l} X_{l} \\
\text { sujeito a: } \\
\quad A x=b \\
\quad X_{l} \leq C_{l}, \quad l=1, \ldots, L \\
0 \leq x_{l}^{m}, \quad l=1, \ldots, L, m=1, \ldots, M
\end{array}\right.
$$

onde:

$x_{l}^{m}:$ fluxo do produto $m$ no arco $l$.

$x_{l}=\left(x_{l}^{(1)}, x_{l}^{(2)}, \ldots, x_{l}^{(M)}\right)$ : fluxo no arcol.

$x=\left(x_{1}^{(1)}, x_{1}^{(2)}, \ldots, x_{1}^{(M)}, x_{2}^{(1)}, x_{2}^{(2)}, \ldots, x_{2}^{(M)}, \ldots, x_{L}^{(1)}, x_{L}^{(2)}, \ldots, x_{L}^{(M)}\right)^{t}:$ vetor de fluxos.

$b^{(m)}=\left(b_{1}^{(m)}, b_{2}^{(m)}, \ldots, b_{N}^{(m)}\right)^{l}:$ demanda de todos os nós relativos ao produto $m \operatorname{com} b_{D_{m}}^{(m)}$ excluído, onde: $N=$ número de nós.

$b=\left(b^{(1)^{t}}, b^{(2)^{t}}, \ldots, b^{(M)^{t}}\right)^{t}:$ demanda em todos os nós com relação a todos os produtos.

$A$ : matriz de restrições diagonal por blocos, isto é, $\left(A^{(1)}, A^{(2)}, \ldots, A^{(M)}\right)$, onde:

$A^{(m)}$ : matriz de incidência nó-arco relativa ao produto $m$, com a linha relativa a $D_{m}$ excluída.

Apresentamos agora algumas proposições que facilitam a solução do problema de fluxo de custo mínimo. Estas proposições nos mostram como obter uma base (vetores linearmente independentes) a partir da matriz de incidência nó-arco. 


\subsubsection{Proposições}

Proposição 1.4: Para o grafo $\tau=[N, L]$, com pelo menos um nó, as seguintes afirmaçōes são equivalentes:

(i) $\tau$ é uma árvore;

(ii) para qualquer par de nós distintos $(i, j)$ de $N$, existe um único caminho em $\tau$ que liga $i$ e $j$;

(iii) $\tau$ tem um arco a menos que o número de nós e é conexa;

(iv) $\tau$ tem um arco a menos que o número de nós e é acíclica.

Proposição 1.5: Seja $\tau=[N, L]$ uma árvore com pelo menos dois nós, $N \geq 2$, cujo nó $i$ é uma folha de $\tau$ e seja $l_{j}$ o arco incidente sobre $i$ em $\tau$. Retirando o nó folha $i$ e o arco $l_{j}$, isto é, $\hat{N}=N-\{i\}$ e $\hat{L}=L-\left\{l_{j}\right\}$, então $\hat{\tau}=[\hat{N}, \hat{L}]$ é uma árvore.

Suponhamos que as redes envolvidas neste problema não contenham arcos múltiplos. Portanto, existe uma correspondência um a um entre os arcos do grafo e as colunas associadas a matriz de incidência. Assim, o arco $l_{j}$ de $A$ corresponde à $j$-ésima coluna da matriz de incidência nó-arco.

Proposição 1.6: Seja $A$ a matriz de incidência nó-arco para o grafo próprio $G$. Seja $\tau=[N, L]$ o subgrafo de $G$ que é uma árvore contendo no mínimo dois nós, então $\left\{L(j): l_{j} \in L\right\}$ é linearmente independente.

Proposição 1.7: Para qualquer grafo conexo $\tau=[N, L]$, com $N \neq \varnothing$, existe um subgrafo $\tau$, que é uma árvore geradora.

As proposiçōes 1.6 e 1.7 indicam que, dado um grafo $G$ com sua correspondente matriz de incidência nó-arco $A$, existe uma árvore geradora para $G$ denominada $\tau$, tal que, as colunas de $A$, correspondentes aos arcos em $\tau$, são linearmente independentes. 
Proposição 1.8: Seja $A$ a matriz de incidência nó-arco no grafo próprio $G=[N, L], \operatorname{com} n$ nós. Seja $\hat{L} \subset L$ tal que $\left\{L(j): l_{j} \in \hat{L}\right\}$ é um conjunto linearmente independente e $\hat{L}$ tenha $N-1$ arcos. Então $\tau=[N, \hat{L}]$ é uma árvore.

No problema de programação linear a matriz de restrições $A$ tem posto completo $N$, diferente do problema de fluxo em redes que o posto da matriz $A$ é $N-1$. Para reformular o problema para que o posto da matriz seja completo, existem dois caminhos:

- reduzir o número de linhas da matriz de incidência nó-arco, retirando por exemplo a linha relativa ao destino do produto envolvido como consideramos anteriormente, ou:

- adicionando um número suficiente de colunas linearmente independentes (isto é, variáveis artificiais), com limitantes superiores e inferiores iguais a zero.

Consideremos a formulação:

$$
\left\{\begin{array}{c}
\text { Minimizar } \sum_{l=1}^{\mathrm{L}} c_{l} x_{l} \\
\text { sujeito a: } \\
A x+a l_{w}=b \\
0 \leq x \leq C \\
0 \leq a \leq 0
\end{array}\right.
$$

onde: $w$ é um inteiro, menor ou igual a $N$.

Como $a$ é zero, uma solução ótima para este problema será também uma solução ótima para o problema de fluxo mínimo em redes.

A proposição 1.9 abaixo nos mostra, que o conjunto de $N$ colunas $\left[A: l^{w}\right]$ gera $E^{N}$.

Proposição 1.9: Seja $A$ a matriz de incidência nó-arco do grafo conexo $G=[N, L]$, tendo $N$ nós. Seja $\tau=[N, \hat{L}]$ a árvore geradora de $G$. Então $\Omega=\left\{A(j): l_{j} \in \hat{L}\right\} \cup\left\{l^{w}\right\}$ é um gerador de $E^{N}$. 
Definição 1.24: No grafo associado ao problema anterior (1.3) a variável artificial $a$ é chamada de arco raiz, e o nó $w$ de nó raiz. Assim este grafo é chamado de grafo enraizado, e suas árvores geradoras $\tau$ são chamadas de árvores enraizadas.

Proposição 1.10: Seja $A$ a matriz de incidência nó-arco do grafo próprio enraizado $G=[N, L]$, com nó raiz $w$. Se $\Omega$ é uma base para $\left[A: l^{w}\right]$, então $l^{w} \in \Omega$ e $\tau=[N, \hat{L}]$ é uma árvore geradora para $G$ onde $\hat{L}=\left\{l_{j}: A(j) \in \Omega\right\}$.

Proposição 1.11: Seja $A$ a matriz de incidência nó-arco do grafo próprio enraizado, com nó raiz $w$. Todas as bases para $\left[A: l^{w}\right]$, são formadas pela coluna $l^{w}$ mais as colunas de $A$ que pertencem às árvores geradoras de $G$.

\subsection{Considerações Finais}

Neste capítulo definimos os principais resultados da teoria dos grafos para uma melhor compreensão do problema que trabalhamos. No seguinte capítulo apresentamos os principais problemas de fluxos e multifluxos existentes na literatura, para assim poder analisar a importância destes problemas na atualidade. 


\section{CAPÍtUlO 2}

\section{PROBLEMAS DE FLUXOS E MULTIFLUXO}

A noção de fluxo em um grafo está historicamente ligada ao cálculo de corrente elétrica contínua em uma rede. Com o passar dos anos os problemas de fluxos foram aplicados a outros setores tais como: transporte, controle de estoque, redes de comunicações, tráfego de veículos, dentre outros.

Neste capítulo apresentamos o modelo de fluxo em redes, bem como os principais tipos de problemas de fluxos encontrados na literatura e também abordamos problemas de multifluxo. O problema de roteamento de dados faz parte dos problemas de multifluxo.

\subsection{Modelo de Fluxo em Redes}

Uma rede pode ser modelada como um grafo orientado, cujos arcos podem ser interpretados como um meio para transporte (estradas, fios, dutos, etc) de produtos e os nós podem ser vistos como pontos terminais conectados pelos arcos.

O problema de fluxo em redes consiste em determinar a quantidade de produto (fluxo) que deve percorrer os arcos da rede de modo a otimizar uma função objetivo. Esta função objetivo visa a obtenção de um fluxo máximo, um fluxo compatível ou fluxo de custo mínimo. Seja qual for a função objetivo a ser considerada podemos fazer com que estes problemas 
recaiam no caso mais clássico que é o Problema de Fluxo de Custo Mínimo (PFCM) [GON84, SAK82, SAK84]. O PFCM consiste em descobrir como encaminhar um fluxo entre dois pontos de modo que o custo seja mínimo. Este pode ser escrito como:

$$
\left\{\begin{array}{l}
\text { Minimizar } z_{l} x_{l} \\
\text { sujeito a: } \\
\quad A x=b \\
0 \leq x \leq \mathrm{C}_{1}
\end{array}\right.
$$

onde:

$z_{l}$ : custo unitário do fluxo que percorre o arco $l$.

$x_{l}$ : quantidade de fluxo que passa pelo arco $l$.

$C_{l}$ : fluxo máximo permitido ou capacidade do arco $l$.

$b_{n}$ : demanda do nó $n$.

se

- $b_{n}>0$, o nó $i$ é denominado nó fonte.

- $b_{n}<0$, o nó $i$ é denominado nó sumidouro.

- $b_{n}=0$, o nó $i$ é denominado nó de passagem.

$A$ : matriz de incidência nó-arco.

Observe que neste problema para cada nó da rede temos uma restrição de conservação de fluxo, isto $e$, a quantidade de fluxo que chega ao nó deve ser igual a que sai e cada arco da rede está associado a uma variável $x_{i}$.

\subsection{Problemas de Fluxos}

Os principais tipos de problemas de fluxos encontrados na literatura são: 


\section{Problema do caminho mínimo}

Os problemas de caminho estão entre os mais antigos da teoria dos grafos [GON84]. Desde a antigüidade existem problemas deste gênero tais como, o da travessia do lobo, do cabrito e do repolho num pequeno barco. Neste caso o barqueiro só pode transportar um de cada vez e deve evitar que, na sua ausência, o lobo coma o cabrito ou o cabrito coma o repolho.

Entre os problemas de caminho, o do caminho mínimo é um dos mais típicos.

Seja $G=[N, L]$ uma rede cujos arcos $l$ possuem comprimento $d_{l}$. O problema do caminho mínimo consiste em encontrar qual o caminho $P$ que liga o nó $s_{m}$ ao nó $t_{m}$ de modo que o comprimento total do caminho seja mínimo.

\section{Problema do fluxo máximo}

Neste problema a capacidade do arco é o único parâmetro relevante [GON84]. Uma vez indicados os nós fonte e sumidouro, o problema consiste em encontrar o fluxo máximo que pode circular na rede com entrada no nó fonte e saída no nó sumidouro. Neste problema todas as demandas são iguais a zero e todos os arcos têm custo zero, exceto o arco que liga o nó fonte ao nó sumidouro que possui custo unitário.

\section{Problema de transporte}

É um problema onde a rede possui somente nós fonte e sumidouro, portanto, este tipo de problema não possui nós de passagem [GON84]. Conseqüentemente, os nós podem ser particionados em dois conjuntos distintos, $N_{1}$ e $N_{2}$, de modo que todos os arcos tenham origem em um nó que pertence ao conjunto $N_{1}$ e destino em um nó que pertence ao conjunto $N_{2}$, ou seja, o grafo representativo da rede é um grafo bipartido.

Neste tipo de problema os arcos têm capacidade infinita e as demandas são todas diferentes de zero $\left(b_{l} \neq 0\right.$, para $\left.l \in N\right)$ e $\sum_{l=1}^{N} b_{l}=0$, onde $N$ e o número de nós. 


\section{Problema de transporte generalizado (Transshipment Problem)}

No problema de transporte os nós do grafo são nós fontes ou nós sumidouros, isto é, o grafo é bipartido. No generalizado o grafo não é bipartido e existem nós que não são fonte nem sumidouro, são apenas nós de passagem. Todos os demais parâmetros deste problema são idênticos ao problema de transporte. Por este motivo ele é considerado como caso geral do problema de transporte.

\section{Problema de designação}

Este problema é um caso particular do de transporte onde o número de nós fonte é igual ao número de nós sumidouro $\left(N_{1}=N_{2}\right)$ e todas as demandas $b_{l}(l \in N)$ são iguais a 1 ou -1 .

Este problema também pode ser visto como o de um "matching" de cardinalidade $N_{1}$ num grafo bipartido. Veja, por exemplo, em Gondran [GON84].

Um exemplo típico deste problema é a designação de $n$ tarefas a $n$ máquinas. É suposto conhecido o custo $z_{i j}$ de se executar a tarefa $t_{i}$ pela máquina $m_{j}$. Se a tarefa $t_{i}$ não puder ser executada pela máquina $m_{j}$, o custo $z_{i j}$ é infinito. Procura-se então a designação que conduz ao menor custo total.

Os problemas de fluxos em redes têm sido objeto de estudo devido a sua grande aplicação prática. Existem na literatura algoritmos específicos para resolver tais problemas. Estes algoritmos procuram explorar as particularidades próprias de cada caso. Como exemplo, podemos citar o PFCM com função objetivo linear. Este problema pode ser resolvido através de qualquer método de programação linear. Entretanto, por se tratar de um modelo de grafo, a matriz de restrições do PFCM possui características especiais: é totalmente unimodular e em cada coluna ela apresenta somente dois elementos não nulos. Estas particularidades permitiram o desenvolvimento de uma especialização do algoritmo simplex, para redes, que agiliza o processo de resolução e soluciona problemas de grande dimensão. 


\section{Problemas de multifluxo}

Quando, numa rede, circulam vários fluxos (produtos) independentes, justapostos mas não misturáveis, temos o chamado problema de multifluxo ou multiproduto. $O$ problema de multifluxo constitui um modelo natural para as redes de comunicação, como por exemplo: redes telefônicas ou de computadores. Evidentemente que o algoritmo geral da programação linear pode ser utilizado para resolver este problema, contudo, se for levado em consideração as estruturas particulares de cada problema, pode-se chegar a algoritmos mais simples de se implementar.

Existem muitos pesquisadores que estudam problemas de multifluxo, um exemplo é Karzanov [KAR97] que estudou problemas envolvendo multifluxo de custo mínimo.

$\mathrm{Na}$ literatura existem dois métodos principais que tratam do problema de multifluxo: o método do particionamento e o da decomposição que podem ser encontrados em vários livros e artigos [BAZ77; FAR93; GON84; HU69; ROT66; SAK73].

\subsection{Problemas de Multifluxo}

\subsubsection{Formulação Matemática}

Considere um grafo orientado $G=[N, L]$ com $N=\{1,2, \ldots, N\}$ e $L=\left\{l_{1}, l_{2}, \ldots, l_{L}\right\}$, onde $N$ é o número de nós e $l_{L}$ é o número de arcos. Um arco $l$ também pode ser escrito pelo par ordenado $l=(O(l), D(l))$ para $L=\left\{l_{1}, l_{2}, \ldots, l_{L}\right\}$. Considere que circulem independentemente $M$ fluxos simples $x^{1}, x^{2}, \ldots, x^{M}$ com componentes não-negativas ( $x^{m} \geq 0, \forall l, \forall m$, isto é, cada arco é percorrido através do sentido do percurso) pelo grafo $G$.

Para $m=\{1,2, \ldots, M\}, x^{m}=\left(x_{l}^{m}\right)$ é um fluxo simples entre um certo nó fonte $s_{m} \in N$ e um nó sumidouro $t_{m} \in N$. Em outras palavras, $A x^{m}=b^{m}$, onde $A$ é a matriz de incidência nóarco de $G$ e $b^{m}$ é um $N$-vetor de demanda dos produtos cujos componentes relativos aos nós $s_{m}$ e $t_{m}$, tomam valores $b^{m} \mathrm{e}-b^{m}$ respectivamente. A soma de todos os fluxos simples (produtos) que se direcionem num mesmo arco, deve ser menor ou igual a capacidade do arco $\left(C_{1}\right)$, ou seja: 


$$
X_{I}=\sum_{n=1}^{M} x_{i}^{m} \leq C_{I} .
$$

Um multifluxo é um conjunto de fluxos nos arcos, dado pelo vetor $X=\left(X_{l}\right)$, que satisfaz as equações de conservação de fluxo e as restrições de não-negatividade.

\subsubsection{Formulação Nó-Arco do Problema de Multifluxo}

Apresentamos, a seguir, a formulação matemática do problema de multifluxo, conhecida por formulação nó-arco [GON84]. Este nome advém do fato de se utilizar a matriz de incidência nó-arco do grafo.

$$
\begin{cases}\text { Minimizar } \sum_{m=1}^{M} z^{m} x^{m} & \\ \text { sujeito a: } & m=1, \ldots, M \\ A x^{m}=b^{m} & \forall l \in L \text { e } m=1, \ldots, M \\ \sum_{m=1}^{M} x_{l}^{m} \leq C_{l} & m=1, \ldots, M \\ 0 \leq x^{m} \leq u^{m} & \end{cases}
$$

onde:

$z_{l}^{m}$ : custo unitário do produto $m$ no arco $l \mathrm{e}$

$z^{m}=\left[z_{l_{1}}^{m}, z_{l_{2}}^{m}, \ldots, z_{l_{L}}^{m}\right]$

$x_{l}^{m}$ : fluxo do produto $m$ no arco $l \mathrm{e}$

$x^{m}=\left[x_{l_{1}}^{m}, x_{l_{2}}^{m}, \ldots, x_{l_{L}}^{m}\right]$.

$A$ : matriz de incidência nó-arco.

$b_{l}^{m}$ : demanda do no $l$, relativo ao produto $m \mathrm{e}$

$b^{m}=\left[b_{1}^{m}, b_{2}^{m}, \ldots, b_{N}^{m}\right]$.

$C_{l}$ : capacidade do arco $l$.

$u^{m}$ : fluxo máximo permitido do produto $m$ no arco $l$. 
Gostaríamos de chamar a atenção para a diferença fundamental existente entre multifluxo e fluxos simples. Nos simples, todos os fluxos que circulam na rede são da mesma natureza (por exemplo, corrente elétrica), logo, em cada arco, eles podem ser somados algebricamente. Já no caso de multifluxo, os fluxos (produtos) são de natureza diferente e, portanto, a soma algébrica deles não tem sentido.

\subsubsection{Formulação Arco-Caminho do Problema de Multifluxo}

Mostramos, a seguir, a formulação arco-caminho do problema de multifluxo, cujo nome advém do fato de se utilizar a matriz de incidência arco-caminho.

Denotamos por $p(m)$ o número de caminhos elementares entre $s_{m}$ e $t_{m}$ em $G$, e para $j=1, \ldots, p(m)$, denominamos por $Q_{j}^{m}, \circ j$-ésimo caminho da lista e definimos o vetor $P_{j}^{m} \circ$ vetor característico, isto é:

$$
\left(P_{j}^{m}\right)_{l}=\left\{\begin{array}{l}
1, \text { se } l \in Q_{j}^{m} \text { : } \\
0, \text { caso contrário }
\end{array}\right.
$$

Finalmente, denotamos por $x_{j}^{m} \geq 0$ a quantidade de fluxo relativa ao produto $m$ circulando no caminho $Q_{j}^{m}$.

Assim, a formulação arco-caminho [GON84] do problema de multifluxo se escreve:

$$
\left\{\begin{array}{l}
\text { Minimizar } \sum_{m=1}^{M} \sum_{j=1}^{p(m)} z_{j}^{m} x_{j}^{m} \\
\text { sujeito a: } \\
\sum_{m=1}^{M} \sum_{j=1}^{p(m)} P_{j}^{m} x_{j}^{m} \leq C \\
\sum_{j=1}^{p(m)} x_{j}^{m}=b^{m} \quad m=1, \ldots, M \\
x_{j}^{m} \geq 0 \quad \forall m \text { e } \forall j=1, \ldots, p(m)
\end{array}\right.
$$

onde:

$C=\left(c_{1}, c_{2}, \ldots, c_{L}\right)^{t}$ é o vetor capacidade do arco.

$z_{j}^{m}$ é o custo do caminho $Q_{j}^{m}$. 
A formulação arco-caminho é bastante usada para a resolução de problemas de multifluxo, por exemplo, Farvolden [FAR93] encontrou uma solução para o problema de multifluxo utilizando a formulação arco-caminho.

\subsection{Considerações Finais}

Embora os problemas de multifluxo não possuam uma estrutura ideal como a dos problemas de simples fluxo, tais como: matriz de incidência totalmente unimodular, validade do teorema do corte mínimo, dentre outros; eles possuem uma estrutura que permite a aplicação de técnicas de decomposição [BAZ77; FAR93; GON84; HU69; ROT66; SAK73].

Observe que as duas formulações apresentadas para os problemas de multifluxo (nó-arco e nó-caminho) recaem num problema de programação linear. É evidente, então, que estes problemas podem ser resolvidos pelos métodos de programação linear. Contudo, a maior parte dos problemas de multifluxo é de grande porte e, conseqüentemente, tem um grande número de variáveis, por isso fica difícil aplicar o método Simplex.

Neste capítulo fizemos uma revisão dos principais tipos de problemas de fluxos encontrados na literatura, para assim podermos avaliar melhor o próximo capítulo, que é o que apresentamos o problema de roteamento de dados. 


\section{CAPÍtUlO 3}

\section{O PROBLEMA DE ROTEAMENTO DE DADOS}

Em uma rede de comunicação, as mensagens que são enviadas de um centro a outro são segmentadas em pequenas quantidades de bytes, chamados packets. Os packets são enviados individualmente pelos arcos da rede até seu destino. Quando um packet chega no seu destino ele é reagrupado com os demais e as mensagens são reconstituídas. Geralmente, o número de caminhos possíveis é grande. Um importante problema em redes de comunicação de packets é o problema de roteamento de dados, que consiste em determinar o encaminhamento ótimo dos packets, através dos arcos da rede, de modo a otimizar um critério. Dos muitos critérios existentes na literatura o mais freqüentemente utilizado é o de minimizar o tempo médio de atraso na transmissão de mensagens.

Cada packet que percorre a rede, indo de um nó origem a um nó destino, sofre um processo de espera (fila) quando passa pelos nós intermediários. Isto é, o packet espera numa fila até que o arco possa ser liberado e ele enviado ao próximo nó da sua rota. $O$ problema de roteamento é de natureza estocástica, pois as taxas de entrada e o tamanho das mensagens são variáveis aleatórias, [BER87].

Kleinrock [KLE64] desenvolveu uma formulação matemática para o problema de roteamento de dados, através da qual, mostrou sob algumas hipóteses estocásticas realistas, que este pode ser formulado como um problema de multifluxo a custo convexo. 
Neste capítulo apresentamos a formulação para o problema de roteamento de dados, que é o problema que trabalhamos. Primeiro mostramos o problema considerando apenas um único produto e, em seguida, a generalização para vários produtos.

\subsection{Problema de Roteamento}

Como já comentamos, em redes de comunicação, as mensagens que são transmitidas através dos arcos, são convertidas em pequenas quantidades de bytes, usualmente chamados packets. Estes packets são enviados individualmente pelos arcos da rede até seu destino.

O problema de multifluxo clássico, em uma rede com $N$ nós e $L$ arcos, consiste em otimizar uma função dada, considerando restrições de não negatividade, de conservação de fluxo em cada nó e de capacidade em cada arco, para cada produto em circulação na rede.

Para o caso de minimização clássico temos:

$$
\left\{\begin{array}{l}
\text { Minimizar } T(x) \\
\text { sujeito a: } \\
A x=b \\
X_{l} \leq C_{l}, \quad l=1, \ldots, L \\
x_{l} \geq 0, \quad l=1, \ldots, L
\end{array}\right.
$$

onde:

$T(X)$ : função objetivo.

$x_{l}^{m}:$ fluxo do produto $m$ no arco $l$.

$x_{l}=\left(x_{l}^{(1)}, x_{l}^{(2)}, \ldots, x_{l}^{(M)}\right)^{l}$ : fluxo no arco $l$.

$x=\left(x_{1}^{(1)}, x_{1}^{(2)}, \ldots, x_{1}^{(M)}, x_{2}^{(1)}, x_{2}^{(2)}, \ldots, x_{2}^{(M)}, \ldots, x_{L}^{(1)}, x_{L}^{(2)}, \ldots, x_{L}^{(M)}\right)^{t}:$ vetor de fluxos,

onde: $M$ é o número de produtos.

$X_{l}=\sum_{j=1}^{M} x_{l}^{(j)}:$ fluxo global no arco $l$.

$C_{l}$ : capacidade do arco $l$.

$A_{((N-1) \times L)}:$ matriz de restrições associadas à conservação do fluxo em cada nó da rede. 
$b_{((N-1) \times 1)}:$ vetor de demanda nos nós da rede.

Kleinrock [KLE64] desenvolveu um modelo matemático para o caso de roteamento de dados, formulando-o como um problema de multifluxo não linear a custo convexo. Neste modelo cada par de nós origem e destino (O,D) de uma mensagem, ou conjuntos de mensagens, é considerado como um produto, ou seja, no caso de um único produto temos somente um par de nó origem-destino, no caso de dois produtos temos dois pares de nós origem-destino, e assim sucessivamente.

\subsubsection{Formulação do Problema para um Único Produto}

Considere uma rede direcionada com $N$ nós e $L$ arcos capacitados de $C_{l}$ bits/segundo e uma única mensagem que deve circular através dos arcos da rede.

Como já dissemos este problema é de natureza estocástica, pois as razões de entrada das mensagens (quantidade de mensagens que entram na rede) bem como seus respectivos comprimentos são aleatórios. Assim, se considerarmos que a chegada de mensagens possa ser aproximada pela distribuição de Poisson, com média de padrão de chegada de $\lambda_{l}$ (mensagens/segundo) e se considerarmos também que o comprimento da mensagem possa ser aproximado por uma distribuição exponencial, cujo comprimento médio é de $1 / \mu_{l}$ (bits/mensagem), então o tempo médio de atraso no arco $l$, usando o critério desenvolvido por Kleinrock, é:

$$
\begin{aligned}
& T_{1}=\frac{1}{\mu_{r} C_{1}-\lambda_{1}}(\text { segundos/mensagem }) \\
& \text { t. }: \text {.. } \because, j^{+}{ }^{+}, i,
\end{aligned}
$$

Por isso o tempo total de atraso em cada arco consiste no atraso de transmissão da mensagem (espera nos buffers) e no tempo gasto durante a própria transmissão.

Em uma rede, com $N$ nós e $L$ arcos, temos que a média total do tempo de atraso é a soma de atrasos em cada arco. Portanto: 


$$
\bar{T}=\frac{1}{\bar{b}} \sum_{l=1}^{L}\left[\lambda_{l} T_{l}+\lambda_{l} T_{l}^{\prime}\right]
$$

onde:

$\bar{b}$ : número médio de mensagens por segundo, entrando na rede.

$\lambda_{l}$ : média de chegada das mensagens (mensagens/segundo).

$T_{1}:$ tempo médio de atraso no arco $l$.

$T_{l}^{\prime}$ : tempo gasto para a transmissão de mensagens no arco $l$.

Deve-se encontrar um padrão médio de chegada de mensagens $\lambda_{l}$, para cada arco $l$, com um número $\bar{b}$ (mensagens/segundo) entrando no nó origem e saindo no nó destino, de maneira que $\bar{T}$ seja mínimo.

Introduzindo-se o conceito de fluxo em redes, tem-se: $\quad x_{i}=\frac{\lambda_{l}}{\mu_{t}}$ representando fluxo médio de mensagens (bits/segundo) no arco $l$.

Para simplificar, foi assumido que todas as mensagens na rede têm o comprimento médio igual a $1 / \mu_{i}$. Assim, utilizando o conceito de fluxo tem-se:

$$
\bar{T}=\frac{1}{\bar{b}} \sum_{l=1}^{L}\left[\lambda_{l} T_{l}+\lambda_{l} T_{l}^{\prime}\right]=\frac{1}{\bar{b}} \sum_{l=1}^{L}\left[x_{l} \mu_{l} T_{l}+x_{l} \mu_{l} T_{l}^{\prime}\right]
$$

como:

$$
T_{i}=\frac{1}{\mu_{t} C_{l}-\lambda_{t}} \text { (segundos/mensagem) }
$$

resulta:

$$
\bar{T}=\frac{1}{\bar{b}} \sum_{l=1}^{\iota}\left[\frac{x_{l} \mu_{l}}{\mu_{l} C_{l}-\lambda_{l}}+T_{i}^{\prime} x_{l} \mu_{l}\right]=\frac{1}{\bar{b}} \sum_{l=1}^{L}\left[\frac{1}{\left(C_{l}-x_{l}\right)}+T_{l}^{\prime} \mu_{l}\right] x_{l}
$$

Para uma maior simplicidade, tomou-se $\mu_{t}=1$. Assim a função final a ser minimizada é: 


$$
\bar{T}=\frac{1}{\bar{b}} \sum_{l=1}^{L} x_{l}\left[\frac{1}{\left(C_{l}-x_{l}\right)}+T_{l}^{\prime}\right],
$$

onde: $x_{l}$ é o fluxo no arco $l$.

No caso de um único produto, o problema de fluxo a ser resolvido é o seguinte:

$$
\left\{\begin{array}{l}
\text { Minimizar } \bar{T} \\
\text { sujeito a: } \\
\qquad \begin{array}{c}
A^{0} x=b \\
x_{l} \geq 0, \quad l=1, \ldots, L
\end{array}
\end{array}\right.
$$

onde:

$\bar{T}$ : função objetivo definida anteriormente;

$b$ : vetor demanda (mensagens) nos nós da rede;

$A^{0}$ : matriz de restrições (definida anteriormente) $((N-1) \times L)$;

com:

$$
a_{n l}^{0}=\left\{\begin{aligned}
1, & \text { se o arco } l \text { sai do nó } n \\
-1, & \text { se o } \operatorname{arco} l \text { entra no nó } n \\
0, & \text { se o arco } l \text { não incide no nó } n
\end{aligned}\right.
$$

O conjunto dos arcos que saem (respectivamente entram) do nó $n$ é denotado por $A_{+}^{0}(n)$ (respectivamente $A_{-}^{0}(n)$ ).

\subsubsection{Generalização para Vários Produtos}

No caso de multifluxo (vários produtos), a função objetivo é determinada pelos fluxos globais nos arcos da rede, ou seja: 


$$
\bar{T}(x)=\frac{1}{\bar{b}} \sum_{l=1}^{L} T_{l}\left(X_{l}\right)
$$

onde:

$$
T_{l}\left(X_{l}\right)=\left\{\begin{array}{cl}
{\left[\frac{1}{\left(C_{l}-X_{l}\right)}+T_{l}^{\prime}\right] X_{l},} & \text { se } 0 \leq X_{l}<C_{l} \\
\infty, & \text { se } \quad X_{l} \geq C_{l}
\end{array}\right. \text { : tempo de atraso em cada arco. }
$$

$X_{l}$ : fluxo global no arco $l$.

Sejam:

M: número de produtos.

$b_{n}^{(m)}$ : demanda no nó $n$, relativo ao produto $m$.

$x_{l}^{(m)}:$ fluxo do produto $m$ no arco $l$.

$$
X_{I}=\sum_{m=1}^{M} x_{l}^{(m)} \text {. }
$$

$$
\bar{b}=\frac{\sum_{m=1}^{M} b^{(m)}}{M}: \text { número médio de mensagens entrando na rede. }
$$

( todas as unidades podem ser tomadas como bits/segundo ).

Para uma melhor simplificação, usaremos uma notação mais compacta:

$x^{(m)}=\left(x_{1}^{(m)}, \ldots, x_{L}^{(m)}\right)^{t}:$ fluxo de cada arco, relativo ao produto $m$.

$x=\left(x^{(1)^{t}}, x^{(2)^{\prime}}, \ldots, x^{(M)^{t}}\right)^{t}:$ fluxos em relação a todos os produtos.

$x_{l}=\left(x_{l}^{(1)}, \ldots, x_{l}^{(M)}\right)^{t}$ : fluxo no arco $l$ em relação a todos os produtos.

$X=\left(X_{1}, X_{2}, \ldots, X_{L}\right)^{t}$ : fluxo global em cada arco.

$b^{(m)}=\left(b_{1}^{(m)}, b_{2}^{(m)}, \ldots, b_{N}^{(m)}\right)^{t}:$ demanda de todos os nós relativos ao produto $m \operatorname{com} b_{D_{m}}^{(m)}$ excluído. 
$b=\left(b^{(1)^{\prime}}, b^{(2)^{\prime}}, \ldots, b^{(M)^{\prime}}\right)^{t}:$ demanda em todos os nós com relação a todos os produtos.

No decorrer do desenvolvimento, a quantidade de fluxo no arco $l$ pode ser denotada de duas maneiras: $x_{l}$ ou $x_{n k}$, quando o arco $l$ sai do nó $n$ e entra no nó $k$.

Um conjunto linearmente independente de restriçōes de fluxo, para cada produto $m$, pode ser escrito na forma:

$$
A^{(m)} x^{(m)}-b^{(m)}=0, \quad m=1,2, \ldots, M
$$

onde:

$A^{(m)}$ : matriz de incidência nó-arco com a linha relativa ao nó destino $D_{m}$ excluída.

Desse modo, o problema de multifluxo pode ser escrito como:

$$
\left\{\begin{array}{l}
\text { Minimizar } \bar{T}(x)=\frac{1}{\bar{b}} \sum_{l=1}^{L} T_{l}\left(X_{l}\right) \\
\text { sujeito a: } \\
\qquad \begin{array}{l}
A x=b \\
\text { com } x \geq 0 \text {, ou seja, cada componente } x_{l}^{(m)} \geq 0
\end{array}
\end{array}\right.
$$

onde:

$$
\begin{aligned}
& A \text { : matriz diagonal }\left(A^{(1)}, A^{(2)}, \ldots, A^{(M)}\right) . \\
& X_{l}=\sum_{m=1}^{M} x_{l}^{(m)} \text { : fluxo global no arco } l .
\end{aligned}
$$

\subsubsection{Restrições do Problema}

As restrições do problema de roteamento de dados, formulado como um problema de fluxo, são de três tipos: 


\section{- Restrições de não negatividade}

O fluxo não deve assumir valores negativos para cada arco da rede, portanto cada componente $x_{l}^{(m)} \geq 0, l=1, \ldots, L ; m=1, \ldots, M$. Assim tem-se que $X_{l} \geq 0$.

\section{- Restrições de capacidade ${ }^{\nu}$}

O fluxo global $X_{l}$ deve ser menor que a capacidade do arco, ou seja, $X_{l}<C_{l}$, $l=1, \ldots, L$.

\section{- Restriçōes de conservação de fluxo nos nós da rede}

O fluxo que chega no nó deve ser igual ao fluxo que deixa o nó, assim, a equação de conservação de fluxo do nó $\underline{i}$, relativo ao produto $m$, pode ser escrita do seguinte modo:

$$
\sum_{n=1}^{N} x_{i n}^{(m)}-\sum_{n=1}^{N} x_{n i}^{(m)}=\left\{\begin{aligned}
b^{(m)}, & i: \text { nó origem } \\
-b^{(m)}, & i: \text { nó destino } \\
0, & \text { caso contrário }
\end{aligned}\right.
$$

Se a equação acima for generalizada para todos os nós da rede e para todos os produtos, obtém-se: $A x=b$, onde:

A: matriz diagonal por blocos, onde cada bloco é a matriz de incidência nó-arco relativa a um produto.

$b$ : vetor representante de demanda em cada nó.

$x$ : vetor de fluxo.

Em vista disso, pode-se escrever o problema de roteamento para uma rede com $N$ nós, $L$ arcos e $M$ produtos como:

$$
\left\{\begin{array}{l}
\text { Minimizar } \bar{T}(x)=\frac{1}{\bar{b}} \sum_{l=1}^{L}\left[\frac{1}{\left(C_{l}-X_{l}\right)}+T_{l}^{\prime}\right] X_{l} \\
\text { sujeito a: } \\
\qquad \begin{array}{l}
A x=b \\
x_{l} \geq 0 \quad l=1, \ldots, L
\end{array}
\end{array}\right.
$$


onde:

$X_{l}=\sum_{m=1}^{M} x_{l}^{(m)}:$ fluxo global no arco $l$.

$A$ : matriz diagonal $\left(A^{(1)}, A^{(2)}, \ldots, A^{(M)}\right)$.

$\mathrm{Na}$ formulação do problema de roteamento, proposta por Kleinrock, não é necessário considerar explicitamente as restrições de capacidade $\left(X_{1} \leq C_{l}\right)$, como acontece no problema (1.1) (página 18), porque elas estão presentes na função objetivo, isto é:

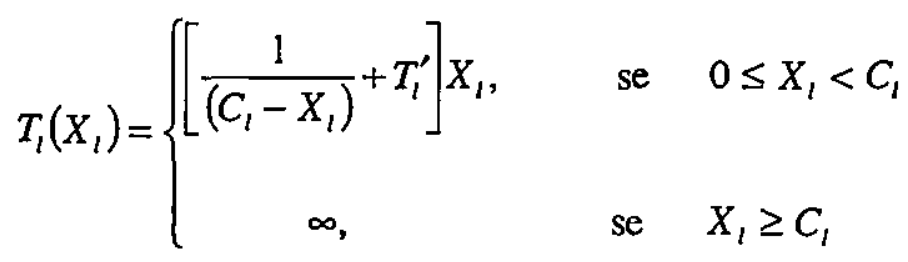

As restriçōes de capacidade $\left(X_{1} \leq C_{l}\right)$ também conhecidas como restriçōes de acoplamento, dificultam a decomposição do problema de multifluxo em subproblemas menores, mas, se elas não estiverem presentes facilitará a resolução do problema, pois ele pode ser facilmente decomposto em subproblemas de dimensões menores. Contudo, a não linearidade da função objetivo é um fator de dificuldade uma vez que, de modo geral, um problema não linear é mais difícil de resolver que o problema linear e a maioria dos algoritmos existentes para se resolver problemas de multifluxo, tratam do caso linear [BER88; GON84; KEN78; KEN80; SAK84].

Castro e Nabona [CAS96] apresentaram um algoritmo para resolver problemas de multifluxo com função objetivo linear ou não linear. Este algoritmo tem como estratégia dividir as variáveis em básicas, não básicas e superbásicas. Castro e Nabona testaram o algoritmo para problemas com 150.000 variáveis e 45.000 restrições.

\subsection{Considerações Finais}

Neste capítulo vimos o problema de roteamento de dados, sua formulação proposta por Kleinrock [KLE64], como sendo um problema de natureza estocástica com uma função não- 
linear, sendo formulado para um único produto e em seguida generalizado para vários. No próximo capítulo mostramos o algoritmo paralelo que decompõe este problema em subproblemas de simples fluxo e também o método que será utilizado para a resolução destes subproblemas, ou seja a minimização dos mesmos. 


\section{CAPÍTULO 4}

\section{ALGORITMO PARALELO PARA ROTEAMENTO DE}

DADOS

Neste capítulo apresentamos um método primal, desenvolvido por Luvezute [LUV95] e Ribeiro [RIB98], de relaxamento para a resolução do problema de roteamento de dados formulado no capítulo 3. Este método faz uma decomposição do problema de multifluxo em subproblemas de simples fluxo. Apresentamos também o método Simplex Convexo utilizado para a resolução da minimização dos subproblemas.

\subsection{Método de Relaxamento}

O método desenvolvido é um algoritmo primal de relaxamento, que decompõe o problema de minimização global de multifluxo em minimizações de subproblemas locais de simples fluxo, isto é, se considerarmos $M$ o número de produtos que deve circular na rede de comunicação, a cada nova iteração o método resolve $M$ subproblemas de simples fluxo, ou seja, com um s 6 produto, que podem ser resolvidos separadamente. Nosso objetivo consiste, então, na implementação em paralelo do método de relaxamento. 


\subsubsection{Decomposição do Problema}

Como visto, no capítulo 3 , pode-se escrever o problema de roteamento de dados como mostrado a seguir:

$$
\left\{\begin{array}{l}
\text { Minimizar } \bar{T}(x)=\frac{1}{\bar{b}} \sum_{l=1}^{L} T_{l}\left(X_{l}\right) \\
\text { sujeito a: } \\
\qquad \begin{array}{l}
A x=b \\
\text { com } \quad x \geq 0, \text { ou seja, cada componente } x_{l}^{(m)} \geq 0
\end{array}
\end{array}\right.
$$

onde:

$$
\begin{aligned}
& T_{l}\left(X_{l}\right)= \begin{cases}{\left[\frac{1}{\left(C_{l}-X_{l}\right)}+T_{l}^{\prime}\right] X_{l},} & \text { se } 0 \leq X_{l}<C_{l} \quad \text { : tempo de atraso em cada arco. } \\
\infty, \quad & \text { se } X_{l} \geq \mathrm{C}_{1}\end{cases} \\
& \bar{T}(x)=\frac{1}{\bar{b}} \sum_{l=1}^{L} T_{l}\left(X_{l}\right): \text { tempo médio de atraso na transmissão das mensagens. }
\end{aligned}
$$

$A$ : matriz diagonal $\left(A^{(1)}, A^{(2)}, \ldots, A^{(M)}\right)$, onde:

$A^{(m)}$ : matriz de incidência nó-arco $((N-1) \times L)$, com relação ao produto $m$, com:

$$
a_{n l}^{(m)}= \begin{cases}1, & \text { se o arcol sai do nó } n \\ -1, & \text { se o } \operatorname{arco} l \text { entra no nó } n \\ 0, & \text { se o arcol } l \text { nãoincideno nó }\end{cases}
$$

Nesta matriz, retira-se a linha relativa ao nó destino $\left(D_{m}\right)$ do produto $m$, para que a matriz tenha posto completo.

$x=\left(x^{(1)^{t}}, x^{(2)^{t}}, \ldots, x^{(M)^{r}}\right)^{t}:$ vetor de fluxos.

$x^{(m)}=\left(x_{1}^{(m)}, x_{2}^{(m)}, \ldots, x_{L}^{(m)}\right)^{t}:$ vetor de fluxos em todos os arcos referentes ao produto $m$.

$b^{(m)}=\left(b_{1}^{(m)}, b_{2}^{(m)}, \ldots, b_{N}^{(m)}\right)^{t}:$ vetor de demanda de todos os nós relativos ao produto $m$, com a coordenada referente ao nó destino do produto $m$ excluída. 
$b=\left(b^{(1)^{\prime}}, b^{(2)^{\prime}}, \ldots, b^{(M)^{\prime}}\right):$ vetor de demanda nos nós da rede, referentes a todos os produtos.

$\bar{b}=\frac{\sum_{m=1}^{M} b^{(m)}}{M}:$ número médio de mensagens entrando na rede.

Seja $x$ uma solução factível inicial para o problema de roteamento de dados apresentado em (4.1). Se fixarmos os valores de $x$ para todos os produtos, com exceção de um produto $p$ que se conserva relaxado, pode-se reescrever o problema (4.1) em função do fluxo $x^{(p)}$, como é mostrado a seguir:

$$
\begin{aligned}
& \left\{\begin{array}{l}
\text { Minimizar } \frac{1}{\overline{\mathrm{b}}} \sum_{l=1}^{L} T_{l}\left(\bar{X}_{l}+x_{l}^{(p)}\right), p=1, \ldots, M, l=1, \ldots, L \\
\text { sujeitoa : }
\end{array}\right. \\
& A^{(p)} x^{(p)}=b^{(p)} \\
& x_{l}^{(p)} \geq 0, \quad p=1, \ldots, M, l=1, \ldots, L \\
& \text { onde: } \quad \bar{X}_{l}=\sum_{m=1, m \neq p}^{M} x_{l}^{(m)}, \quad x^{(p)}=\left(x_{1}^{(p)}, \ldots, x_{l}^{(p)}\right)^{t} \\
& T_{l}\left(\bar{X}_{l}+x_{l}^{(p)}\right)= \begin{cases}{\left[\frac{1}{C_{l}-\left(\bar{X}_{l}+x_{l}^{(p)}\right)}+T_{l}^{\prime}\right]\left(\bar{X}_{l}+x_{l}^{(p)}\right),} & \text { se } 0 \leq\left(\bar{X}_{l}+x_{l}^{(p)}\right)<C_{l} \\
\infty, & \text { se }\left(\bar{X}_{l}+x_{l}^{(p)}\right) \geq \mathrm{C}_{l}\end{cases}
\end{aligned}
$$

Como os valores de $\bar{X}_{l}, l=1,2, \ldots, L$ são pré-fixados, podemos escrever: $\bar{C}_{l}=C_{l}-\bar{X}_{l}$. Então o problema (4.2) pode ser escrito somente em função de $x_{l}^{(p)}, \quad l=1,2, \ldots, L, \quad p=1,2, \ldots, M$ como mostrado a seguir: 


$$
\left\{\begin{array}{l}
\text { Minimizar } \frac{1}{\mathrm{~b}} \sum_{l=1}^{\mathrm{L}} T_{i}\left(x_{i}^{(p)}\right), p=1, \ldots, M, \quad l=1, \ldots, L \\
\text { sujeito a: } \\
\qquad A^{(p)} x^{(p)}=b^{(p)} \\
x_{i}^{(p)} \geq 0, \quad p=1, \ldots, M, \quad l=1, \ldots, L
\end{array}\right.
$$

onde:

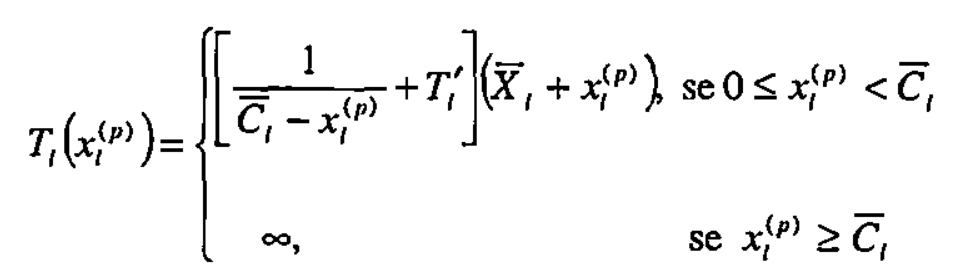

Observamos que ao fixar um valor factível para os demais fluxos, em todos os arcos da rede, com relação aos $(M-1)$ produtos restantẹ, tem-se um problema de simples fluxo cuja variável é $x^{(p)}$. Repetindo este processo com os $(M-1)$ produtos restantes tem-se no total $M$ subproblemas de um único produto, que podem ser resolvidos separadamente.

\subsubsection{Procedimentos do Método}

O método de relaxamento consiste em resolver o problema de roteamento de dados decomposto (problema 4.3), iterativamente, ou seja, a partir de uma solução factível inicial, resolve=se $M$ subproblemas de simples fluxo. $O$ valor de $x$ encontrado para estes $M$ subproblemas servirá de solução inicial para se resolver os $M$ subproblemas da iteração seguinte.

$O$ processo iterativo de atualização do fluxo $x$ pode ser realizado de duas maneiras:

(i) Semelhante ao utilizado na resolução de sistemas pelo método iterativo de Jacobi, ou seja, a partir de uma solução inicial factível $x$, resolve-se o problema (4.3) com todos os valores de $\left(x_{l}^{(m)}\right)$ fixos, com exceção do fluxo do produto $1\left(x_{l}^{(1)}\right)$ que se conserva relaxado. A mesma coisa é feita para todos os produtos, que utilizam sempre a mesma solução inicial, isto é, resolvese o problema (4.3) para $x$ fixado e o produto $2\left(x_{i}^{(2)}\right)$ relaxado e assim, sucessivamente, para os $M$ produtos. Com os valores de $x$, assim obtidos, inicia-se uma nova iteração. Então, para se 
calcular $x^{(p)}$, na iteraçāo $[k+1]$, usa-se todos os valores de $x^{(1)}$ até $x^{(M)}$ da iteração $[k]$. E o processo se repete até que $\left\|x_{i}^{[k+1]}-x_{i}^{[k]}\right\| \leq \varepsilon$ para o produto $m=1, \ldots, M$ e para todo o arco $l=1, \ldots, L$.

(ii) Semelhante ao utilizado na resolução de sistemas pelo método iterativo de GaussSeidel, ou seja, primeiro resolve-se o problema (4.3) relaxando-se o produto 1. A solução $x^{(1)}=\left(x_{1}^{(1)}, x_{2}^{(1)}, \ldots, x_{L}^{(1)}\right)^{\prime}$ encontrada aqui, juntamente com os valores dos demais fluxos que estão fixados, servirão como solução inicial para resolver novamente o problema (4.3) relaxandose agora o produto 2. A seguir, relaxa-se o produto 3 e resolve-se novamente o problema (4.3) e se utiliza os valores de $x^{(1)}=\left(x_{1}^{(1)}, \ldots, x_{L}^{(1)}\right)^{\prime}$ e $x^{(2)}=\left(x_{1}^{(2)}, \ldots, x_{L}^{(2)}\right)^{\prime}$ até agora obtidos, juntamente com os demais fluxos que estão fixados. Este processo é repetido sucessivamente para todos os produtos. Portanto, para se calcular $x^{(p)}$, na iteração $[k+1]$, são utilizados os valores de $x^{(1)}$ até $x^{(p-1)}$ calculados na iteração $[k+1]$ e os valores de $x^{(p+1)}$ até $x^{(M)}$ da iteração $[k]$. O processo iterativo é repetido até que o valor de $x$ na iteração $[k]$ esteja suficientemente próximo do valor de $x$ na iteração $[k+1]$, isto é, até que para todo produto $m=1, \ldots, M$ e para todo arco $l=1, \ldots, L$, tenhamos $\left\|x_{i}^{[k+1]}-x_{i}^{[k]}\right\| \leq \varepsilon$

Como em cada subproblema os arcos estão com a capacidade reduzida da soma dos fluxos que estão fixados, a factibilidade da nova solução é garantida.

Este método de relaxamento pode ser utilizado porque, como já dissemos, no problema de roteamento, as restrições de capaçidade estão embutidas na função objetivo. Deste modo nãoé necessário trabalhar com as restrições de acoplamento $\left(X_{1} \leq C_{1}\right)$ que dificultam a decomposição do problema em subproblemas e interferem no grau de independência dos mesmos.

* Para maiores detalhes sobre problemas de multifluxo com restrições de acoplamento ver, por exemplo, em Gondran [GON84]. 


\subsubsection{Algoritmo de Relaxamento (multifluxo)}

A seguir apresentamos uma descrição sucinta do algoritmo de relaxamento para 0 problema de roteamento de dados.

Seja $x^{[0]}$ uma solução inicial factível.

Seja $\varepsilon>0$ uma precisão para o critério de parada.

Solução ótima global := false.

$\mathrm{k}:=0$.

Enquanto ( Solução ótima global = false ) faça:

início

$\mathrm{k}:=\mathrm{k}+1$.

Para $m:=1, \ldots, M$ faça, em paralelo:

início

Fixar todos os fluxos, exceto os valores de $x^{(m)}$, de acordo com

os processos iterativos de atualização de fluxo descrito

anteriormente.

Minimizar o problema (4.3) para o produto $m$.

fim (para).

Se para todo $m=1, \ldots, M$ e, para todo arco $l=1, \ldots, L$ :

$$
\left\|x_{l}^{[k+1]}-x_{l}^{[k]}\right\| \leq \varepsilon, \text { solução ótima global }:=\text { true. }
$$

fim (enquanto).

Como se pode verificar este algoritmo pode ser implementado usando qualquer um dos processos iterativos de atualização de fluxo: Jacobi ou Gauss-Seidel.

O processo (ii), semelhante ao de Gauss-Seidel, tem a desvantagem de diminuir a independência entre os subproblemas, o que dificultaria uma implementação em paralelo do método, sobretudo no aspecto de comunicação de dados. Por outro lado, o referido processo poderia convergir mais rapidamente que o processo $(i)$, uma vez que ele utiliza informações mais atuais. $O$ processo $(i)$ semelhante ao de Jacobi tem a vantagem de manter total independência dos subproblemas. Este fato faz com que o método seja perfeito para execução em paralelo, numa 
máquina de memória distribuída, porque o número de comunicaçōes entre processadores, a cada iteração, será pequeno. Por este motivo, optamos pela implementação paralela do método que utiliza o processo iterativo semelhante ao de Jacobi.

A etapa de minimização dos subproblemas (problema 4.3) pode ser feita por qualquer método de simples fluxo a critério convexo. Neste trabalho usamos o método Simplex Convexo. "

Luvezute [LUV95], em seu trabalho, também utilizou o método do Gradiente Projetado, para a minimização dos subproblemas, porém verificou-se que o método Simplex Convexo é mais eficiente, por isso optamos pela utilização do mesmo.

\subsection{Método Simplex Convexo}

O método Simplex Convexo [KEN80] foi desenvolvido para resolução de problemas de fluxos em redes, com custo convexo, que se apresenta da forma:

$$
\left\{\begin{array}{r}
\text { Minimizar } \bar{T}(x) \\
\text { sujeito a: } \\
A x=b \\
0 \leq x \leq C
\end{array}\right.
$$

onde:

$A$ : matriz de incidência nó-arco da rede $(N \times L)$.

$1 . b=0$, onde: $1=(1, \ldots, 1)^{t}$, com dimensão $(1 \times N)$.

$\bar{T}(x)$ : função convexa.

Este método, originalmente desenvolvido por Willard Zangwill, pode ser analisado como uma generalização do método Simplex Linear [BAZ77].

Como sabemos, no problema de fluxo em redes a matriz de restrições tem posto igual a $(N-1)$. Neste caso, para se obter uma matriz de posto completo para o problema proposto (4.3) foi adicionado uma variável artificial $a$ para uma linha (nó) $w$, e obteve-se o seguinte problema: 


$$
\left\{\begin{array}{l}
\text { Minimizar } \bar{T}(x) \\
\text { sujeito a: } \\
\qquad x+e^{w} \phi^{\prime}=b \\
0 \leq x \leq C \\
0 \leq a \leq 0
\end{array}\right.
$$

onde: $A$ é a matriz de incidência nó-arco e wé um inteiro menor ou igual a $N$.

Como $a$ é zero, a solução ótima para o problema (4.5) será também uma solução ótima para o problema (4.4).

\section{Descrição do Método}

O método Simplex Convexo, do mesmo modo que o Simplex Linear, parte de uma solução inicial factível e depois procura uma direção factível de melhoria. Gostaríamos de relembrar que, uma direção $d$ é dita factível para $x$ se $x+\alpha d$ é factível para algum $\alpha>0$. Esta direção é chamada de melhoria no ponto $x$, se $d$ é factível para $x$ e a derivada direcional de $\bar{T}($. na direção $d$, sobre o ponto $x$, é negativa.

O Simplex Convexo, assim como no caso linear, particiona as variáveis em dois tipos: variáveis básicas $\left(x_{Y}\right)$ e não básicas $\left(x_{Z}\right)$. A cada iteração, o método permite que as variáveis não básicas mudem de fluxo. Entretanto, aqui, as variáveis não básicas podem assumir outros valores que seus limitantes inferiores e superiores, ou seja, $0 \leq x_{z} \leq C_{z}$.

No desenvolvimento do método Simplex Convexo é assumido que o gradiente de $\bar{T}($.) existe sobre $\left\{x: 0 \leq x_{l} \leq C_{l}\right\}$ e que $\bar{T}($.$) é separável, ou seja:$

$$
\bar{T}_{l}(x)=\sum_{l} \bar{T}_{l}\left(x_{l}\right)
$$

Suponha que particionamos as equações de conservação de fluxo $A x=b$ em $[Y: Z] x=b$, onde $Y$ é uma base. Igualmente particionamos $x$ em $\left[x_{Y} \vdots x_{z}\right]$ e $\mathrm{C}$ em $\left[C_{Y} \vdots C_{z}\right]$. Então, o problema pode ser escrito como: 


$$
\left\{\begin{array}{l}
\text { Minimizar } \bar{T}\left(\left[x_{Y} \vdots x_{z}\right]\right) \\
\text { sujeito a: } \\
\qquad x_{y}=Y^{-1} b-Y^{-1} Z x_{z} \\
0 \leq x_{Y} \leq C_{Y} \\
0 \leq x_{z} \leq C_{Z}
\end{array}\right.
$$

Substituindo $x_{Y}$ em (4.6), obtemos:

$$
\left\{\begin{aligned}
\text { Minimizar } & f\left(x_{z}\right)=\bar{T}\left[Y^{-1} b-Y^{-1} Z x_{z} \vdots x_{z}\right] \\
\text { sujeito a: } & \\
0 & \leq \mathrm{Y}^{-1} b-Y^{-1} Z x_{z} \leq C_{Y} \\
0 & \leq x_{Z} \leq C_{Z}
\end{aligned}\right.
$$

Como o problema foi transformado num problema de minimização em função das variáveis não-básicas, toma-se o conjunto de direções no espaço não básico.

$$
D=\left\{e^{1}, e^{2}, \ldots, e^{L-N},-e^{1},-e^{2}, \ldots,-e^{L-N}\right\}
$$

onde:

$e^{i}$ : vetor unitário, com a $i$-ésima coordenada igual a um e as outras coordenadas são nulas.

Para garantir a factibilidade deve-se assegurar que $0 \leq x_{z} \leq C_{z}$. Assim o conjunto de direçð̃es factíveis que asseguram $0 \leq x_{z}+\alpha d \leq C_{z}$ é:

$$
\left\{\begin{array}{c}
e^{i} \text { é direção factível se }: x_{z}^{i}<C_{z}^{i} \\
\left(-e^{i}\right) \text { é direção factível se }: x_{z}^{i}>0
\end{array}\right.
$$

Considerando o conceito de derivada direcional no espaço não básico indicamos a seguir como selecionar uma direção factível de melhoria. 
A derivada direcional de $f\left(\right.$.) no ponto $x_{z}$, na direção $d$, desde que o limite exista, é definida por:

$$
D_{d} f\left(x_{z}\right)=\lim _{t \rightarrow 0^{+}} \frac{f\left(x_{z}+t \frac{d}{\|d\|}\right)-f\left(x_{z}\right)}{t},
$$

Mostra-se que a derivada direcional no espaço não-básico é dada por:

$$
D_{d} f\left(x_{z}\right)=\frac{\nabla f\left(x_{z}\right) d}{\|d\|}
$$

onde: $\nabla f\left(x_{z}\right)$ é o gradiente de $f\left(\right.$.) avaliado no ponto $x_{z}$.

Como $f\left(x_{z}\right)=\bar{T}\left[Y^{-1} b-Y^{-1} Z x_{z} \vdots x_{z}\right]$ e podemos particionar

$\nabla \bar{T}$ em $\nabla \bar{T}(x)=\left[\nabla \bar{T}_{Y}(x) \vdots \nabla \bar{T}_{z}(x)\right]$, assim, obtemos:

$$
\nabla f\left(x_{z}\right)=\nabla \bar{T}_{z}(x)-\nabla \bar{T}_{Y}(x) Y^{-1} Z \text {. }
$$

Queremos que $\nabla f\left(x_{z}\right) d<0$. Assim, para tomarmos uma direção de melhoria no espaço não básico, devemos escolher uma direção que satisfaça cada coordenada $i$ :

$$
\left\{\begin{array}{clll}
e^{i}, & \text { se } x_{Z}^{i}<C_{Z}^{i} & \text { e } & \nabla \bar{T}_{Z}\left(x^{i}\right)-\nabla \bar{T}_{Y}\left(x^{i}\right) Y^{-1} Z<0 \\
\left(-e^{i}\right), & \text { se } x_{Z}^{i}>0 & \text { e } & \nabla \bar{T}_{Z}\left(x^{i}\right)-\nabla \bar{T}_{Y}\left(x^{i}\right) Y^{-1} Z>0
\end{array}\right.
$$

Este conjunto representa o conjunto dos arcos que são candidatos a entrar na base. Para avaliá-lo precisamos calcular o valor de $\nabla f\left(x_{z}\right)$ que indicará o crescimento da função objetivo.

Tomemos $Y$ uma base qualquer para (4.7), e seja $\tau_{Y}$ sua árvore correspondente.

Podemos calcular as componentes de $\nabla \bar{T}$, diretamente sobre a árvore $\tau_{Y}$, como mostramos a seguir:

Se $l_{k}$ for um arco que não está na árvore $\tau_{Y}$, e o $P=\left\{n_{1}, l_{j_{1}}, n_{2}, l_{j_{2}}, \ldots, n_{t}, l_{j_{t}}, n_{t+1}\right\}$, denotar o caminho do arco $l_{k}$ que liga os nós origem $O\left(l_{k}\right)$ e destino $D\left(l_{k}\right)$ na árvore $\tau_{Y}$, e se $c^{\prime}(k)$ for o ciclo formado por $P$, com adição de $l_{k}$ à árvore $\tau_{Y}$, e também, sua correspondente 
sequiência de orientação $O R(k)$. Assim, pode-se determinar o conjunto dos arcos que são candidatos a entrar na base (direção de melhoria) de duas maneiras:

(i) Através da seqüência de orientação $O R(k)$, isto é:

$$
\vec{c}_{k}=\sum_{i=1}^{t} O R_{i}(k) \frac{\partial \bar{T}(x)}{\partial x_{j_{i}}}
$$

onde:

$t$ : número de nós no ciclo $\left(P+/ l_{k}\right)$.

$x_{f_{i}}$ : fluxos nos arcos da árvore correspondente aos arcos $l_{j_{i}}$.

Assim, tomando $\varepsilon$ como uma precisão para o critério de parada, o conjunto se define:

$$
\left\{\begin{array}{l}
l_{k}, \text { se } x_{Z}^{k}<C_{z}^{k} \text { e } \bar{c}_{\mathrm{k}}>\varepsilon \\
l_{k}, \text { se } x_{Z}^{k}>0 \text { e } \bar{c}_{\mathrm{k}}<-\varepsilon
\end{array}\right.
$$

(ii) Ou através das variáveis duais $\pi_{i}$ (também chamadas de potenciais dos nós), isto é, calcular

$$
\bar{c}_{k}=\pi_{o\left(l_{k}\right)}-\pi_{D\left(l_{k}\right)}-\frac{\partial \bar{T}(x)}{\partial x_{l_{k}}}
$$

da seguinte forma:

$$
\begin{cases}\pi_{w}=0, & \text { onde } w=\text { nó raiz de } \tau_{Y} \\ \pi_{O\left(l_{j}\right)}-\pi_{D\left(l_{j}\right)}=\frac{\partial \bar{T}(x)}{\partial x_{j}}, & \text { para } l_{j} \in \tau_{Y}\end{cases}
$$

Deste modo, o conjunto se define como anteriormente.

Qualquer uma destas maneiras pode ser estendida para o método do algoritmo Simplex Convexo. 
Uma vez conhecida a direção de melhoria, uma busca unidimensional é requerida para determinar o tamanho do passo a ser dado nesta direção.

A base é atualizada caso o resultado da alteração torne uma das variáveis básicas nula ou a faça atingir seu limite superior.

Agora, apresentamos o algoritmo para o caso específico, onde $\bar{T}(X)$ é separável.

\section{Algoritmo Simplex Convexo}

\section{(0) Inicialização}

Seja $\bar{x}$ um fluxo factível e determine uma árvore $\tau_{\gamma}$. Seja $\varepsilon>0$ uma precisão para o critério de parada.

\section{(1) Avaliação}

Para $l_{k} \notin \tau_{Y}$, seja $P=\left\{n_{1}, l_{j_{1}}, n_{2}, l_{j_{2}}, \ldots, n_{t}, l_{j_{t}}, n_{t+1}\right\}$ denotando o caminho em $\tau_{Y}$ que liga $O\left(l_{k}\right)$ ao $D\left(l_{k}\right)$.

Seja $c^{\prime}(k)$ o ciclo formado por $P$ com a adição de $l_{k}$, e seja $O R(k)$ a sequiência de orientação correspondente a este ciclo.

Sejam:

- $\overrightarrow{\mathrm{c}}_{\mathrm{k}}=\sum_{i=1}^{t} O R_{i}(k) \frac{\partial \bar{T}(\bar{x})}{\partial x_{j_{t}}}$

ou

- $\bar{c}_{k}=\pi_{O\left(l_{k}\right)}-\pi_{D\left(l_{k}\right)}-\frac{\partial \bar{T}(\bar{x})}{\partial x_{l_{k}}}$

- $\psi_{1}=\left\{l_{k}: x_{k}<C_{k}\right.$ e $\left.\bar{c}_{k}>\varepsilon\right\}$

- $\psi_{2}=\left\{l_{k}: x_{k}>0 \mathrm{e} \bar{c}_{\mathrm{k}}<-\varepsilon\right\}$

- Se $\psi_{1} \cup \psi_{2}=\varnothing \Rightarrow \bar{x}$ é uma solução ótima para o problema.

- Senão seja: $l_{k} \in \psi_{1} \cup \psi_{2}$ e $\delta= \begin{cases}+1 & \text { se } l_{k} \in \psi_{1} \\ -1 & \text { se } l_{k} \in \psi_{2}\end{cases}$ 


\section{(2) Cálculo do bloqueio}

Sejam:

- $\Delta_{1}=\min _{O_{i}\left(\mu_{k}\right)=\delta}\left\{\bar{x}_{j i}, \infty\right\}$

- $\Delta_{2}=\min _{-O_{i}\left(l_{k}\right)=\delta}\left\{C_{j_{i}}-\bar{x}_{j_{i}}, \infty\right\}$

- $\Delta=\min \left\{\Delta_{1}, \Delta_{2}\right\}$

Se $\Delta=0 \Rightarrow$ vá para o passo 5

\section{(3) Atualização do fluxo}

Neste passo, verificamos se a solução é factível e determinamos a magnitude do passo.

Definimos o vetor $u$ como segue:

$$
u_{j}=\left\{\begin{array}{cc}
O R_{j}(k), & \text { se } l_{j} \in c^{\prime}(k) \\
0, & \text { caso contrário }
\end{array}\right.
$$

Seja:

$$
\gamma=-\delta \sum_{i=1}^{t} O R_{i}(k)\left[\frac{\partial \bar{T}(\bar{x}-\Delta \delta u)}{\partial x_{i}}\right]
$$

- Se $\gamma<0 \Rightarrow\left\{\begin{array}{l}\bar{x}=\bar{x}-\Delta \delta u \\ \text { vá para o passo5 }\end{array}\right.$

\section{(4) Procedimento de busca (bissecção)}

Este passo pode ser substituído por qualquer outro procedimento de Busca Unidimensional conhecido.
a) Seja: $\alpha_{0}=0$ e $\alpha_{1}=\Delta$
b) Seja: $\alpha=\frac{\left(\alpha_{0}+\alpha_{1}\right)}{2}$
c) Seja: $\gamma=-\delta \sum_{i=1}^{t} O R_{i}(k)\left[\frac{\partial \bar{T}(\bar{x}-\alpha \delta u)}{\partial x_{i}}\right]$
d) $\operatorname{Se}|\gamma|<\varepsilon \Rightarrow\left\{\begin{array}{l}\text { Seja } \bar{x}=\bar{x}-\alpha \delta u \text { e } \\ \text { retorne ao passo } 1\end{array}\right.$
e) Se $\gamma>0 \Rightarrow\left\{\begin{array}{l}\alpha_{1}=\alpha \text { e } \\ \text { retorne ao passo b }\end{array}\right.$ 
Senão $\left\{\begin{array}{l}\alpha_{0}=\alpha \mathrm{e} \\ \text { retorne ao passo b }\end{array}\right.$

\section{(5) Mudança de base}

Verifique se algum fluxo $x_{i}$, no arco $l_{i}$ de $c^{\prime}(k)$, tornou-se nulo ou atingiu seu limitante superior, caso isto tenha ocorrido remova o arco $l_{i}$ de $\tau_{Y}$ e adicione o arco $l_{k}$, formando, assim, uma árvore. Retorne ao passo 1.

\subsection{Considerações Finais}

Com relação a trabalhos referentes a algoritmos paralelos para problemas de fluxos em redes podemos, por exemplo, citar Tseng [TSE90] que desenvolveu um algoritmo paralelo para redes parcialmente assíncrono. $\rightarrow$ ?

Neste capítulo apresentamos o algoritmo paralelo para o problema de roteamento de dados e também o método Simplex Convexo, bem como seu algoritmo, que será utilizado para a resolução dos subproblemas de simples fluxo. Como implementamos este algoritmo paralelo, estudamos então no próximo capítulo alguns conceitos de computação paralela úteis para uma melhor compreensão da implementação. 


\section{CAPÍTULO 5}

\section{COMPUTAÇÃO PARALELA}

A computação paralela consiste basicamente em um conjunto de elementos de processamento, que cooperam e comunicam-se entre si para solucionarem grandes problemas, de maneira mais rápida do que se estivessem sendo solucionadas seqüencialmente [ALM94; SOU96].

A capacidade de aumentar o processamento em uma única máquina foi a principal razão para o surgimento da computação paralela. Suas principais vantagens são:

- alto desempenho para programas lentos;

- solução mais natural para problemas intrinsecamente paralelos;

- maior tolerância à falhas.

Neste capítulo falamos de algumas características fundamentais de computação paralela, abordando os tópicos mais relevantes, e também sobre o computador paralelo IBM-SP2, que foi utilizado para a implementação do problema. Sobre computação paralela comentamos das classificações existentes quanto as arquiteturas, para assim saber qual é o tipo de arquitetura em que o computador paralelo IBM-SP2 se enquadra, e também sobre a problemática do cálculo em paralelo, ou seja, quais as vantagens e desvantagens de se trabalhar com computação paralela. 


\subsection{Histórico}

O paralelismo é muito recente. Os primeiros computadores modemos surgiram durante a segunda guerra mundial, os quais se baseavam no princípio de von Neumam, com funcionamento seqüencial e dependência causal das tarefas a executar. Estes computadores executam uma instrução e em seguida passa para a próxima.

Com isso resultaram o desenvolvimento considerável de algoritmos numéricos seguindo o esquema seqüencial [RIB91].

Os primeiros artigos sobre paralelismo datam do final dos anos 50. Por meio deles foram introduzidos os conceitos de paralelismo e concorrência, que levam em conta a independência causal de algumas tarefas e por conseguinte de tratamento simultâneo, não seqüencial e algumas vezes, de funcionamento não determinista [OLI97].

\subsection{Motivações para o Paralelismo}

Dentre os fatores que incentivaram o desenvolvimento e a aplicação do paralelismo, o desempenho, a tolerância à falhas e os avanços recentes da microeletrônica são os principais.

Tratando-se do desempenho é evidente que, quanto maior for o número de processadores disponíveis, mais rápido tende a ser o processamento das informações. Deve-se observar que, os problemas advindos das comunicações entre processadores podem comprometer o desempenho esperado, dado que a aceleração proporcionada pela elevação do número de processadores (speedup) pode não acompanhar proporcionalmente o número de elementos incluídos [OLI97].

Quanto as falhas no "hardware", estas não devem em definitivo comprometer o seu funcionamento, pois o paralelismo permite a continuidade de operações do software visto que conta com mais processadores.

Com os avanços da microeletrônica foi possível a construção de microprocessadores de alto desempenho. 


\subsection{Arquiteturas Paralelas}

Por arquitetura paralela entende-se a máquina capaz de executar mais de uma tarefa ao mesmo tempo, excluindo-se o paralelismo de baixo nível. Existem várias propostas para classificação de arquiteturas de computadores mas, devido à sua constante evolução, nenhuma consegue abranger todas as arquiteturas existentes.

A classificação de Flynn [FLY72] apesar de antiga, é bastante respeitada e utilizada, embora não consiga englobar todos os tipos de arquiteturas existentes atualmente. A classificação de Flynn baseia-se no fluxo de instruções e no fluxo de dados. Duncan [DUN90] propôs uma classificação mais recente, com o objetivo de acrescentar as arquiteturas surgidas, porém sua classificação é menos conhecida do que a de Flynn.

\subsubsection{Classificação de Flynn}

Flynn propôs sua classificação das arquiteturas em quatro categorias de máquinas conforme a multiplicidade do fluxo de dados e de instruções.

Num computador encontramos dois tipos de fluxos:

I - fluxo de instrução ("instruction stream");

D - fluxo de dados ("data stream").

Estes fluxos podem ser do tipo:

S - único;

M - múltiplo.

As classes assim obtidas são as seguintes:

- SISD: Single Instruction / Single Data. Computadores seqüenciais.

- MISD: Multiple Instruction / Single Data. Computadores que operam com pipeline.

- SIMD: Single Instruction / Multiple Data. Supercomputadores vetoriais.

- MIMD: Multiple Instruction / Multiple Data. Computadores paralelos intrínsecos. 


\section{SISD ("Single Instruction / Single Data")}

Esta categoria é a arquitetura dos computadores clássicos (sequienciais), possui apenas um fluxo de instruções e um fluxo de dados, as instruções são executadas seqüiencialmente sobre um único fluxo de dados. A unidade de controle é única, mas pode dispor de mais de uma unidade funcional. A figura abaixo ilustra um esquema desta arquitetura.

FI = Fluxo de Instruçōes

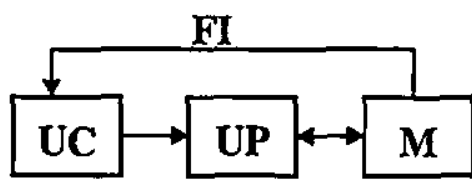

UC = Unidade de Controle

UP = Unidade de Processamento

M = Memória

Figura 5.1 - Exemplo de arquitetura SISD.

\section{MISD ("Multiple Instruction / Single Data")}

Este tipo de arquitetura envolve múltiplos processadores que executam diferentes instruçöes em um único conjunto de dados. Geralmente, nenhuma arquitetura é classificada como MISD, todavia alguns autores consideram o pipeline como um representante desta categoria.

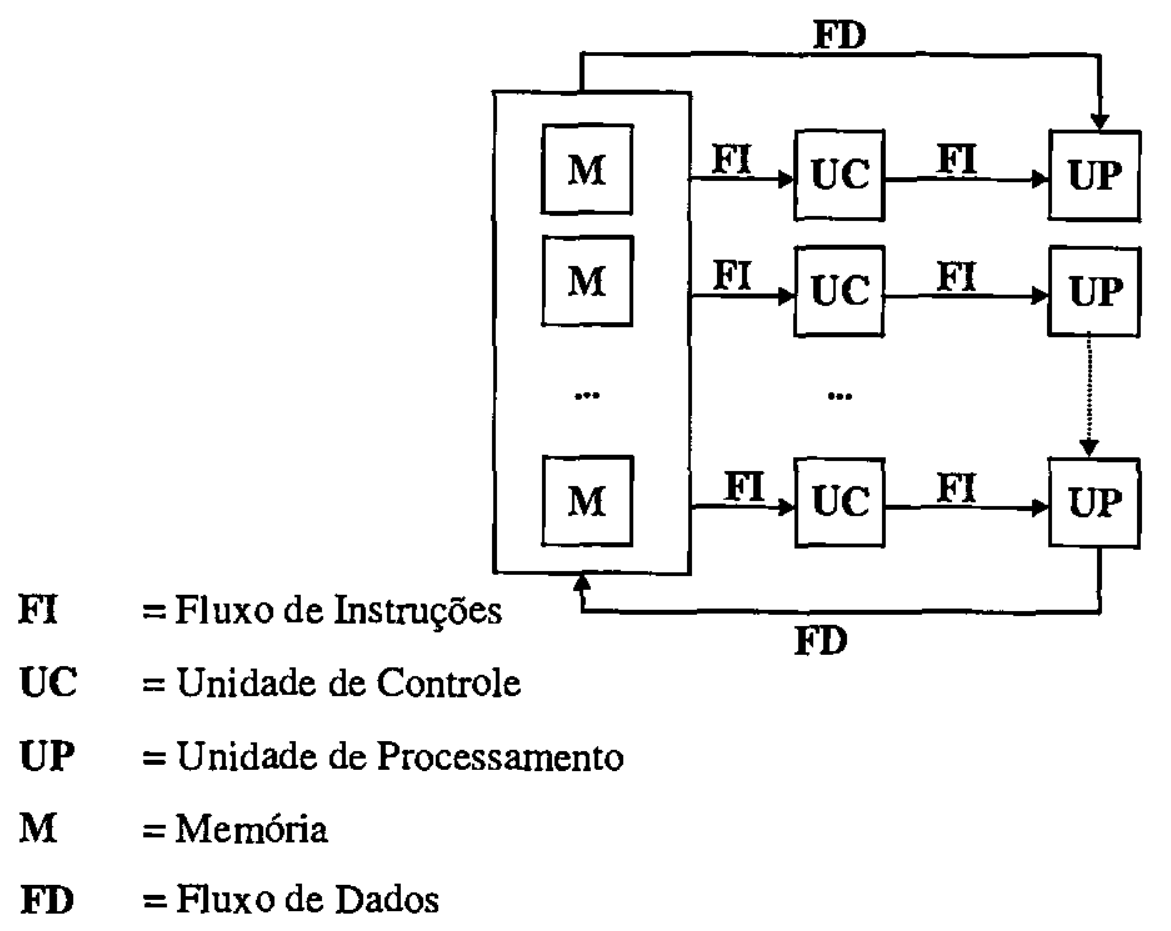

Figura 5.2 - Exemplo de arquitetura MISD. 


\section{SIMD ("Single Instruction / Multiple Data")}

Esta categoria possui um único fluxo de instruções com múltiplos fluxos de dados, ou seja, envia as mesmas instruções aos processadores sendo que estes as executam simultaneamente sobre dados diferentes.

Possuem funcionamento síncrono.

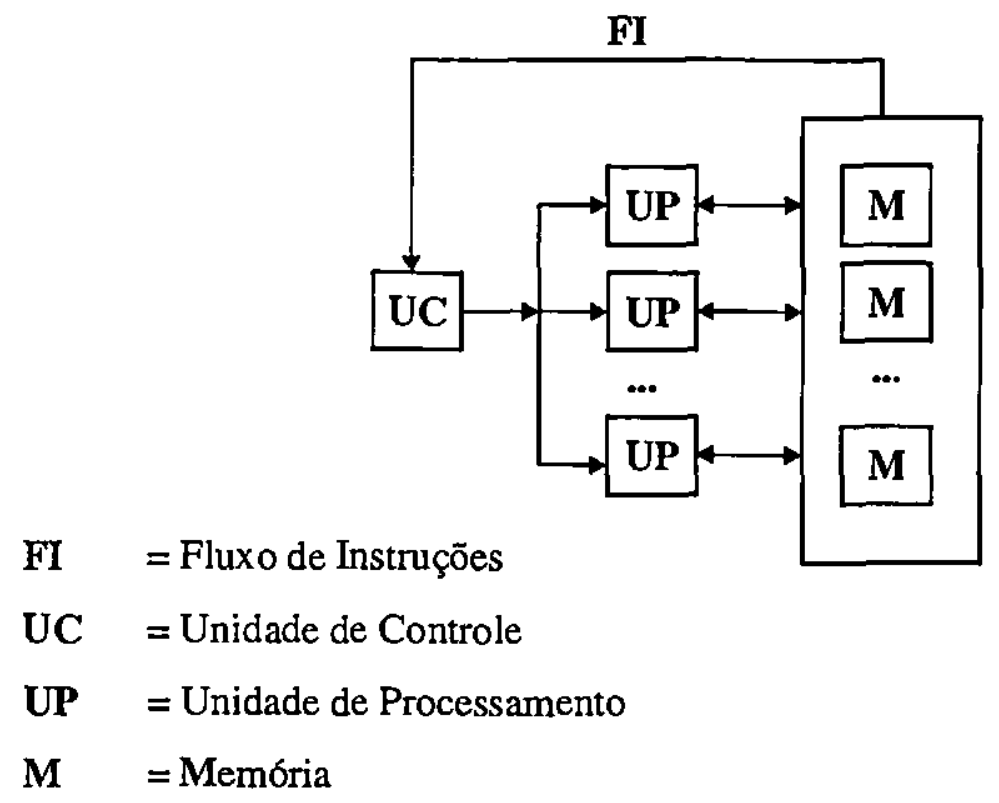

Figura 5.3 - Exemplo de arquitetura SIMD.

As máquinas que dispõem de um grande número de processadores simples e de baixo desempenho (mais de 10000) são máquinas SIMD. Às vezes não se pode utilizar estes processadores isoladamente. Alguns só trabalham sobre um bit e são dotados de uma memória de milhares de bits (exemplo: "connexion machine"). Como resultado, os programas não podem ser armazenados na memória de cada processador [OLI97].

\section{MIMD ("Multiple Instruction / Multiple Data")}

Múltiplos fluxos de instruções que operam sobre múltiplos fluxos de dados caracterizam as arquiteturas MIMD. Cada unidade de processamento possui sua unidade de controle executando instruções sobre conjunto de dados. A comunicação entre os diversos processadores é feita através da memória. Seu funcionamento é assíncrono. 


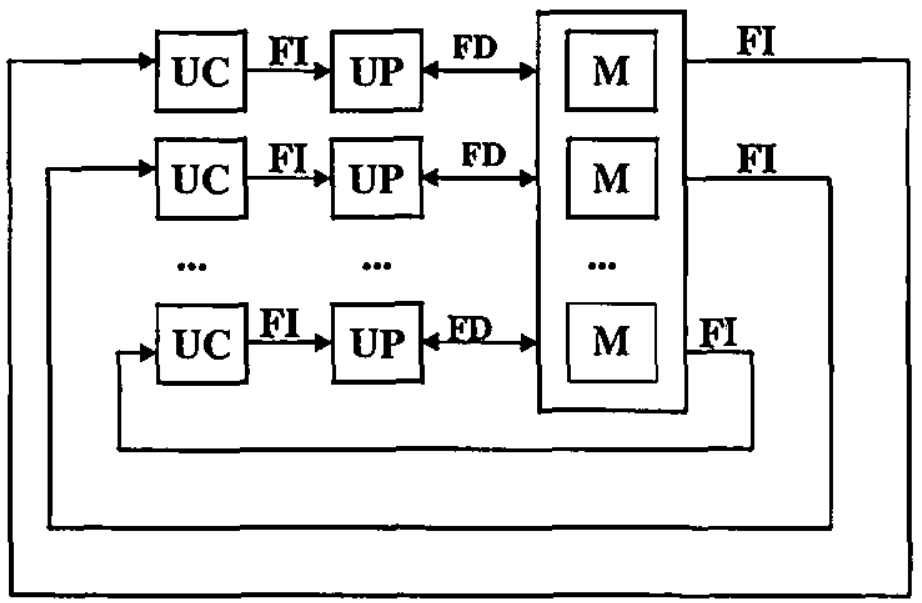

FD $=$ Fluxo de Dados

FI $=$ Fluxo de Instruçōes

UC = Unidade de Controle

UP = Unidade de Processamento

M = Memória

Figura 5.4 - Exemplo de arquitetura MIMD.

As máquinas que constituem este tipo de arquitetura dispōem de poucos processadores independentes os quais são relativamente potentes. Neste tipo de arquitetura as trocas de informaçōes são feitas de forma desordenada e guiadas através dos dados. O computador paralelo SP2 que utilizamos possui este tipo de arquitetura.

\subsubsection{Classificação de Duncan}

Duncan [DUN90] propôs uma classificação de arquiteturas paralelas mais moderna e abrangente com o objetivo de encaixar as inovações arquiteturais dos últimos anos e uma taxonomia mais coerente. Para o desenvolvimento dessa classificação, três aspectos básicos são considerados:

- excluir arquiteturas que possuem mecanismos de paralelismo de baixo nível, os quais são características comuns nos computadores atuais. Um exemplo desses mecanismos é a utilização de pipeline;

- manter os elementos da classificação de Flynn devido a sua ampla utilização; 
- incluir arquiteturas que foram criadas após a classificação de Flynn e que não se encaixam nela.

A classificação de Duncan divide as arquiteturas em dois grupos principais: arquiteturas síncronas e assíncronas (figura 5.5).

Arquiteturas Síncronas $\left[\begin{array}{l}\text { Processadores Vetoriais } \\ \text { Processadores Matriciais (Arquiteturas SIMD) } \\ \text { Arquiteturas Sistólicas }\end{array}\right.$

Arquiteturas Assíncronas $\left[\begin{array}{l}\text { Arquiteturas MIMD } \begin{array}{l}\text { Memória Compartilhada } \\ \text { Memória Distribuída }\end{array} \\ \text { Arquiteturas não convencionais }\left[\begin{array}{l}\text { Arquiteturas Híbridas (MIMD/SIMD) } \\ \text { Arquiteturas a Fluxo de Dados } \\ \text { Arquiteturas de Redução } \\ \text { Arquiteturas de Frente de Onda }\end{array}\right.\end{array}\right.$

Figura 5.5 - Classificação de Duncan.

Arquiteturas Síncronas: as operações concorrentes são coordenadas por uma unidade de controle central e por um relógio comum ao sistema. Fazem parte desta categoria:

- Processadores Vetoriais: possuem um hardware específico para a otimização de operações sobre vetores. A organização básica de um processador vetorial consiste de: um processador de instrução (busca de decodificação da instrução), uma unidade de processamento vetorial e um processador escalar.

- Arquiteturas SIMD: as máquinas SIMD são compostas por um único fluxo de instruções atuando sobre diferentes dados, como já descrito anteriormente. Os processadores matriciais são exemplos dessa categoria síncrona, onde a unidade de controle supervisiona e sincroniza as unidades de processamento (figura 5.3).

- Arquiteturas Sistólicas: são arquiteturas projetadas para solucionar problemas de sistemas de propósito específicos que demandam computação intensa e grande quantidade de operações de E/S. Os processadores das pontas possuem comunicação com a memória. 
Arquiteturas Assíncronas : caracterizam-se pelo controle descentralizado de hardware e são compostas por vários processadores que executam independentemente instruções sobre diferentes dados. Em outras palavras, trata-se das arquiteturas MIMD da classificação de Flynn, sejam elas convencionais ou não [DUN90].

- Arquiteturas MIMD convencionais: corresponde as arquiteturas MIMD discutidas na classificação de Flynn. A organização da memória é que determina como serão feitas as comunicações e o sincronismo entre os processadores, podendo ser compartilhada (comum a todos os processadores) ou distribuída (cada processador possui sua própria memória, sendo que ela é utilizada apenas por ele).

- Arquiteturas MIMD não convencionais: essa classe engloba as arquiteturas que apesar de possuírem múltiplos fluxos de dados e instruções, possuem também características próprias que dificultam a classificação como puramente MIMD. Nessa classe encontram-se as máquinas híbridas (MIMD/SIMD), arquiteturas a fluxo de dados (dataflow), arquiteturas de redução e arquiteturas de frente de onda. Elas apresentam aspectos MIMD, pois são assíncronas e com múltiplos fluxos de instruções e de dados, mas possuem características próprias, impedindo que sejam classificadas apenas como MIMD [DUN90].

\subsection{Problemática do Cálculo Paralelo}

As máquinas paralelas trouxeram mudanças, na área de métodos numéricos, para o tratamento das partes independentes de um mesmo programa de maneira concorrente. No contexto sequiencial a solução de um problema é composta de três partes [OLI97]:

- escolha do algoritmo;

- implementação do algoritmo em uma máquina;

- estudo do desempenho.

No contex to do cálculo paralelo, o mesmo problema é composto de seis etapas [OLI97]:

- escolha do algoritmo;

- divisão das tarefas;

- atribuição das tarefas aos processadores; 
- sincronização das tarefas;

- implementação do algoritmo paralelo;

- estudo do desempenho.

Em conseqüência disto, a problemática do paralelismo é constituída, por problemas do tipo matemática aplicada e por problemas de natureza computacional.

\subsubsection{Escolha do Algoritmo}

Para se escolher um algoritmo paralelo tem-se as seguintes alternativas:

- construir um algoritmo paralelo de alto desempenho, que se adapte a um tipo de arquitetura paralela;

- adaptar um algoritmo seqüencial em função do seu desempenho, da sua complexidade algorítmica e da sua aptidão a ser paralizado.

\subsubsection{Divisão das Tarefas}

Esta fase não é desvinculada da fase da escolha do algoritmo, pois, deve-se procurar as tarefas importantes que podem ser executadas por processadores independentes, de forma que minimize as ligações entre as tarefas que serão implementadas em processadores diferentes. Com isto, é preciso fazer um estudo da complexidade algorítmica e da complexidade das comunicações.

\subsubsection{Atribuição das Tarefas aos Processadores}

Existem duas maneiras para se atribuir as tarefas a um ou vários processadores para a execução:

- modo estático;

- modo dinâmico.

No modo estático, cada processador é concedido, de maneira definitiva, a um conjunto de tarefas. Esta atribuição tem a vantagem de minimizar as transferências de dados no caso da 
utilização de arquiteturas paralelas, onde cada processador possui memória. O problema deste modo consiste na intolerância à falhas. Se ocorrer uma falha o algoritmo não pode ser executado.

No modo dinâmico, cada processador é dado a um conjunto de tarefas diferentes. Isto causa o aumento das comunicações de informações. A vantagem é a tolerância à falhas. Enquanto existir um processador sem falhas, o algoritmo continua a sua execução.

\subsubsection{Sincronização das Tarefas}

Especificar uma ordem de execução das tarefas que garanta o desempenho do problema. Por isso pode-se escolher diversos esquemas de evolução do conjunto de tarefas: totalmente sincronizadas, parcialmente sincronizadas, assíncronas.

Deve-se levar em conta a natureza particular do problema, o tipo de arquitetura computacional utilizada e o desempenho da máquina, para a escolha do tipo de sincronização.

\subsubsection{Implementação do Algoritmo Paralelo}

Refere-se aos aspectos computacionais ligados à utilização de um algoritmo paralelo sobre uma máquina paralela. Notadamente deve-se observar: a codificação do algoritmo paralelo, as comunicações entre processadores, o funcionamento das sincronizações, a rede, o teste de parada e a proteção dos dados.

\subsubsection{Estudo do Desempenho}

Vários fatores podem ser significativos para o estudo do desempenho de uma implementação paralela.

- A influência do sistema: tipo de arquitetura;

número de processadores, topologia da rede de interconexão; características dos processadores, da rede e das memórias.

- A influência dos diferentes parâmetros do algoritmo: equilíbrio das tarefas;

dimensão das tarefas.

- Comparação com outros algoritmos paralelos. 
Um dos fatores mais importantes da computação paralela é o aumento da velocidade de processamento obtida com o paralelismo. Para se calcular o aumento obtido, dois parâmetros são abordados: Speedup e eficiência.

O "speedup" pode ser definido como o aumento da velocidade observado quando se executa um algoritmo paralelo em um computador paralelo em relação ao sequiencial. Ele permite medir o ganho de tempo devido à utilização de $p$ processadores [EAG89]:

$$
S_{p}=\frac{T_{1}}{T_{p}}
$$

onde:

$$
\begin{aligned}
& p \text { - corresponde ao número de processadores; } \\
& T_{1} \text { - tempo para executar o programa em um processador; } \\
& T_{p} \text { - tempo para executar o programa em } p \text { processadores. }
\end{aligned}
$$

O caso ótimo é obtido quando $S_{p}=p$, ou seja, à medida em que aumenta o número de processadores, aumenta-se diretamente a velocidade de processamento. Sistemas onde $S_{p}=p$ são conhecidos como sistemas escalares [MCB94]. Fatores que influenciam na obtenção do caso ótimo estão relacionados principalmente com a comunicação entre os processadores e a parte seqüencial (aquela que não pode ser paralelizada) do algoritmo.

A "eficiência" é a medida da taxa média de utilização de $p$ processadores, ou seja, é o quanto os processadores estão sendo utilizados. A mesma é dada por:

$$
E_{p}=S_{p} / p
$$

A variação de $E_{p}$ é entre 0 e 1, sendo que o valor 1 indica uma eficiência de $100 \%$, mas, dificilmente a eficiência é igual a 1, pois, sempre haverá perdas na paralelização do algoritmo e sobrecarga de comunicação e sincronismo entre os processadores [KIR91]. 


\subsection{Introdução ao SP2}

Faremos uma breve introdução sobre o computador paralelo IBM-SP2. Comentamos sobre sua arquitetura, sua estrutura de hardware e seu software.

\subsubsection{Arquitetura IBM Power}

O computador paralelo IBM-SP2 que utilizamos possui uma arquitetura IBM POWER (Performance Optimized With Enhanced RISC (Reduced Instruction Set Computer)), que consiste em uma arquitetura super-escalar a qual executa até seis instruções por ciclo de clock e prevê saltos pela unidade de cache de instruções, instruções combinadas de multiplicação e soma em ponto flutuante ( 1 ciclo).

\subsubsection{Hardware do SP2}

As partes principais do hardware do SP2 são:

- bastidores do SP2;

- nós de processamento;

- rede de comunicação de alto desempenho;

- estação de controle.

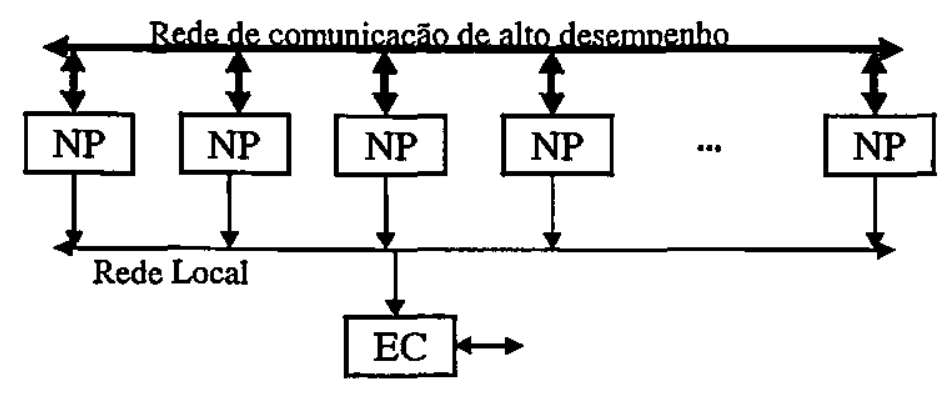

EC: Estação de Controle

NP: Nó de Processamento

Figura 5.6 - Visão geral do sistema. 


\section{Bastidores}

O SP2 possui de 2 a 16 nós de processamento por bastidor, ou seja, comporta no máximo 16 nós do tipo thin (ou thin-2) ou 8 nós do tipo wide. É possível conectar vários bastidores. Os nós não precisam ser os mesmos, isto é, no SP2 pode-se utilizar nós do tipo thin e wide juntos no mesmo bastidor.

O bastidor contém fontes de alimentação redundantes, de modo que se um nó falhar, o sistema inteiro não será afetado. É projetado para possibilitar manutenção concorrente dos nós, ou seja, cada nó de processamento pode ser removido e reparado sem interromper as atividades dos outros nós. Desta forma, o SP2 fornece um sistema altamente confiável para seus usuários.

\section{Nós de processamento}

Os nós de processamento para o SP2 são de três formas: nós do tipo wide, thin e thin-2 [CEN98]. Cada um destes nós possuem sua própria memória, disco e vários slots Micro Channel, utilizados para operações de E/S e conectividade. Comentamos, a seguir, suas características:

- wide são configurados para agirem como servidores do sistema, utilizam o processador POWER2, suportam quantidades de memoria (tanto secundária, quanto primária e caches) maiores que a suportada pelos nós thin. Além disso, o número de slots disponível é também maior.

- thin e thin-2 fornecem alto poder de processamento, sendo os mais adequados para executar os programas do usuário. Estes oferecem a flexibilidade de rodar alguma combinação de jobs interativos, em batch, seriais e paralelos simultaneamente, podendo ser compartilhados por qualquer um destes jobs ou ser dedicados a rodar uma única aplicação.

A máquina SP2, que trabalhamos, possui três nós de processamento, sendo um nó do tipo wide e dois nós do tipo thin-2. Cada um dos nós thin-2 possui processador POWER2 de 66.7 MHz, 256 Mbytes de memória, 128 Kbytes de cache de dados e barramento de memoria de 128 bits. Já o nó wide possui processador POWER2 de $66.7 \mathrm{MHz}, 256$ Mbytes de memória, 256 Kbytes de cache de dados e barramento de 256 bits. Estes nós estão interligados através da rede de alto desempenho que chega a ter um bandwidth de 35 Mbytes/segundo e latência de 50 microssegundos, além de possuir conexões para redes Ethernet, Token Ring e FDDI. 
O SP2 possui também uma estação de trabalho IBM RISC/600 3CT que é utilizada como nó interativo. Este nó interativo possui as mesmas características de hardware dos nós do tipo thin-2, exceto o barramento de memória que é de 64 bits. Enquanto os nós de processamento do SP2 são destinados ao processamento em batch de programas paralelos, a estação de controle é dedicada ao processamento interativo e a submissão, em batch, de programas de usuários, através do software de gerenciamento LoadLeveler. O acesso do usuário ao SP2 deve ser efetuado através dessa estação (quanto a utilização do LoadLeveler ver o anexo I).

\section{Rede de comunicação de alto desempenho}

A rede de comunicação de alto desempenho conecta todos os nós de processamento juntos, permitindo que todos eles possam enviar mensagens simultaneamente [IBM95].

A rede de comunicação do SP2 é bidirecional com interconexão multi-estágio [FOR97]. A rede multi-estágio foi escolhida para que a rede de comunicação pudesse oferecer uma característica muito importante que é a escalabilidade. Com esse tipo de rede é possível o acréscimo de novos nós de processamento, quando há a necessidade de mais poder computacional, sem afetar o desempenho do sistema [CEN98].

Uma outra característica da rede de comunicação é a existência de caminhos redundantes entre os nós de processamento, permitindo que novas rotas sejam geradas na presença de componentes defeituosos, isto possibilita que o sistema seja tolerante à falhas [FOR97].

A confiabilidade é um outro fator de extrema importância, principalmente, pelo fato da rede suportar utilização multi-usuário. Uma necessidade para sistemas multi-usuário é a distribuição de mensagens livres de erros, e para isso, o sistema fornece proteção nas transmissões de mensagens, através do uso de códigos de detecção de erros, que são transportados nos pacotes transmitidos e checados no nó de processamento receptor.

Além disso, a rede opera com chaveamento de pacotes.

\section{Estação de controle}

O gerenciamento de sistemas grandes é sempre uma tarefa difícil. No SP2, com a existência de uma única estação de controle, responsável pelo controle, monitoramento, manutenção e administração do sistema, esta tarefa se torna mais simples. Geralmente, o administrador do sistema utiliza a estação de controle, juntamente como um software chamado PSSP (Parallel Systems Support Programs) disponível com o SP2, para realizar tarefas como 
gerenciamento de contas de usuários, gerenciamento de filas de impressão e filas de submissão de jobs (tarefas), instalação de nós de processamento do SP2, etc [FOR97].

A estação de controle deve ser uma máquina RISC System $/ 6000$, que pode ser utilizada também como um servidor de arquivos. O bastidor do SP2 é interligado com a estação de controle através de uma conexão extema (Ethemet).

\subsubsection{Software do SP2}

O sistema operacional utilizado no SP2 é AIX/6000 que é similar ao UNIX. Esse sistema operacional é instalado por completo em todos os nós de processamento, como também no nó interativo (estação de controle). Os seguintes softwares estāo disponíveis no SP2:

- conjunto de utilitários para administração do sistema (como o software PSSP, citado na subseção anterior);

- ambiente de programação paralela, consistindo de passagem de mensagem (como MPI, PVM, PVMe, MPL), ambiente operacional paralelo (POE - Parallel Operating Environment) e ferramentas como depuradores paralelos e ferramentas de visualização [FOR97];

- LoadLever, software responsável pelo gerenciamento, escalonamento de jobs e pelo balanceamento de carga nos nós de processamento.

O SP2 é uma implementação moderna da arquitetura MIMD com memória distribuída. Como toda máquina de alto desempenho, para mantê-la atualizada, são necessários investimentos periódicos. Utilizar um processamento paralelo, em alguma de suas modalidades, pode melhorar substancialmente o desempenho de suas aplicações, preparando-as para a disseminação das arquiteturas, ora em curso.

\subsection{Considerações Finais}

Os últimos anos têm apresentado um grande avanço tecnológico, o qual tem possibilitado tanto o desenvolvimento de arquiteturas com maior poder computacional bem como de novas 
tecnologias de redes de comunicação. Como consequiência ocorreu um grande aumento na aceitação e adoção do processamento paralelo para diversos fins.

Neste capítulo apresentamos os problemas de se programar em paralelo, as arquiteturas paralelas e a máquina paralela IBM-SP2 a fim de possibilitar uma visão geral sobre computação paralela. É importante compreender essas características visto que são essenciais par uma melhor conclusão sobre o desempenho do algoritmo que implementamos. No próximo capítulo comentamos sobre a biblioteca paralela PVM que foi usada durante a implementação do algoritmo paralelo. 


\section{CAPÍTULO 6}

\section{PVM - PARALLEL VIRTUAL MACHINE}

PVM é um conjunto integrado de bibliotecas e de ferramentas de software, cuja finalidade é de emular um sistema computacional concorrente heterogêneo, flexível e de propósito geral [BEG94]. Seu principal objetivo é permitir que um grupo de computadores conectados, possivelmente com diferentes arquiteturas, possa trabalhar cooperativamente formando assim uma máquina paralela virtual [GEI94].

O projeto PVM iniciou em 1989 no ORNL - Oak Ridge National Laboratory, onde a primeira versão (PVM 1.0) foi desenvolvida por Vaidy Sundram e Al Geist. Esta versão foi utilizada apenas pelo laboratório e não disponibilizada para outras instituições. Entretanto a partir da versão 2.0 (1991), com a participação da University of Tennessee, o PVM começou a ser utilizado em muitas aplicações científicas, dando início à sua distribuição gratuita. Após várias revisões, em fevereiro de 1993, o PVM foi completamente reescrito gerando a versão 3.0, quando começou a ser distribuído como um software de domínio público, fato que contribuiu significativamente para a sua divulgação e difusão. A partir de então, várias atualizações foram feitas, sendo que a versão mais recente é a versão 3.4. O sistema PVM permite aplicações nas linguagens Fortran, $\mathrm{Ce} \mathrm{C}++$.

Neste capítulo descrevemos as principais características de implementação do PVM, salientando seus aspectos mais importantes. 


\subsection{Componentes do PVM}

O sistema PVM é composto de duas partes [GEI94]: um daemon (Pvmd) e uma biblioteca de rotinas com a interface PVM (Libpvm).

O Pvmd atua como "gerenciador" da máquina e roteador de mensagens, sendo executado em cada host que compõe a máquina virtual.

A Libpum contém um conjunto de primitivas que atuam como elo entre uma tarefa e a máquina virtual, ou seja o $P v m d$ e as outras tarefas.

\subsubsection{Pvm Daemon (Pvmd)}

Para que uma aplicação no PVM seja executada por um usuário, primeiro a máquina virtual deve ser criada, iniciando com o Pvmd. Com isso a aplicação poderá ser iniciada, a partir do prompt do sistema operacional, em qualquer computador da máquina virtual. É possível haver mais de uma máquina virtual utilizando os mesmos equipamentos no mesmo instante, sem que uma atrapalhe as outras.

O Pvmd é executado em cada host da máquina virtual e são configurados para trabalharem juntos. O Pvmd que faz parte da máquina virtual de um usuário não tem acesso ao pertencente a outra máquina virtual. O Pvmd foi projetado para executar sob um login sem privilégios, reduzindo assim os riscos de uma máquina virtual interferir na execução de outras [SOU96].

O Pvmd não faz nenhum processamento, atuando somente como um roteador e controlador de mensagens, agindo assim como um ponto de contato entre cada host autenticando mensagens, fazendo o controle de processos e detectando falhas.

O primeiro Pvmd executado é chamado de mestre (master) enquanto que os outros são chamados de escravos (slaves). Durante a execução normal, não existem grandes diferenças estruturais entre os dois. A única diferença é que apenas o Pvmd mestre pode efetuar as operações de gerenciamento, como iniciar outros daemon e anexá-los à configuração atual da máquina paralela virtual.

Para armazenar informações a respeito da máquina virtual, o Pvmd mantém algumas estruturas de dados. Entre elas estão as tabelas de hosts e a tabela de tarefas, que armazenam informações a respeito das tarefas que estão sendo executadas. Estruturas de dados para a 
manipulação de filas de pacotes e mensagens são incorporadas às tabelas de tarefas, além de salvadores de contexto (wait contexts), que permitem a manipulação consistente da informação durante o processo multitarefa executado pelo Pvm daemon [BEG94; SOU96].

\subsubsection{Biblioteca de Comunicação (Libpvm)}

A biblioteca Libpvm tem como características principais, o reduzido número de rotinas (pois a mesma utiliza o mesmo espaço de endereçamento da aplicação paralela), um padrão fortemente estabelecido (facilitando a comunicação entre mestre e escravos) e a flexibilidade de suas rotinas, sendo facilmente utilizadas para a obtenção de outras mais complexas.

As funções de mais alto nível da Libpvm são responsáveis pela interface com o usuário e são escritas de forma independente da máquina onde o PVM está sendo executado, enquanto que as funções de mais baixo nível são dependentes da plataforma utilizada.

\subsection{Identificadores de Tarefas (TID)}

Todas as tarefas que estão sendo executadas no PVM possuem um identificador inteiro único, chamado de identificador de tarefa (TID - task identifier), fornecido para a aplicação pelo PVM daemon (mestre ou escravo). Mensagens são enviadas e recebidas especificando as tarefas envolvidas pelo seu TID. Os TIDs são formados por quatro campos dispostos dentro de um dado do tipo inteiro (32 bits), os quais estão disponíveis em grande quantidade de máquinas.

A figura abaixo mostra os campos do TID. S, G, H são interpretados da mesma forma em todos os Pvmds da máquina virtual.

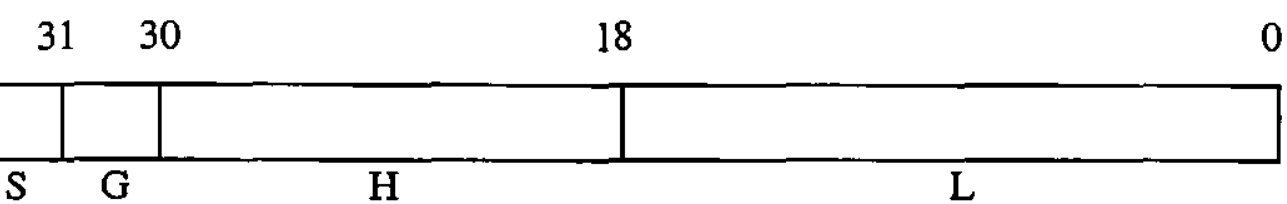

Figura 6.1 - Identificador de tarefas genérico.

Onde:

$\mathrm{H}$ - possui o número do host da máquina virtual, visto que cada host (Pvmd) possui um 
único número a partir do momento em que é colocado em execução, o qual é conhecido por todos os outro Pvmds da máquina virtual.

$\mathrm{S}$ - indica quando o TDD está designando um Pvmd. Nessa situação o campo H possui o seu número e o L ainda está vazio.

L - contém vários significados, sendo a sua finalidade designar uma tarefa.

$\mathrm{G} \rightarrow$ é utilizado para indicar tarefas de um mesmo grupo.

Com a utilização do TW na forma apresentada surgem várias vantagens, como:

- tarefas podem receber seus TIDs sem precisar da comunicação entre os Pvmds;

- como o número de host precede o número de tarefa, desta forma as mensagens podem ser roteadas mais facilmente;

- o uso dos campos L e/ou H possibilita o retomo de códigos de erros.

No caso da implementação desenvolvida neste trabalho, apesar de os identificadores de tarefas possuírem estes quatro campos, optamos pela não agregação de valor aos mesmos, uma vez que foi utilizado um campo específico e mais complexo em nosso registro, com as informações necessárias, para a comunicação e controle entre o processos mestre e escravos. Outro padrão adotado neste trabalho foi a utilização de apenas um TID para cada nó, tais TIDs estão referenciando os processos escravos que estarão sendo executados simultaneamente com o mestre que, ao terminar, desaloca todos os nós que estavam executando os respectivos processos escravos.

\subsection{Comunicação}

Para o envio de uma mensagem, o PVM possui rotinas para o empacotamento e o envio das mesmas entre tarefas. Com exceção da quantidade de memória disponível em cada host, o modelo assume que qualquer tarefa pode enviar mensagens para outra e que não há limite para o tamanho das mesmas.

Para enviar uma mensagem existem três passos:

- criar um buffer;

- empacotar a mensagem no buffer; 
- enviar a mensagem.

Uma mensagem é recebida pela chamada tanto à uma recepção bloqueante quanto à uma não bloqueante, seguido do "desempacotamento" no buffer de recepção de cada item que foi empacotado. A rotina de recepção pode ser programada para receber:

- qualquer mensagem;

- qualquer mensagem de uma determinada fonte;

- qualquer mensagem com identificador específico;

- somente mensagens com uma fonte e uma identificação específica.

Embora o PVM forneça condiçōes de trabalho com diferentes tipos de processos escravos, os quais são responsáveis pelo tratamento de tipos de dados distintos, tal característica não foi utilizada neste trabalho, pois o método Simplex Convexo necessita de processo escravos que possuam a mesma função de tratamento de dados. Caso necessitássemos de processos escravos distintos sendo executados simultaneamente com o processo mestre precisaríamos gerenciar os TIDs de modo diferente, pois não poderíamos alocar um processo escravo a um nó específico.

As formas de comunicação existentes no PVM são:

- send bloqueante assíncrono;

- receive bloqueante assíncrono;

- receive bloqueante síncrono.

O send bloqueante retorna assim que o buffer utilizado para o envio da mensagem estiver livre para ser utilizado novamente. É assíncrono porque não depende do receptor executar um receive para poder retornar, ou seja, está somente interessado em quando a mensagem foi enviada. O send bloqueia o processo no momento em que a mensagem exceder o tamanho do buffer e precisar ser dividida. Neste caso, é necessário que o host receptor execute um receive para liberar o buffer permitindo assim, a continuidade do envio.

Um receive é não bloqueante quando retorna imediatamente após ter verificado o buffer no host receptor. No caso da mensagem não estar disponível é retornado um código indicando que o buffer não continha mensagem. Um receive bloqueante somente retorna quando a mensagem for recebida e inserida no buffer [BEG94; GEI94; SUN94].

O PVM oferece comunicação ponto-a-ponto, broadcasting (para um grupo de tarefas 
definido pelo usuário) e multicasting (para o conjunto de tarefas).

\subsection{Utilização do Pvmd}

\subsubsection{Inicialização e Finalização}

O Pvmd é inicializado e configurado, como mestre ou como escravo. Porém sua inicialização e o ajuste de variáveis, que possibilitam a execução do processo mestre e dos processos escravos, são ajustes automatizados pelo software LoadLeveler, que tem como funções principais o ajuste de ambiente e o controle de filas de execução. Como as suas finalidades principais são o roteamento de mensagens e a configuração da máquina virtual, o primeiro passo do Pvmd consiste em criar mecanismos de comunicação entre os processos (os sockets) e permitir a sua utilização. Isto possibilita a comunicação com as tarefas e outros Pvmds. O segundo passo do Pvind é a criação das estruturas de dados que irão conter as informações sobre os outros hosts e sobre as tarefas PVM que estão em execução sob a sua supervisão.

Após configurado, o Pvmd entra em um loop na função work( ), cuja finalidade é aguardar o recebimento de mensagens, que podem ser de tarefas locais ou de outros Pvmds.

Assim que o Pvmd termina suas atividades realiza duas açōes:

- envia um sinal (signal SIGTERM) eliminando todas as tarefas subordinadas a ele (as tarefas são "mortas");

- envia uma mensagem de finalização a todos os outros Pvmds informando que sairá da máquina virtual. Apesar dos outros Pvmds terem condições de descobrir sozinhos a falta de outro host, visto que a cada período de tempo é feita uma comunicação para verificar as condições da máquina virtual, a mensagem indicando uma finalização acelera o processo.

A finalização do mestre implica na finalização da máquina virtual [SOU96]. 


\subsubsection{Pvmd' - Shadow Pvmd}

As atividades da criação de novos escravos podem bloquear o Pvmd mestre por um determinado intervalo de tempo. O Pvmd' tem a finalidade de criar novos escravos, liberando assim o Pvmd mestre para fazer outras atividades, uma vez que este deve estar pronto para responder outras mensagens durante criação dos escravos.

O Pvmd' só é executado quando for necessário a criação de novos Pvmds escravos, e ele é eliminado da memória logo após o término de sua atividade. Apesar da tarefa de criação de novos escravos não ser muito utilizada (normalmente os hosts disponíveis são iniciados no começo da aplicação), a inicialização e a finalização do Pvmd' traz mais benefícios do que o custo de colocar mais um processo em execução.

O Pvmd' é referenciado pelo número zero, é o Pvmd de número zero e comunica-se com o mestre através do protocolo Pvmd-Pvmd, embora nunca receba ou envie mensagem alguma de qualquer tarefa ou de outro Pvmd.

O Pvmd' é colocado em execução através do comando fork( ), existente nos sistemas operacionais UNIX, o qual permite a geração de processos concorrentes através da duplicação do processo atual (no caso o Pvmd mestre). São duplicados todos os seus dados, seu ponto de execução e sua pilha, ou seja, é criado um processo idêntico ao original, facilitando assim a configuração inicial que o Pvmd' necessita para comunicar-se com o Pvmd mestre [SOU96].

\subsubsection{Tolerância à Falhas}

Na sua versão 3, o PVM foi projetado para resistir à maioria das falhas envolvendo hosts e redes. Ele não recupera automaticamente uma aplicação depois de algum erro, porém fornece ferramentas necessárias para que o usuário construa aplicações tolerantes à falhas.

Quando um host escravo perde a sua comunicação com o mestre, ele mesmo provoca a sua saída da máquina virtual, eliminando assim todas as tarefas e operações pendentes nos salvadores de contexto.

Se o host mestre perde a comunicação com um host escravo, este é retirado da máquina virtual pelo mestre. Se o host mestre for "terminado", toda a máquina virtual é finalizada. Não há nenhuma implementação que evite este problema.

Apesar de possuirmos tais recursos de tolerância à falhas, os mesmos não estão sendo 
utilizados neste projeto, devido ao tempo computacional necessário por um processo de gerenciamento específico, e como a quantidade de nós que estamos trabalhando é reduzida (dois), se em algum momento da execução dos processos escravos ocorresse perda de um nó alocado teríamos que realocar o nó perdido, empacotar e enviar informação para este nó para que o mesmo possa começar a trabalhar com os dados, e caso este seja o último buffer de dados a ser enviado (produto), o outro nó ficaria ocioso. Tal gerenciamento é extremamente viável, quando existe uma quantidade significativa de nós.

\subsubsection{Roteamento de Pacotes e Mensagens}

Os buffers de pacotes (struct pkt) são os responsáveis pela manipulação dos pacotes enviados e/ou recebidos pelos Pvmds.

A função sendmessage( ) é utilizada para o Pvmd enviar mensagens a qual irá roteá-las até o destino. Quando a mensagem é enviada para outro Pvmd ou para tarefas, a mensagem é anexada aos buffers de pacotes e estes inseridos em filas para um posterior envio. Quando o destino de uma mensagem é o próprio Pvmd, esta é colocada diretamente no local onde entram as mensagens vindas da rede, sendo passada como parâmetro à função netentry( ), economizando assim todo o custo computacional da divisão da mensagem em pacotes e o envio pela rede.

\subsection{Libpvm}

A biblioteca Libpvm consiste em um conjunto de funções (bibliotecas) que são utilizadas para implementar a interface entre a aplicação e o PVM, através da qual a aplicação pode conectar-se ao seu respectivo PVM daemon e, conseqüentemente, unir-se à máquina virtual. $\mathrm{Na}$ biblioteca (libpvm) as funções são ativadas para efetuar trocas de mensagens, gerar processos, coordenar tarefas (sincronização) e modificar a máquina virtual.

A Libpvm permite o desenvolvimento de aplicações nas linguagens C, C++ e Fortran. 


\subsection{Protocolos de Comunicação}

A comunicação realizada pelo PVM é baseada em TCP (Transmission Control Protocol), UDP (User Datagrama Protocol) e sockets do domínio UNIX, assumindo que todos os hosts da máquina virtual sejam capazes de se conectarem através desses mecanismos de comunicação.

Como no PVM a comunicação é feita entre os Pvmds e as tarefas há três conexões a serem consideradas:

- entre Pvmds (Pvmd-Pvmd);

- entre um Pvmd e suas tarefas (Pvmd-Tarefas);

- entre tarefas (Tarefa-Tarefa).

A seguir fazemos um breve comentário destas conexões existentes.

\subsubsection{Pvmd-Pvmd}

A comunicação entre os Pvmds é feita através de UDP. Como UDP não é um protocolo confiável, o PVM implementa serviços de confirmação e retransmissão das mensagens. O UDP limita o tamanho de cada pacote, ocorrendo assim uma divisão das mensagens em pacotes.

Um socket UDP aberto pode comunicar-se com qualquer outro socket UDP remoto. $\mathrm{O}$ sistema detecta que um Pvmd remoto está com problemas ou que a rede está paralisada através de timeouts preestabelecidos [BEG94; SOU96].

\subsubsection{Pvmd-Tarefa e Tarefa-Tarefa}

Devido ao fator de confiabilidade a comunicação entre o Pvmd e suas tarefas e entre tarefas é realizada com TCP, pois o UDP necessita de confirmações extras e de retransmissões que geram maiores overheads. Como as comunicações entre Pvmd-Tarefa e entre tarefas (TarefaTarefa) não têm o mesmo estilo que as comunicações entre Pvmds, pois o tamanho e a ocorrência da mensagens dependem da aplicação desenvolvida, a melhor saída é a utilização do protocolo TCP.

A partir da versăo 3.3, o PVM começou a utilizar os sockets do domínio UNIX entre o Pvmd e suas tarefas locais e entre tarefas localizadas no mesmo host, para assim diminuir o 
tempo de latência dos sockets.

\subsection{Limitações do PVM}

O PVM foi construído para, sempre que possível, não impor limitações de acessos aos seus recursos. Entretanto, na maioria das vezes, os limites são impostos pelo hardware ou pelo sistema operacional utilizado. Sistemas multiusuários afetam dinamicamente os limites do sistema.

\subsubsection{No Pvmd}

Os fatores de limitação do Pvmd são: a quantidade de tarefas que cada PVM pode gerenciar e a quantidade de memória disponível para tais processos.

A limitação em relação a quantidade de tarefas está relacionado com o número de processos concorrentes permitidos pelo sistema operacional, sendo dificilmente esgotado pelo PVM. Não faz sentido ter uma quantia demasiadamente grande de processos em um único host. O Pvmd pode tornar-se o "gargalo do sistema" se todas as tarefas tentarem comunicar-se através dele.

O Pvmd aloca dinamicamente memória para armazenar as mensagens por ele roteadas. Enquanto a tarefa destino não aceitar a sua mensagem, os pacotes são armazenados em filas no Pvmd, sendo que não há nenhum controle de fluxo para tais pacotes.

\subsubsection{Na Libpvm}

As tarefas PVM também possuem um limite no número de conexões diretas que elas podem fazer com outras tarefas, embora este problema não exista se a comunicação for feita através do Pvmd.

A maior mensagem possível para uma tarefa é limitada pela quantia de memória disponível para realizá-la. Quando a mensagem é enviada via Pvmd, este aloca memória para poder roteá-la, diminuindo o tamanho considerado como disponível. 
Se muitas tarefas enviam mensagens ao mesmo tempo para a mesma tarefa destino, tanto o Pvmd quanto a tarefa destino ficarão sobrecarregados tentando armazenar as mensagens. Estes problemas devem ser considerados, projetando-se aplicações para usarem mensagens pequenas, eliminando "gargalos" e gerenciando as mensagens na mesma ordem que elas foram geradas.

\subsection{Considerações Finais}

Possuindo características como simplicidade, robustez e portabilidade, o PVM destaca-se como um ambiente de passagem de mensagens amplamente discutido e utilizado. Entre os usuários do PVM destacam-se: Ford, Boeing, Texaco, General Electric, Siemens, Mobil Oil, Crau Research, Shell Oil, IBM, entre outros [GEI95].

Uma vantagem da implementação do PVM é a de não impor limites aos recursos utilizados. Em geral os limites são impostos pela plataforma utilizada (hardware e software), sendo responsabilidade da aplicação paralela tratar os erros gerados nesse sentido.

O PVM foi projetado para ser o mais simples possível. Para permitir sua portabilidade evitaram as características de sistemas operacionais e de linguagens de programação que seriam difíceis de implementar em outros sistemas.

Neste capítulo comentamos sobre a biblioteca PVM, o qual utilizamos durante a implementação do algoritmo. No próximo capítulo apresentamos esta implementação e os resultados obtidos. 


\section{CAPÍTULO 7}

\section{IMPLEMENTAÇÃO E RESULTADOS \\ COMPUTACIONAIS}

Neste capítulo apresentamos aspectos computacionais relativos à implementação do método de resolução dos subproblemas de simples fluxo, também da implementação em paralelo, às condições físicas nas quais foi executado o método de relaxamento, bem como os resultados computacionais obtidos pela execução do programa. Também fizemos uma comparação entre resultados.

\subsection{Implementação}

$\mathrm{O}$ método proposto foi implementado em linguagem $\mathrm{C}$ e executado no computador paralelo IBM-SP2. A máquina SP2 adotada neste trabalho possui três nós de processamento, sendo um do tipo wide e dois do tipo thin 2. Cada nó do tipo thin 2 possui processador POWER2 de $66.7 \mathrm{MHz}$, 256 Mbytes de memória, 128 Kbytes de cache de dados e barramento de memória de 128 bits. O nó wide possui processador POWER2 de $66.7 \mathrm{MHz}, 256 \mathrm{Mbytes} \mathrm{de} \mathrm{memória,} 256$ Kbytes de cache de dados e barramento de 256.

$\mathrm{Na}$ apresentação do Algoritmo do método de relaxamento (página 46) pode-se notar que o corpo do programa principal é de fácil compreensão e implementação seqüencial. A única subrotina do programa principal é a que se refere à minimização do subproblema de simples 
fluxo (problema 4.1 do capítulo 4). Este procedimento foi implementado usando o método Simplex Convexo.

O problema de roteamento de dados, com o qual trabalhamos, consiste em minimizar o tempo médio de atraso das mensagenis, neste caso o tempo está avaliado em segundos/mensagem. O critério de parada utilizado pelo algoritmo de relaxamento é o de erro absoluto. Adotamos na execução do algoritmo a precisão para o critério de parada na ordem de $10^{-3}$, obtendo assim um erro de milésimos de segundo o que é bastante satisfatório para o problema de roteamento.

Apresentamos as técnicas de implementação dos passos mais relevantes do método Simplex Convexo e da implementação em paralelo.

\subsubsection{Implementação do Método Simplex Convexo}

O método Simplex Convexo trabalha essencialmente com a estrutura de árvores em grafos. Na procura de uma direção de descida é necessário detectar um ciclo formado pela adição de uma arco não-básico à árvore básica. Quando o problema envolve uma rede muito grande, este fato pode aumentar consideravelmente o tempo de convergência do programa.

Para solucionarmos este problema, encontramos o arco não-básico, que é o primeiro arco disponível e que não tenha sido o último arco a ser utilizado (pois caso contrário o programa poderia entrar em loop), depois de encontrado o arco, ainda na fase de implementação tínhamos duas opções para encontrarmos o ciclo o qual este arco não-básico deveria estar incluso.

A primeira opção, a qual consistia em construir uma estrutura de árvore completa a partir dos dados entrados, processo este que deveria se repetir a cada inclusão ou exclusão de um arco (pois a inclusão e exclusão de arcos específicos nesta árvore se tomaria inviável no futuro processamento paralelo), exigia um algoritmo menos complexo, porém seu tempo computacional de construção traria um acréscimo relevante para o programa, pois estaríamos analisando todo o conjunto de dados entrados, conjunto este que possui dados irrelevantes para determinados ciclos.

A segunda opção, a qual consistia em estruturar apenas os arcos que fariam parte do ciclo gerado pela inclusão do arco não-básico, reduzindo assim o tempo computacional, uma vez que a única estrutura gerada seria um vetor (iniciado pelo arco não-básico) que iria conter apenas os 
arcos pertencentes ao ciclo, com suas respectivas orientações. Tal implementação exigia um algoritmo mais complexo, porém como nossa maior preocupação seria justamente o tempo computacional, optamos por tal implementação.

Uma maneira mais sucinta de se escrever o algoritmo Simplex Convexo para simples fluxo é:

Seja uma solução factível inicial.

Determine uma árvore básica.

Solução ótima:= false.

Enquanto Solução otima = false faça:

Início

Verifique se existe candidato

Se existe então:

Inicio

Calcule o tamanho do passo $h$.

Atualize o fluxo

Se algum arco básico atingiu algum de seus limitantes então

Atualize a base

Fim (Se).

Senão

Solução ótima: $=$ True.

Fim (enquanto).

Depois de determinado o arco não-básico, existem dois métodos possíveis para verificar se este arco será incluso ou não na base: a) usando a sequiência de orientação; b) usando as variáveis duais. O método que utiliza a seqüência de orientação necessita que o ciclo seja gerado antes de utilizá-lo (sendo portanto um método pouco complexo, mas que exige muito processamento) enquanto que o método que utiliza as variáveis duais não necessita que o ciclo seja gerado, pois este utiliza o calculo de potênciais para realizar uma pré-verificação da construção ou não do ciclo a ser utilizado, a seguir descrevemos estas duas maneiras: 


\section{Utilizando a Seqüência de Orientação}

Inicialmente é inserido o arco não-básico $l_{k}$ na árvore, gerando assim um ciclo. A seguir, determina-se quais os arcos da árvore fazem parte do ciclo. Estes arcos oferecem um caminho alternativo em relação ao caminho direto do arco não básico $l_{k}$, pois eles ligam os nós origem e destino de $l_{k}$. Uma vez determinado os arcos que compõem o ciclo faz-se uma avaliação para verificar se a entrada do arco $l_{k}$ pode melhorar a solução factível atual. Esta avaliação é feita do seguinte modo:

(i) se o custo do caminho direto pelo arco não-básico é menor que o custo pelo caminho alternativo dizemos que o arco não-básico é barato. Então, se o arco nãobásico não atingiu seu limitante superior podemos aumentar o valor de fluxo, passando por $l_{k}$, que a solução básica atual vai melhorar,

(ii) se o custo do caminho direto pelo arco não-básico é maior que o custo pelo caminho alternativo dizemos que o arco não-básico é caro. Então, se o arco nãobásico não atingiu seu limitante inferior, podemos diminuir o valor de fluxo, passando por $l_{k}$, que obteremos uma nova solução básica melhor que a anterior.

Assim, se $l_{k}$ satisfaz alguma das condições anteriores é candidato a entrar na base.

\section{Utilizando as Variáveis Duais}

Inicialmente são calculados os potenciais, $\pi_{i}$, de todos os nós da rede. Após calculados os potenciais, escolhe-se um arco não-básico $l_{k}$, calcula-se o $\bar{c}_{k}$ pela fórmula das variáveis duais. $O$ valor de $\bar{c}_{k}$ nos indica se $l_{k}$ é candidato ou não a entrar na base. Se $l_{k}$ for incluso na base encontra-se o ciclo que é formado pela sua inclusão na árvore. A seguir faz-se os mesmos cálculos utilizados na seqüência de orientação para atualização dos fluxos e da árvore, obtendose assim uma nova solução básica.

Observamos que, com a utilização das variáveis duais, o procedimento de busca e construção do ciclo só será realizado quando o arco não-básico estiver apto a ser inserido na base, dispensando assim a construção excessiva de ciclos, realizada no método da sequiência de 
orientação, tornando portanto o método mais adequado para a implementação de nosso programa.

\section{Dificuldades:}

A major dificuldade da implementação do método Simplex Convexo está especificamente em detectar o ciclo formado na árvore pela adição do arco não-básico. Pois para que possamos encontrar o ciclo devemos a partir do destino do arco não-básico conseguir obter uma sequiência de arcos que tenha como alvo final a origem do determinado arco.

Este procedimento consiste em localizarmos todos os arcos que estejam relacionados ao nó destino do arco não-básico, ou melhor, todos os possíveis caminhos que têm como origem o nó destino deste arco, para que possamos percorrer tais caminhos em busca do nó origem do arco não-básico. Observamos porém que ao deslocarmos por um determinado nó podemos ter mais que uma opção para continuarmos a busca pelo ciclo, e que apenas um ciclo deverá ser formado com a inclusão deste arco, neste caso para cada nó que nos fornecer mais de uma opção, armazenamos todos os possíveis nós a serem seguidos, para que caso optemos pelo nó errado, possamos retornar ao último ponto crítico encontrado. Desta forma podemos garantir a obtenção do único ciclo gerado pela inclusão do arco não-básico. Esta forma de guardar o nó que tem mais de um arco básico associado a ele é parecido com o procedimento de backtracking.

\subsubsection{Implementação em Paralelo}

$\mathrm{Na}$ implementação em paralelo as comunicaçōes entre os processadores foram feitas utilizando a biblioteca paralela PVM. O computador paralelo em que executamos este programa possui três nós de processamento, sendo que um nó foi alocado para executar o processo mestre e os demais foram alocados para executar os processos escravos.

O nó alocado para executar o processo mestre não pode ser considerado na análise de performance do algoritmo, pois mesmo que este esteja alocado fisicamente, logicamente ele não desenvolve nenhuma tarefa enquanto os processos escravos estão sendo executados, pois o processo mestre tem como função principal analisar os dados de entrada, distribuí-los de forma paralela (divisão por produtos), contabilizar o tempo de processamento, empacotar e controlar o fluxo de informações com os escravos, e principalmente utilizar os pacotes recebidos dos 
escravos para poder transformá-los em novas informaçōes, que depois de validadas poderão ou não serem enviadas novamente para os escravos. Observamos porém que quando o processo mestre envia os pacotes para os processos escravos, o nó alocado para o processo mestre não realiza nenhuma operação, ficando apenas aguardando o retorno das informações que foram enviadas aos escravos, e que esta perda de processamento poderia ser minimizada se determinássemos estatisticamente o tempo de resposta dos escravos para que pudéssemos utilizar o mestre em um intervalo temporal confiável (proposta futura).

Os nós alocados para executarem os processos escravos têm como função executar a implementação do algoritmo Simplex Convexo, usando o processo iterativo semelhante ao de Jacobi, que trabalha com um único conjunto de dados (produto) que lhe foi enviado pelo processo mestre. Desta forma, assim que o nó é alocado para o processo escravo, este é executado e permanece na memória do nó até que o processo mestre o retire (kill), este procedimento foi utilizado para evitar a carga do processo escravo toda vez que este fosse acionado pelo processo mestre. Os processos escravos, os quais estão em constante execução para que através dos dados recebidos pelo mestre possam gerar uma rede adequada a um determinado produto, até que o mestre consiga obter a solução ótima desejável, tornam-se fundamentais para o cálculo do tempo computacional. Como dispomos de apenas dois nós de processamento para serem alocados para tais processos, se uma determinada rede possuir um número impar de produtos, em algum momento um escravo pode ficar ocioso enquanto o outro está trabalhando com os dados que recebera. Este fato acarreta uma distorção na execução de algumas redes com número ímpar de produtos.

As comunicações entre o processo mestre e os processos escravos são realizadas através da utilização de rotinas contidas na biblioteca PVM e que são específicas para cada tipo de dado. Tais rotinas transformam um determinado tipo de dado (por exemplo inteiro) em uma cadeia de caracteres do tipo ASC II e a esta cadeia de caracteres é acoplado um cabeçalho (header) também em ASC II que especifica o tipo de variável que está sendo enviado. A seguir estes dados são recuperados utilizando a rotina inversa, que através dos dados em ASC II cria a mesma variável inteira que foi enviada. Ao realizarmos uma comunicação entre o processo mestre e o processo escravo temos que estabelecer um padrão para que o tipo de dado enviado pelo mestre seja do mesmo tipo que o escravo esteja aguardando, e que a quantidade de informações enviadas seja a mesma recebida, pois tanto o mestre quanto o escravo recebem e enviam informações, e qualquer desigualdade pode comprometer a execução do programa. 
Sobre a comunicação realizada utilizando a biblioteca PVM podemos destacar a possibilidade de enviarmos e recebermos grande quantidades de informações de um mesmo tipo, bastando para isto, especificar o tipo de dados que será enviado ou recebido e a quantidade de registros do mesmo. Porém se quisermos determinar qual o processo escravo que está respondendo ao mestre temos que inserir um campo extra em nossos registros, para que o processo escravo envie além das informações o seu número de identificação que será reconhecido pelo mestre.

O esquema abaixo mostra como o algoritmo paralelo implementado está funcionando, enfatizamos que o forte do paralelismo, deste algoritmo, está nos processos escravos.

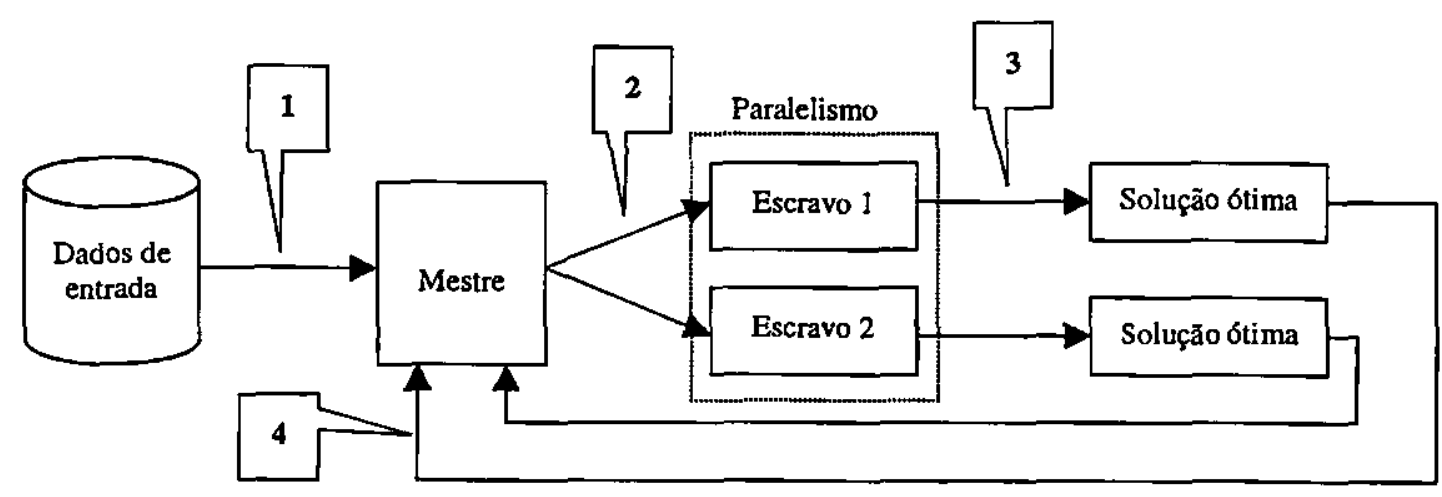

Legenda:

1 - O mestre faz a leitura do arq. de entrada.

2 - $O$ mestre distribui o arquivo de entrada juntamenle com as tarefas aos escravos.

3 - Os escravos resolvem o Simplex Convexo num processo iterativo semeihante ao Jacobi.

4 - O escravo envia a soluçắo obtida para o mestre, e este verifica se o critério de parada foi satisfeito, se foi satisfeito o programa termina, caso contrário o mestre distribui novamente as tarefas aos escravos

Figura 7.1 - Esquema do programa paralelo.

\subsection{Resultados}

O algoritmo paralelo foi testado para 26 redes. Estas redes possuem variações de números de produtos, arcos e nós. Por exemplo, as redes 1a, 1b e 1c são a mesma rede em termos de arcos e de nós, a variação consiste somente no número de produtos que são 2,4 e 6 respectivamente. O mesmo sucede com as demais redes a, b e c. 
A tabela abaixo fornece as descriçōes dos exemplos testados.

Tabela 7.1: Descriçōes das redes testadas.

\begin{tabular}{|c|c|c|c|c|c|}
\hline Desc. Rede & Num. Nós & Num. Arcos & Num. Produtos & Capacidade & Atraso \\
\hline Rede 1a & 4 & 8 & 2 & 10 & 0.5 \\
\hline Rede 1b & 4 & 8 & 4 & 10 & 0.5 \\
\hline Rede 1c & 4 & 8 & 6 & 10 & 0.5 \\
\hline Rede $2 \mathbf{a}$ & 10 & 16 & 2 & 10 & 0.05 \\
\hline Rede 2b & 10 & 16 & 4 & 10 & 0.05 \\
\hline Rede 2c & 10 & 16 & 6 & 10 & 0.05 \\
\hline Rede 3a & 23 & 32 & 2 & 10 & 0.05 \\
\hline Rede $3 b$ & 23 & 32 & 4 & 10 & 0.05 \\
\hline Rede 3c & 23 & 32 & 6 & 10 & 0.05 \\
\hline Rede 3d & 23 & 32 & 8 & 10 & 0.05 \\
\hline Rede 4a & 43 & 68 & 2 & 10 & 0.05 \\
\hline Rede $4 b$ & 43 & 68 & 4 & 10 & 0.05 \\
\hline Rede 4c & 43 & 68 & 6 & 10 & 0.05 \\
\hline Rede 5a & 99 & 174 & 2 & 10 & 0.05 \\
\hline Rede $5 \mathbf{b}$ & 99 & 174 & 4 & 10 & 0.05 \\
\hline Rede 5x & 99 & 174 & 5 & 10 & 0.05 \\
\hline Rede 6a & 166 & 297 & 2 & 10 & 0.05 \\
\hline Rede $6 \mathrm{~b}$ & 166 & 297 & 4 & 10 & 0.05 \\
\hline Rede 6x & 166 & 297 & 5 & 10 & 0.05 \\
\hline Rede 6c & 166 & 297 & 6 & 10 & 0.05 \\
\hline Rede 7a & 191 & 342 & 2 & 10 & 0.05 \\
\hline
\end{tabular}




\begin{tabular}{|c|c|c|c|c|c|}
\hline Rede 7x & 191 & 342 & 3 & 10 & 0.05 \\
\hline Rede 7b & 191 & 342 & 4 & 10 & 0.05 \\
\hline Rede 8a & 214 & 383 & 2 & 10 & 0.05 \\
\hline Rede 8x & 214 & 383 & 3 & 10 & 0.05 \\
\hline Rede 8b & 214 & 383 & 4 & 10 & 0.05 \\
\hline
\end{tabular}

A tabela a seguir mostra os valores encontrados após executadas as redes tanto no seqüencial quanto no paralelo, pois como sabemos os valores tem que ser iguais, e também mostra o número de iterações que foram necessárias para que o critério de parada fosse satisfeito.

Tabela 7.2: Valores das soluções iniciais e finais da rede.

\begin{tabular}{|c|c|c|c|}
\hline Desc. Das Redes & Função Inicial & Funcão Final & Número de Iteracões \\
\hline Rede 1a & 2.752357 & 2.037037 & 2 \\
\hline Rede 1b & 7.883276 & F.044902 & 2 \\
\hline Rede 1c & 12.518003 & 4.912451 & 2 \\
\hline Rede 2a & 1.395701 & 1.081324 & 2 \\
\hline Rede 2b & 3.829460 & 2.732430 & 2 \\
\hline Rede 2c & 8.278841 & 5.547962 & 6 \\
\hline Rede 3a & 4.834313 & 3.351106 & 2 \\
\hline Rede 3b & 15.323308 & 11.146631 & 3 \\
\hline Rede 3c & 33.213898 & 21.064026 & 3 \\
\hline Rede 3d & 48.266876 & 27.847805 & 3 \\
\hline Rede 4a & 10.075253 & 5.952882 & 3 \\
\hline Rede 4b & 29.759302 & 19.215855 & 3 \\
\hline Rede 4c & 64.768105 & 37.330341 & 3 \\
\hline Rede 5a & 18.449183 & 11.869645 & \\
\hline
\end{tabular}




\begin{tabular}{|c|c|c|c|}
\hline Rede 5b & 64.085075 & 37.785686 & 3 \\
\hline Rede 5x & 92.866577 & 54.547169 & 5 \\
\hline Rede 6a & 31.999470 & 20.684452 & 3 \\
\hline Rede 6b & 112.373955 & 67.194832 & 4 \\
\hline Rede 6x & 161.910614 & 93.954834 & 8 \\
\hline Rede 6c & 219.258865 & 127.554619 & 12 \\
\hline Rede 7a & 38.267460 & 24.064466 & 3 \\
\hline Rede 7x & 78.414871 & 48.717426 & 3 \\
\hline Rede 7b & 132.428696 & 78.422310 & 4 \\
\hline Rede 8a & 42.333569 & 26.921736 & 3 \\
\hline Rede 8x & 87.128815 & 54.676403 & 4 \\
\hline Rede 8b & 146.839966 & 88.592255 & 5 \\
\hline
\end{tabular}

\subsubsection{Diferença entre Seqüência de Orientação e Variáveis Duais}

Quando implementamos o método Simplex Convexo, na fase do cálculo de $\bar{c}_{k}$, primeiro implementamos utilizando a seqüência de orientação, mas, após o término da implementação analisando os tempos verificamos que o programa estava muito lento e então resolvemos mudar para as variáveis duais e percebemos que esta maneira é mais eficiente, logo optamos pela mesma. Esta conclusão pode ser vista pela tabela abaixo, onde temos o tempo de execução de algumas redes, tanto usando as seqüências de orientações quanto as variáveis duais, executados em um computador Pentium II de $266 \mathrm{MHz}, 64 \mathrm{Mb}$ de memória RAM, $512 \mathrm{~Kb}$ de external cache, e $32 \mathrm{~Kb}$ de internal cache. As implementações utilizando as seqüências de orientações não foram executadas no SP2 pelo fato de serem muito demoradas, pois, tem algumas redes que chegaram a 13 horas de execução no Pentium II. 
Tabela 7.3: Tempo de execução das redes (implementação seqüencial).

\begin{tabular}{|c|c|c|}
\hline Desc. Das Redes & $\begin{array}{c}\text { Tempo Execução Utilizando } \\
\text { Variáveis Duais } \\
\end{array}$ & $\begin{array}{l}\text { Tempo Execução Utilizado } \\
\text { Seqüuência de Orientação }\end{array}$ \\
\hline Rede 1a & $00: 00: 00.00$ & 00:00:00.00 \\
\hline Rede 1b & $00: 00: 00.01$ & $00: 00: 00.03$ \\
\hline Rede 1c & $00: 00: 00.01$ & $00: 00: 00.03$ \\
\hline Rede $\mathbf{2 a}$ & $00: 00: 00.01$ & $00: 00: 00.15$ \\
\hline Rede $2 \mathbf{b}$ & $00: 00: 00.01$ & $00: 00: 00.38$ \\
\hline Rede 2c & $00: 00: 00.12$ & $00: 00: 00.59$ \\
\hline Rede 3a & $00: 00: 00.30$ & $00: 00: 00.58$ \\
\hline Rede 3b & 00:00:00.54 & $00: 00: 00.70$ \\
\hline Rede 3c & $00: 00: 00.73$ & $00: 00: 01.73$ \\
\hline Rede 3d & $00: 00: 00.68$ & $00: 00: 01.43$ \\
\hline Rede 5a & $00: 00: 31.43$ & $00: 14: 27.75$ \\
\hline Rede 5b & $00: 01: 02.41$ & $00: 29: 49.51$ \\
\hline Rede 5x & $00: 01: 23.47$ & $00: 44: 07.39$ \\
\hline Rede 6a & $00: 07: 06.46$ & $5: 31: 56.68$ \\
\hline Rede 6b & $00: 15: 30.31$ & $12: 58: 39.96$ \\
\hline
\end{tabular}

Obs: Os tempos estão em horas, minutos, segundos e centésimos de segundos.

Pela tabela acima verificamos que o método Simplex Convexo utilizando as variáveis duais é mais eficiente do que utilizando a sequiência de orientação, isto fica claro quanto maior for a rede, como percebemos a partir da rede 5 . 


\subsubsection{Desempenho das Redes}

Os dados e gráficos que serão mostrados e discutidos, a partir de agora, foram executados utilizando as variáveis duais, para o cálculo do $\bar{c}_{k}$ no método Simplex Convexo.

A tabela abaixo mostra o tempo de execução do algoritmo implementado usando um único processador do SP2, sendo este denominado de tempo seqüencial, e o tempo de execução do algoritmo implementado usando três processadores, sendo este denominado de tempo paralelo. $\mathrm{Na}$ execução do tempo paralelo utilizamos os três processadores, sendo que um é o mestre e os outros dois os escravos. Também, nesta tabela, mostramos o speedup e a eficiência. Sabemos que a eficiência é calculada pela divisão entre o tempo de execução do programa em um computador paralelo sobre o número de processadores. Na tabela a eficiência foi calculada como sendo o tempo paralelo sobre dois, pois o computador que utilizamos possui três processadores, sendo um deles o mestre, e o mestre não executa processos, seu papel é apenas de distribuir as tarefas aos demais e verificar se o critério de parada foi satisfeito.

Tabela 7.4: Resultados gerais.

\begin{tabular}{|c|c|c|c|c|}
\hline Desc. Das Redes & Tempo Seqüencial & Tempo Paralelo & Speedup & Eficiência \\
\hline Rede 1a & $00: 00: 01$ & $00: 00: 17$ & 0.058823529 & 0.029411765 \\
\hline Rede 1b & $00: 00: 01$ & $00: 00: 14$ & 0.071428571 & 0.035714286 \\
\hline Rede 1c & $00: 00: 01$ & $00: 00: 14$ & 0.071428571 & 0.035714286 \\
\hline Rede 2a & $00: 00: 01$ & $00: 00: 15$ & 0.066666667 & 0.033333333 \\
\hline Rede 2b & $00: 00: 01$ & $00: 00: 16$ & 0.0625 & 0.03125 \\
\hline Rede 2c & $00: 00: 01$ & $00: 00: 15$ & 0.066666667 & 0.033333333 \\
\hline Rede 3a & $00: 00: 01$ & $00: 00: 15$ & 0.066666667 & 0.033333333 \\
\hline Rede 3b & $00: 00: 01$ & $00: 00: 14$ & 0.071428571 & 0.035714286 \\
\hline Rede 3c & $00: 00: 02$ & $00: 00: 16$ & 0.125 & 0.0625 \\
\hline Rede 3d & $00: 00: 02$ & $00: 00: 15$ & 0.133333333 & 0.066666667 \\
\hline Rede 4a & $00: 00: 04$ & $00: 00: 17$ & 0.235294118 & 0.117647059 \\
\hline
\end{tabular}




\begin{tabular}{|c|c|c|c|c|}
\hline Rede 4b & $00: 00: 05$ & $00: 00: 16$ & 0.3125 & 0.15625 \\
\hline Rede 4c & $00: 00: 09$ & $00: 00: 19$ & 0.473684211 & 0.236842105 \\
\hline Rede 5a & $00: 02: 21$ & $00: 01: 27$ & 1.620689655 & 0.810344828 \\
\hline Rede 5b & $00: 04: 40$ & $00: 02: 48$ & 1.666666667 & 0.833333334 \\
\hline Rede 5x & $00: 06: 15$ & $00: 04: 16$ & 1.46484375 & 0.732421875 \\
\hline Rede 6a & $00: 33: 12$ & $00: 18: 32$ & 1.791366907 & 0.895683454 \\
\hline Rede 6b & $01: 12: 24$ & $00: 41: 49$ & 1.731367079 & 0.86568354 \\
\hline Rede 6x & $01: 46: 22$ & $01: 12: 24$ & 1.469152855 & 0.734576427 \\
\hline Rede 6c & $02: 07: 42$ & $01: 18: 42$ & 1.622617535 & 0.811308768 \\
\hline Rede 7a & $01: 04: 11$ & $00: 36: 23$ & 1.76408612 & 0.88204306 \\
\hline Rede 7x & $01: 36: 23$ & $01: 12: 39$ & 1.326680431 & 0.663340216 \\
\hline Rede 7b & $02: 21: 48$ & $01: 26: 17$ & 1.643422832 & 0.821711416 \\
\hline Rede 8a & $01: 50: 03$ & $01: 05: 45$ & 1.673764259 & 0.83688213 \\
\hline Rede 8x & $02: 46: 40$ & $02: 08: 13$ & 1.299883011 & 0.649941505 \\
\hline Rede 8b & $03: 52: 57$ & $02: 22: 01$ & 1.640300434 & 0.820150217 \\
\hline & & & & \\
\hline
\end{tabular}

Na tabela 7.4 verificamos, para redes maiores, que o tempo do processamento em paralelo é mais eficiente que o seqüencial. Já para redes menores o processamento em seqüencial é mais eficiente, isto deve-se ao fato de que o tempo de comunicação entre mestre e escravos mais o tempo de execução dos processos é maior do que o tempo de execução do algoritmo seqüencial.

Analisando a tabela anterior percebemos, a partir da rede 5, que o speedup é sempre acima de 1.6 com exceção das redes que possuem números de produtos ímpares que fícam abaixo, e isto já era esperado, pois como estamos trabalhando em um computador paralelo com três nós de processamento sendo um o mestre, então os outros dois são os que fazem os cálculos, logo o ideal seria trabalhar com redes de números pares de produtos, para não ocorrer como nestes casos, pois, tem um momento em que apenas um processo escravo fica trabalhando 
enquanto o outro e o mestre ficam ociosos, isso acarreta uma diminuição no speedup e conseqüentemente na eficiência.

Como executamos todas a redes para dois e quatro produtos, os gráficos 7.1 e 7.2 , a seguir, mostram a eficiência obtida quando variamos o tamanho da rede em termos de nós e arcos e mantemos fixado o número de produtos.

Para determinarmos o tamanho das redes, para os gráficos a seguir, fizemos o produto entre o número de nós e o número de arcos, que é o tamanho da matriz de incidência nó-arco.

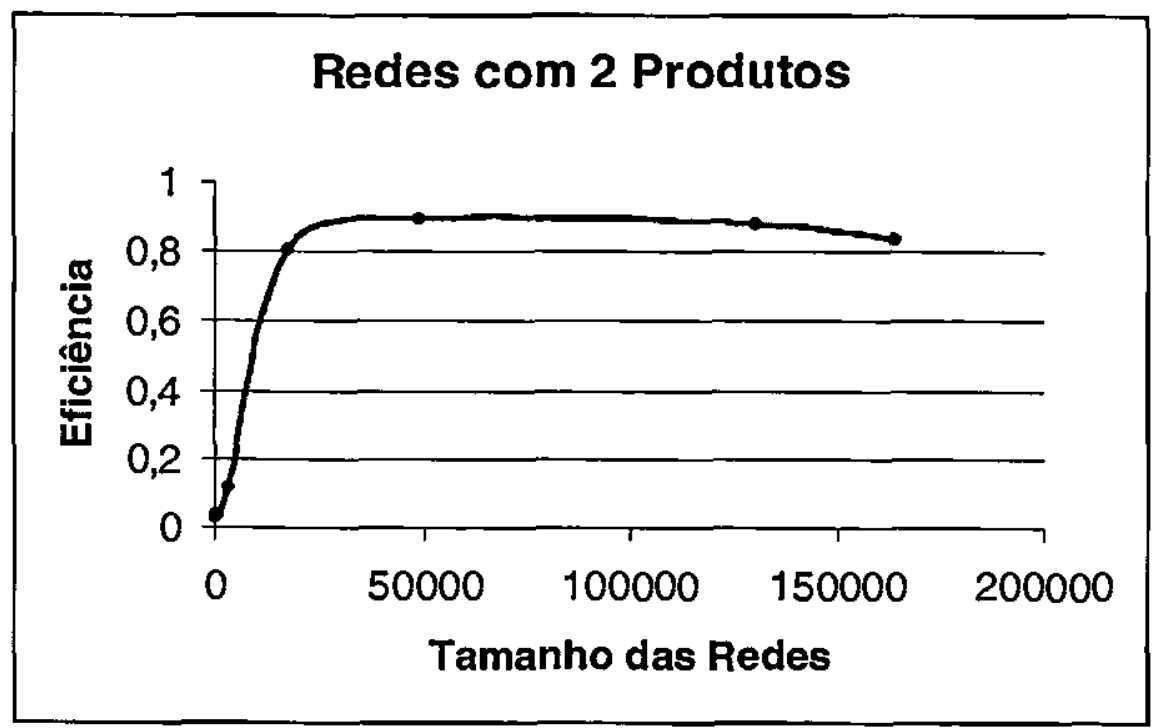

Gráfico 7.1: Redes com 2 produtos. 


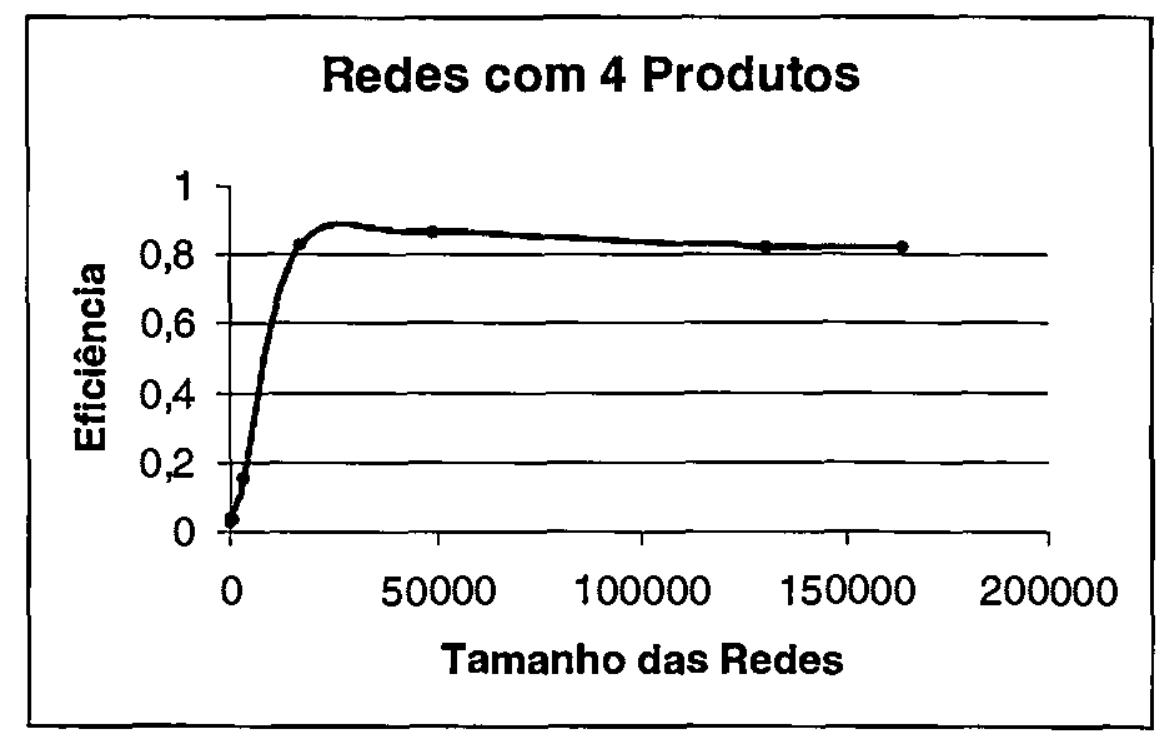

Gráfico 7.2: Redes com 4 produtos.

Percebemos que os gráficos 7.1 e 7.2 possuem comportamento bastante parecidos, isto deve-se ao fato de que ambos possuem redes com números pares de produtos. Percebemos também que à medida que o tamanho da rede vai aumentando, a eficiência vai se tornando próximo de 0.8 .

O gráfico 7.3, apresentado a seguir, mostra a eficiência obtida para a rede 4 variando somente o número de produtos.

Não foram feitos gráficos em relação as redes 1,2 e 3 , porque os tempos de processamento destas são pequenos e seria muito difícil analisar um gráfico para verificar os seus desempenhos, pois percebemos que nestes casos os tempos computacionais tendem a oscilar de acordo com um conjunto de características, que estão mais associadas com a máquina do que com o algoritmo em si. Basta verificarmos que para um processador o tempo computacional da rede $3 a$ é igual ao da rede $1 \mathrm{a}$, e no paralelo o tempo da rede $2 \mathrm{~b}$ é menor do que o da rede $1 \mathrm{a}$. Com isso verificamos que se tivéssemos que executar apenas redes de pequeno porte seria inviável executar em paralelo, pois, além de não trazer benefícios em relação ao tempo computacional traria perda de tempo, uma vez que é mais difícil e demorado programar em paralelo do que em seqüencial. 


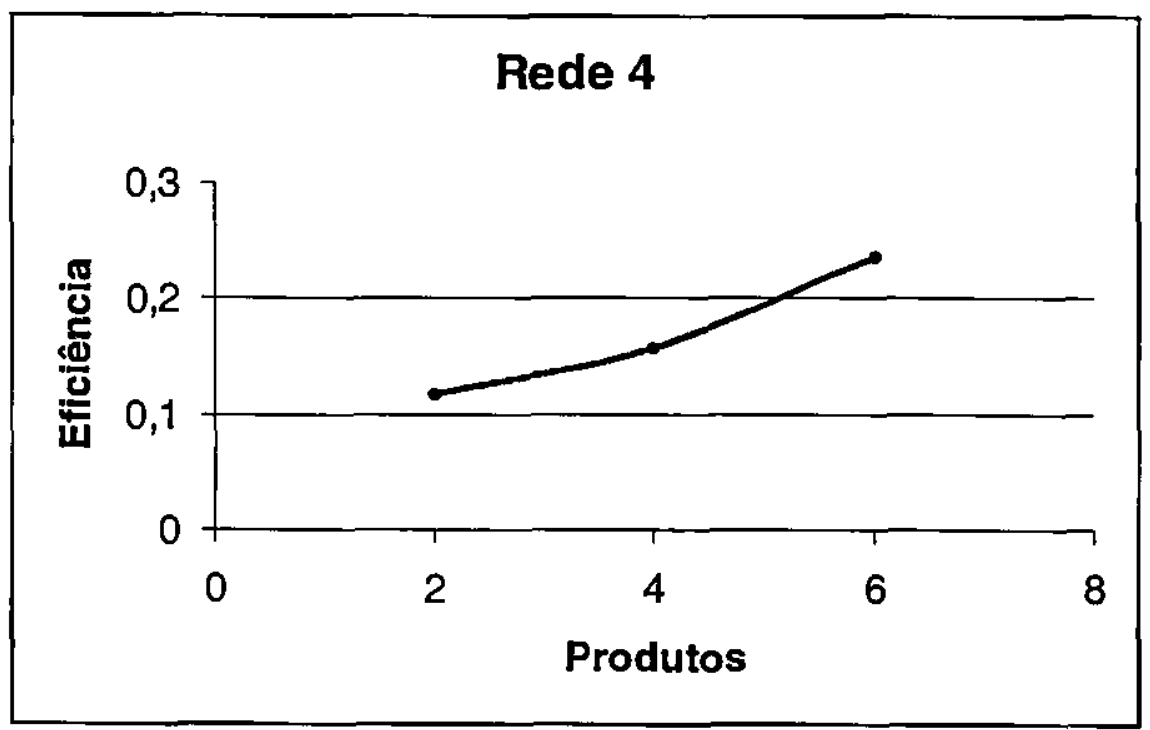

Gráfico 7.3: Desempenho da rede 4.

O gráfico acima é irrelevante, pois, como ainda se trata de uma rede pequena, o tempo de processamento seqüencial é melhor do que o do paralelo, como foi comentado abaixo da tabela 7.4, mas, percebemos que à medida em que o número de produtos vai aumentando a sua eficiência também aumenta.

O gráfico 7.4, a seguir, mostra o desempenho da rede 5 , que já pode ser considerada como uma rede de porte médio, para o nosso caso. Neste gráfico percebemos que a rede não é muito eficiente, devido ao fato desta possuir um número de produtos ímpar. No momento em que o número de produtos é ímpar a sua eficiência fica abaixo de 0.8 , isto porque um processo escravo ficou parado sem executar nenhuma tarefa enquanto que o outro trabalhava. Concluímos, no nosso caso, para as redes testadas, que todas as redes com número de produtos pares a eficiência do algoritmo implementado ficou em tomo de 0.8 , ou seja de $80 \%$. 


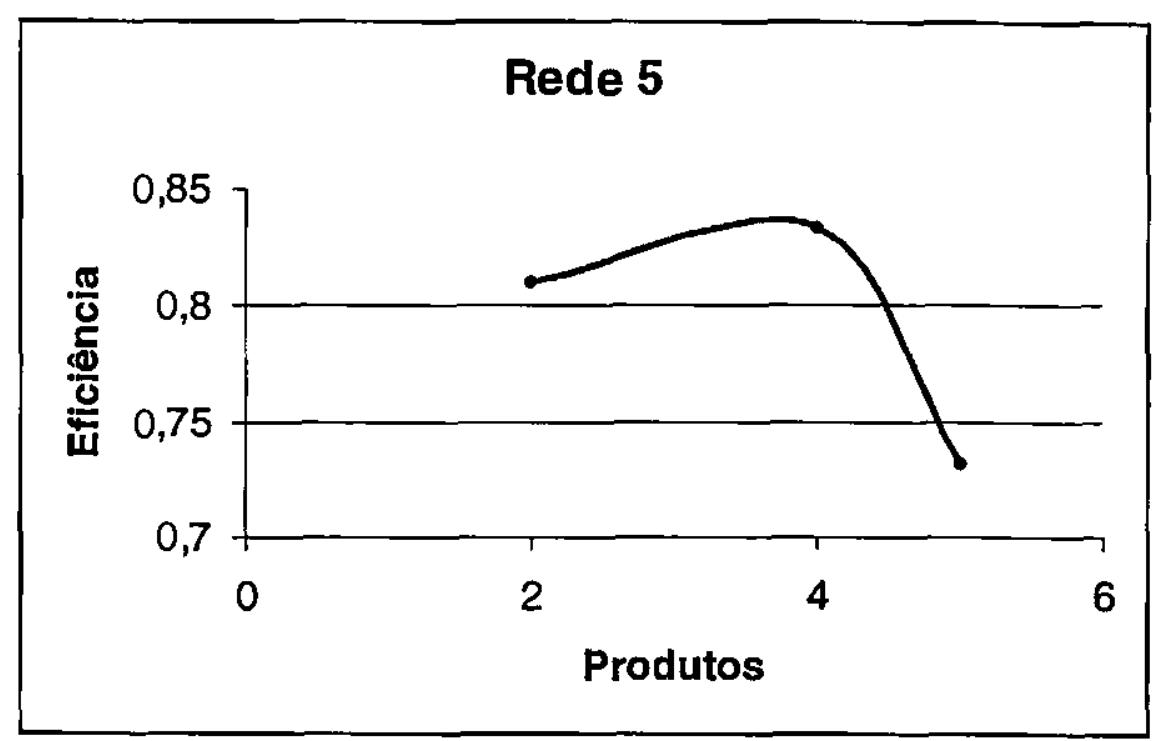

Gráfico 7.4: Desempenho da rede 5.

Embora o gráfico da rede 6, abaixo, apresente uma queda na eficiência, à medida em que o número de produtos aumenta, percebemos que é um desempenho normal, pois, ela não ultrapassou abaixo de 0.8 , os números de produtos que foram considerados nesta rede são pares, não foi considerada a rede $6 x$.

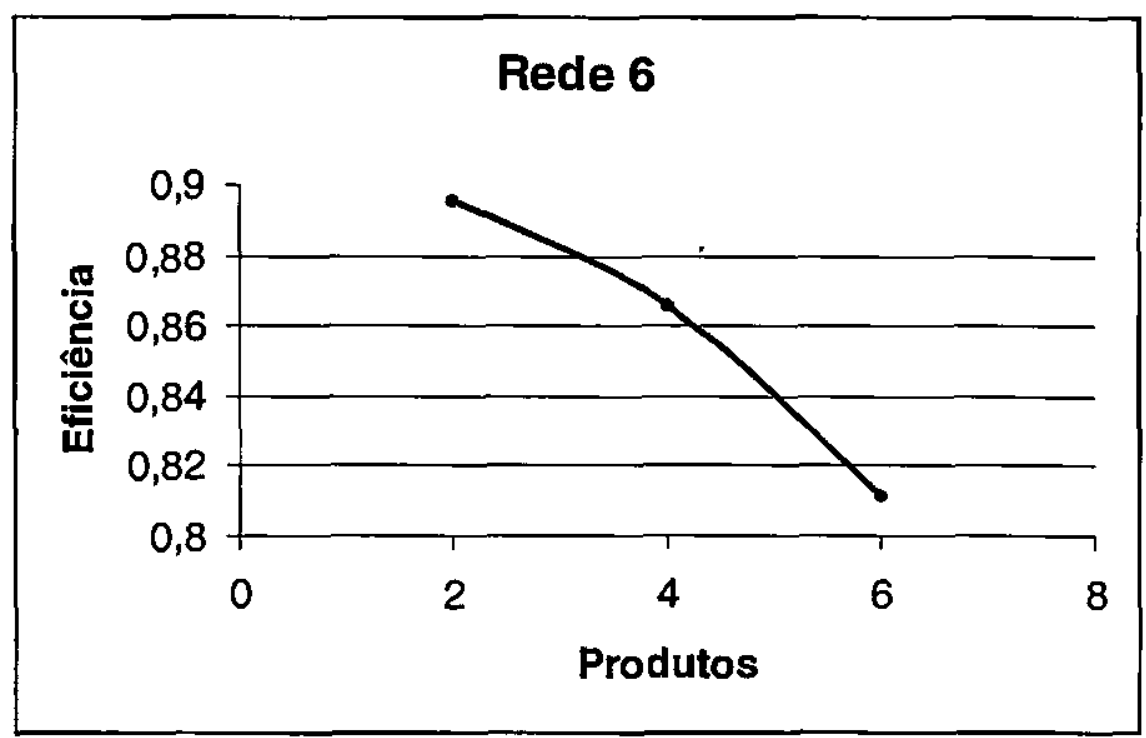

Gráfico 7.5: Desempenho da rede 6. 
Considerando a mesma rede do gráfico 7.5 , rede 6 , mas, com um número de produtos ímpar, vemos que a eficiência, deste número de produtos fica abaixo de 0.8 .

Os gráficos em relação às redes 7 e 8 não foram feitos, pelo fato das mesmas somente terem sido testadas para 2, 3 e 4 produtos, sendo que o gráfico não iria visualizar o desempenho das mesmas. Pela tabela 4 vemos que as eficiências destas ficam acima de 0.8 , quando o número de produtos é par, isto comprova a nossa afirmação de que à medida em que as redes e o número de produtos aumentam, em números pares, a eficiência do nosso algoritmo fica em torno de 0.8 ou $80 \%$ e quando o número de produtos é ímpar a eficiência da rede fica abaixo de 0.8 .

\subsubsection{Comparações entre os Tempos Seqüencial e Paralelo}

O gráfico apresentado abaixo nos mostra a relação de tempo de execução e tamanho da rede, tanto para execução seqüencial como para execução em paralelo.

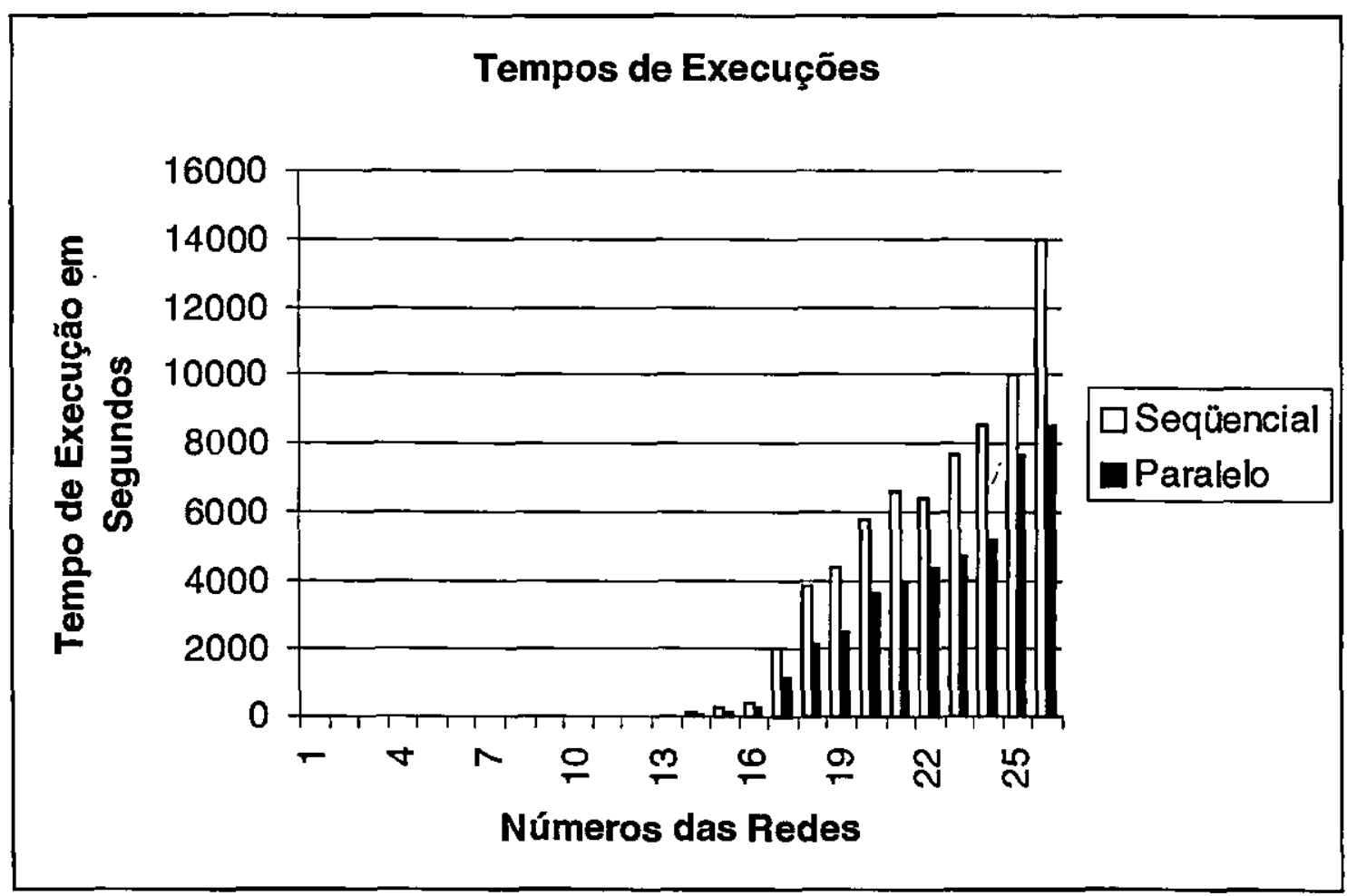

Gráfico 7.6: Tempos de execuções. 
No gráfico anterior percebemos que à medida em que a rede vai aumentando, a diferença entre o tempo de execução sequiencial vai ficando maior do que o tempo de execução em paralelo, isto para as redes com número de produtos par, uma vez que na penúltima rede do gráfico vemos que o paralelo não é tão maior do que o sequiencial, em proporções, do que os outros, este fato já comentamos anteriormente. Concluímos que nosso algoritmo é eficiente sobretudo quando o tamanho da rede aumenta. Infelizmente só pudemos trabalhar com dois escravos, pois acreditamos que se pudéssemos trabalhar com mais processadores a eficiência seria melhor.

\subsection{Considerações Finais}

Neste capítulo discutimos sobre a implementação e os resultados obtidos, comparamos os tempos computacionais e verificamos a eficiência do algoritmo, perante o SP2. Na próxima seção apresentamos as conclusões obtidas com esta implementação e também falamos das dificuldades encontradas e propostas para futuros trabalhos, no intuito de complementar este. 


\section{CONCLUSÕES}

Nesta seção comentamos algumas conclusões e contribuições do projeto, as dificuldades encontradas e algumas propostas para futuros trabalhos.

\section{Conclusões Obtidas}

Com o término do nosso projeto, tiramos algumas conclusões importantes:

- o método de resolução é eficaz, de fácil implementação seqüencial e próprio para implementação paralela;

- o algoritmo de relaxamento possui a vantagem de ser um método primal, portanto, a solução obtida a cada iteração será sempre factível, logo, se necessário, pode-se parar o processo de execução antes do final da convergência uma vez que a solução oferecida é satisfatória. Este recurso pode ser utilizado quando o problema a ser tratado é de grande dimensão e o tempo de execução é muito grande;

- no método Simplex Convexo a utilização da seqüência de orientação para o cálculo de $\bar{c}_{k}$ torna o algoritmo mais lento do que se forem utilizadas as variáveis duais;

- durante a execução em paralelo verificamos que os três nós de processamento tem a mesma capacidade de processamento. 
Quanto aos dados analisados concluímos:

- o algoritmo é eficiente, como foi testado em redes de médio porte e em um computador com somente dois processos escravos a sua eficiência ficou em torno de $80 \%$, isto quando trabalhamos com redes com números pares de produtos;

- como trabalhamos com um número par de escravos, verificamos que o método não seria tão eficaz, se executássemos uma rede com o número de produtos ímpares;

- para redes de pequeno porte o algoritmo seqüencial é mais eficiente que o paralelo, visto que o tempo de comunicação entre os processos mestre e escravo mais o tempo de execução é maior que o tempo de execução seqüiencial.

\section{Contribuições deste Trabalho}

Algumas contribuições oferecidas por este trabalho devem ser ressaltadas:

- apresenta resultados práticos para comparar os pontos fortes e fracos;

- constata que o algoritmo é eficiente, comprovando as afirmações de Luvezute [LUV95] e Ribeiro [RIB98], sobretudo para problemas de porte médio;

- analisa o desempenho do computador paralelo IBM-SP2.

\section{Dificuldades Encontradas}

Várias dificuldades foram encontradas durante o desenvol vimento deste trabalho:

- desenvolver o procedimento de busca do ciclo, na fase de implementação seqüencial do método Simplex Convexo;

- dividir o programa em dois programas fontes, que quando compilados transformavam-se em um único programa executável, pois isto seria necessário para a implementação paralela;

- a implementação dos algoritmos paralelos, visto que são passíveis de erros e algumas vezes de difíceis diagnósticos. 
- a execução do programa utilizando o LoadLever, uma vez que o mesmo possuía al gumas variáveis de ambiente ajustadas erroneamente;

- a execução dos algoritmos paralelos na máquina SP2, em virtude de ser utilizada por vários usuários, muitos destes usuários executando programas seriais, o que ocasionou na divisão do seu uso em intervalos semanais, não possibilitando assim que as execuções dos algoritmos fossem realizadas continuamente;

- pouca documentação referente à máquina paralela SP2, o que de certa forma dificultou estudá-la mais profundamente.

Com o término da execução do projeto, e com um certo amadurecimento surgiram algumas propostas para futuras complementações deste projeto.

\section{Sugestões para Propostas Futuras}

Durante o nosso projeto, foram surgindo argumentos para completar este projeto, porém como o tempo para se elaborar uma dissertação de mestrado é escasso, estes ficaram como propostas para futuros trabalhos:

- executar o programa em um computador paralelo com maior número de processadores, isto não foi possível pelo fato de o SP2 utilizado só possuir três processadores e a autorização para que fosse utilizado o computador paralelo da USP de São Paulo não chegou a tempo embora tivéssemos feito este pedido a muito tempo;

- a implementação de uma fase I para o problema, poderia melhorar muito o algoritmo. Chegamos até a pensar em como fazê-la mas não tivemos tempo hábil para isto;

- estudar o problema de ciclagem que é muito comum em problemas de fluxo com custo não linear. 
Quanto ao aspecto computacional, várias complementações surgiram:

- trabalhar em ambiente paralelo para PCs utilizando o sistema operacional Windows;

- trabalhar em ambiente paralelo para PCs utilizando o sistema operacional Linux;

- inclusão de algoritmos de árvores binárias, para a busca de alguns componentes;

- fazer uma forma com que o processo mestre também execute cálculos nos momentos em que ele fica esperando as respostas dos escravos. 


\section{ANEXO I}

\section{LOADLEVELER}

Loadleveler é um sistema de gerenciamento de jobs (tarefas), desenvolvido pela IBM para máquinas SP2 e clusters RISC/6000, serve como um escalonador de processos e fornece facilidades como: construir jobs, submetê-los e processá-los rapidamente em ambiente dinâmico [LOA95]. Além disso, o LoadLeveler faz o balanceamento de carga e a distribuição dos jobs entre os processadores, de forma eficiente, evitando-se que determinados nós fiquem mais sobrecarregados e que recursos, como a rede, sejam melhor compartilhados entre os usuários do SP2 [IBM95].

Para se executar alguma aplicação no SP2 é necessário que este programa seja submetido a alguma fila do ambiente. Para isso, é necessário criar um arquivo de comandos do LoadLeveler, também chamados de jobs. Os comandos săo necessários para indicar o programa a ser submetido, a fila em que o job será submetido, os recursos necessários para a execução do programa, entre outros. Este arquivo pode ser editado em qualquer editor de texto, como $v i$ ou pico [LOA95]. O LoadLeveler requisita o gerenciador de recursos do ambiente paralelo do SP2 para que possa alocar todos os recurso solicitados pelo usuário.

Para uma melhor compreensão do ambiente em que foi desenvolvido, e posteriormente executado nosso projeto, elaboramos um esquema "visual" contendo todos as estações de execução, e manipulação de jobs. 
ENTIDADE

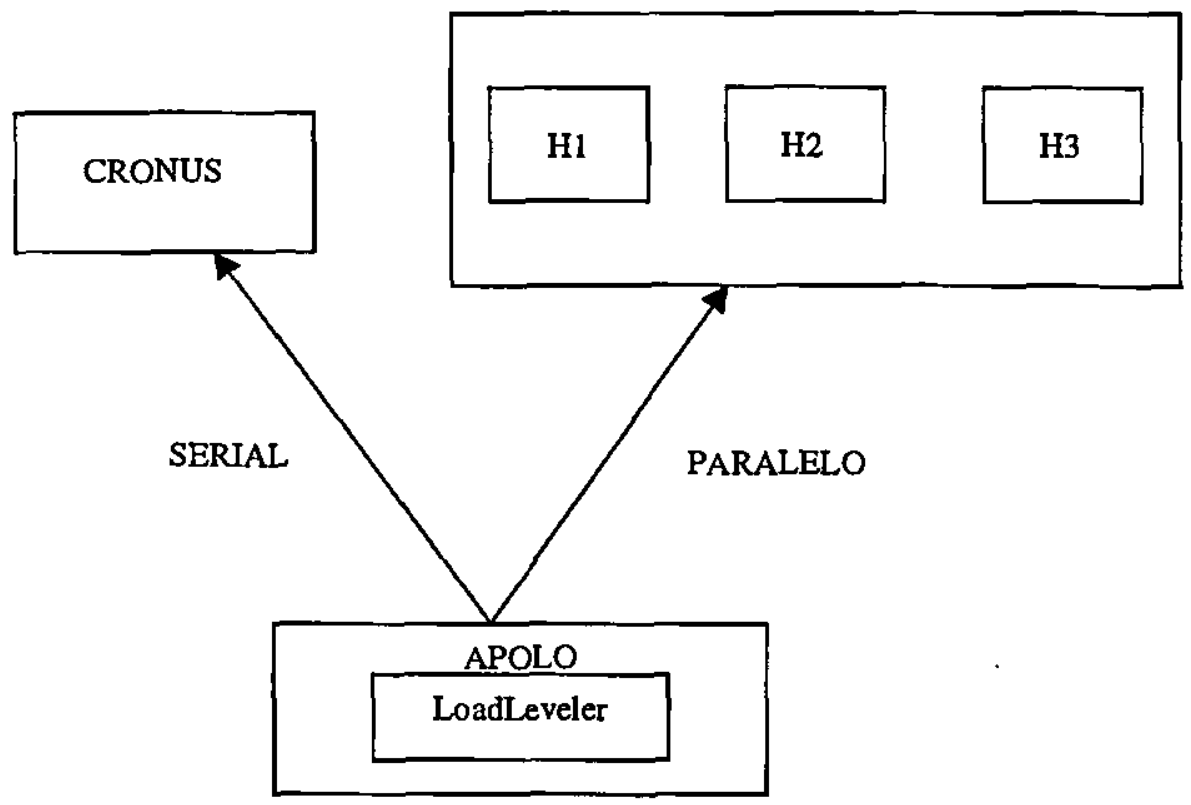

Figura A1 - Esquema do LoadLeveler

Como observamos no esquema acima, todo job é desenvolvido e enviado com suas respectivas especificações ao LoadLeveler, que está localizado na máquina Apolo a qual tem como principal função servir de interface entre o usuário e o ambiente paralelo. Tal gerenciador de jobs, recebe do usuário um arquivo de comandos com todas as especificaçōes necessárias para executar um programa no ambiente seqüencial (máquina Cronus) ou no ambiente paralelo (máquinas Hades01, Hades02, e Hades03).

Para executarmos um programa no ambiente seqüencial basta desenvolvermos um arquivo de comandos específico para o programa, e que contém como principal parâmetro o tempo relativo de execução do programa, escolhido através do tipo de fila em que o job deve ser enviado.

Entretanto, quando queremos utilizar o ambiente paralelo devemos desenvolver um arquivo de comandos um pouco mais complexo, no qual devem constar parâmetros de controle temporais e estruturais. Entre os diversos parâmetros, estão o tempo relativo de execução, que também é escolhido através do tipo de fila em que o job será enviado, o número de nós (máximo, 
e mínimo) que o LoadLeveler deverá utilizar para a execução do job, e a prioridade de utilização do equipamento.

Através do esquema anterior verificamos que no ambiente paralelo existem três máquinas disponíveis, e que tais máquinas estão dispostas segundo um esquema dinâmico de alocação, sendo que qualquer máquina poderá assumir a execução do processo mestre. Este mesmo dinamismo de alocação das máquinas é utilizado pelo LoadLeveler para a execução de mais de um job simultaneamente, sendo portanto a opção mais relevante do nosso arquivo de comandos. Tal opção nos permite escolher entre um processamento compartilhado (muito utilizado quando estamos focando a funcionalidade do programa, permitindo que outros jobs possam rodar simultaneamente) e um processamento exclusivo (muito utilizado quando estamos focando a performance do programa, pois neste caso, o tempo computacional terá um peso significativo para a tomada de decisões). 


\section{REFERÊNCIAS BIBLIOGRÁFICAS}

[ALM94] ALMASI, G.S.; GOTTLIEB, A. Highly Parallel Computing. $2^{\mathrm{a}}$ edição. The Benjamin Cummings Publishing Company, Inc., 1994.

[ARM97] ARMSTRONG, R.D.; IIN, Z. A New Strongly Polynomial Dual Network Simplex Algorithm. Mathematical Programming, v. 78, p.131-148, 1997.

[AUT87] AUTHIE, G. Contribution à L'optimization des Flots Dans les Réseaux. Un Multiprocesseur Expérimental por L'étude des itérattions Asynchrones. Thèse de Doctorat d'Etat, Université Paul Sabatier, Toulouse, França, 1987.

[BAZ77] BAZARAA, M.S.; JARVIS, J.J. Linear Programming and Network Flows. John Wiley \& Sons, 1977.

[BEG94] BEGUELIN, A.; et al. PVM: Parallel Virtual Machine. A User's Guide and Tutorial for Networked Parallel Computing. The MIT Press, 1994.

[BER83] BERTSEKAS, D.P.; GAFNI, M. Projected Newton methods and optimization of multicommodity flows. IEEE Trans. Automat. Control, v.28, p.1090-1096, 1983.

[BER87] BERTSEKAS, D.P.; GALLAGER, R. Data Network. Prentice - Hall, Englewood Cliffs, NJ. 1987.

[BER88] BERTSEKAS, D.P.; TSENG, P. Relaxation Methods for Minimum Cost Ordinary na Generalized Network Flow Problems. Operations Research, v.36, n.1, p.93-114, 1988.

[CAS96] CASTRO, J.; NABONA, N. An Implementation of Liner and Nonlinear Multicommodity Network Flows. European Journal of Operational Research, v.92, p.37-53, 1996. 
[CEN98] CENTORION, A.M. Análise de Desempenho de Algoritmos Paralelos Utilizando Plataformas de Portabilidade. São Carlos, 1998. Dissertação (Mestrado) Instituto de Ciências Matemáticas e de Computação, Universidade de São Paulo.

[DUN90] DUNCAN, R. A Survey of Parallel Computer Architectures. IEEE Computer, p.5-16, fevereiro, 1990.

[EAG89] EAGER, D.L.; ZAHORJAN, J.; LAZOWSKA, E.D. Speedup Versus Efficiency in Parallel System. IEEE Transaction on Computer, v.38, n.3. march, 1989.

[FAR93] FARVOLDEN, J.M.; POWELL, W.B.; LUSTING, I.J. A Primal Partitioning Solution for the Arc-Chain Formulation of a Multicommodity Network Flow Problem. Operations Research, v.41, n.4, p.669-693, 1993.

[FLY72] FLYNN, M.J. Some Computer Organizations and Their Effectiveness. IEEE Transaction on Computer, v.C-21, p.948-960, 1972.

[FOR97] FORTUNA, A.O. TRINDADE, O.JR. Introdução à Programação Paralela no IBM SP2. Apostila (Curso de Especialização), Centro de Informática de São Carlos, Universidade de São Paulo. São Carlos, junho, 1997.

[FRA73] FRATTA, L.; GERLA, M.; KLEINROCK, L. The Deviation Method: An Aproach to Store and Forward Communication Netword Design. Networds, v.3, p.97-133, 1973.

[GAL77] GALLAGER, R.G. A Minimum Delay Routing Algorithm Using Distributed Computation. IEEE Transactions on Communications, v.c-25, n.1, p.73-85, 1977.

[GEI94] GEIST, A.; et al. PVM3 User's Guide and Reference Manual. Oak National Laboratory, setembro, 1994.

[GEI95] GEIST, A. PVM HOME PAGE, Recente PVM Highlights. Página HTML (http://www.epm.oml.gov/pvm/highlight.html/), 1994.

[GOL97] GOLDFARB, D.; CHEN, W. On Strongly Polynomial Dual Simplex Algorithms for the Maximum Flow Problem. Mathematical Programming, v.8, p.159-168, 1997. 
[GON84] GONDRAN, M.; MINOUX, M. Graphs and Algorithms. John Wiley \& Sons, 1984.

[HU69] HU, T.C. Integer Programming and Network Flows. Addison-Wesley, 1969.

[IBM95] IBM Corporation. POWER2:Next Generation of RISC System/6000. Página HTML (http://ibm.tc.cornell.edu/ibm/pps/power/power2/index.html), 1995.

[IBM97] IBM Corporation. RS/6000 SP System. Página HTML. (http://www.rs6000.ibm.com/hardware/largescale/index.html), 1997.

[KAR97] KARZANOV, A.V. Multiflows and Disjoint Paths of Minimum Total Cost. Mathematical Programming, v.78, p.219-242, 1997.

[KEN78] KENNINGTON, J.L. A Survey of Linear Cost Multicommodity Network Flows. Operations Research, v.26, n.2, p.209-236, 1978.

[KEN80] KENNINGTON, J.L.; HELGASON, R.V. Algorithms for Network Programming. John Wiley \& Sons, 1980.

[KIR91] KIRNER, C. Arquitetura de Sistemas Avançados de Computação. Anais da Jornada EPUSP/IEEE em Sistemas de Computação de Alto Desempenho, p.307$353,1991$.

[KLE64] KLEINROCK, L. Communication Nets: Stochastic Message Flow and Delay. MacGraw-Hill, 1964.

[LOA95] IBM Corporation LoadLeveler User's Guide. Release 2.1, $3^{\mathrm{a}}$ edição. Agosto, 1995.

[LUV95] LUVEZUTE, R.M. Algoritmo para o Problema de Multifluxo Não linear: Uma Aplicação ao Problema de Roteamento de Dados em Redes de Comutação. São Carlos, 1995. 90p. Dissertação (Mestrado) - Instituto de Ciências Matemáticas de São Carlos, Universidade de São Paulo.

[MCB94] MCBRYAN, O.A. An Overview of Message Passing Environments. Parallel Computing, v.20, p.417-444, 1994. 
[MCB98] MCBRIDE, R.D. Progress Made in Solving the Multicommodity Flow Problem. Siam Journal on Optimizaction, v.8, n.4, p.947-955, novembro, 1998.

[OLI97] OLIVEIRA, M.M.B. de. Seqüenciamento da Produção ccom Divisão em Células de Manufatura e uso de Processamento Paralelo. São Carlos, 1997. 127p. Tese (Doutorado) - Escola de Engenharia de São Carlos, Universidade de São Paulo.

[ORL97] ORLIN, J.B. A Polynomial Time Primal Network Simplex Algorithm for Minimum Cost Flows. Mathematical Programming, v.78, p. 109-129, 1997.

[RIB91] RIBEIRO, C.M. Une methode Parallele pour le Routage dans les Reseaux a Commutation de Paquets. Toulouse, França, 1991. Tese (Doutorado) - INSATLAAS-Toulouse.

[RIB92] RIBEIRO, C.M.; BAZ, D.E. A Parallel Optimal Routing Algorithm. Parallel Computing, v.18, p.1393-1402, North Holland, 1992.

[RIB98] RIBEIRO, C.M.; LUVEZUTE, R.M.; RIBEIRO J.F.F. An Algorithm for Optimal Routing. Aceito para publicação no 8th IFAC/IFORS/IMACS/IFIP. Symposium on Large Escale Systems: Theory and Application, 15-17 Julho 1998. University of Patras. Patras, Grécia, julho, 1998.

[ROC84] ROCKFELLAR, R.T. Network Flows and Monotropic Optimization. John Wiley \& Sons, 1984.

[ROT66] ROTHSCHLD, B.; WHINSTON, On Two-Commodity Network Flows. Operations Research, v. 14, p.377-387, 1966.

[SAK73] SAKAROVITCH, M. Two-commodity Network Flows and Linear Ptogramming. Mathematical Programming, v.4, n.1, p.1-20, 1973.

[SAK82] SAKAROVITCH, M. Techniques Mathematiques de la Recherche Operationnelle: Optimisation dans les réseaux. INPG-ENSIMAG-GRENOBLE, França, 1982.

[SAK84] SAKAROVITCH, M. Optimisation Combinatoire: Graphes et Programation Linéaire. Hermann, 1984. 
[SCH76] SCHWARTZ, M.; CHENG,C. The gradient Projection Algorithm for Multiple Routing in Message-Switched Networks. IEEE Transaction on Communications, p.449 - 456, 1976.

[SOK97] SOKKALINGAM, P.T.; SHARMA, P.; AHUJA, R.K. A New Pivot Selection Rule for the Network Simplex Algorithm. Mathematical Programming, v.78, p.149-158, 1997.

[STE77] STERN, T. A Class of Descentralized Routing Algoritms Using Relaxation. IEEE Transaction on Computers, v.c-25, p.1092-1102, 1977.

[SOU96] SOUZA, P.S.L. Máquina Paralela Virtual no Ambiente Windows. São Carlos, Maio, 1996. 145p. Dissertação (Mestrado) - Instituto de Ciências Matemáticas de São Carlos, Universidade de São Paulo.

[SUN94] SUNDERAM, A. S., et. Al. The PVM concurrent computing system: evolution, experiences and trends. Parallel computing, v.20, p531 - 545, 1994.

[SZW86] SZWARCFITER, J. L. Grafos e Algoritmos Computacionais. Editora Campus, 1986.

[TAR97] TARJAN, R.E. Dynamic Trees as Search Trees via Euler Tours, Applied to the Network Simplex Algorithm. Mathematical Programming, v.78, p.169-177, 1997.

[TSA89] TSAI, K.; HUANG, G.; ANTONIO, K.; TSAI,T. Distribuited Iterative Aggregation Algorithms for Box Constrained Minimization Problems and Optimal Routing in Data Networks. IEEE Trans. Automat. Control, v.34, p.34 - 46, 1989.

[TSE90] TSENG, P.; BERTSEKAS, D.P.; TSITSIKLIS, J.N. Partially Asynchronous, Parallel Algorithms for Network Flow and Other Problems. Siam Journal Control and Optimization, v.28, n.3, p.678-710, 1990.

[TS186] TSITSIKLIS, J.; BERTSEKAS, D. P. Distribuited Asynchronous Optimal Routing in Data Networks. IEEE Trans. Automat. Control, v.31, p.325 - 332, 1986. 


\section{APÊNDICE I}

Exemplo de um Arquivo de Entrada do Algoritmo Paralelo Implementado

ARQUIVO DE ENTRADA $\Rightarrow$ prob3c.dat

n. nós n. arcos n. produtos

$\begin{array}{lll}23 & 32 & 6 \\ \text { Arco } & \text { Or. Dest. Cap. } \stackrel{\text { Base }}{ } \text { Atraso }\end{array}$

$\begin{array}{llllll}1 & 2 & 1 & 10 & i & 0.05\end{array}$

$\begin{array}{llllll}2 & 4 & 2 & 10 & 1 & 0.05\end{array}$

$\begin{array}{llllll}3 & 3 & 2 & 10 & 1 & 0.05\end{array}$

Onde:

$\begin{array}{llllll}4 & 2 & 5 & 10 & 1 & 0.05\end{array}$

n. nós: número de nós da rede

$\begin{array}{llllll}5 & 6 & 5 & 10 & 1 & 0.05\end{array}$

n. arcos: número de arcos da rede

$\begin{array}{llllll}6 & 5 & 10 & 10 & 0 & 0.05\end{array}$

n. produtos: número de produtos

que circulam na rede.

$\begin{array}{llllll}7 & 5 & 8 & 10 & 1 & 0.05\end{array}$

$\begin{array}{llllll}8 & 8 & 7 & 10 & 1 & 0.05\end{array}$

$m$ do arco

$\begin{array}{llllll}9 & 9 & 8 & 10 & 1 & 0.05\end{array}$

$\begin{array}{llllll}10 & 7 & 6 & 10 & 0 & 0.05\end{array}$

$\begin{array}{llllll}11 & 6 & 1 & 10 & 0 & 0.05\end{array}$

$\begin{array}{llllll}12 & 10 & 4 & 10 & 0 & 0.05\end{array}$

$\begin{array}{llllll}13 & 9 & 10 & 10 & 1 & 0.05\end{array}$

$\begin{array}{llllll}14 & 10 & 11 & 10 & 1 & 0.05\end{array}$

$\begin{array}{llllll}15 & 14 & 9 & 10 & 1 & 0.05\end{array}$

$\begin{array}{llllll}16 & 8 & 15 & 10 & 0 & 0.05\end{array}$

$\begin{array}{llllll}17 & 16 & 15 & 10 & 1 & 0.05\end{array}$

$\begin{array}{llllll}18 & 15 & 14 & 10 & 1 & 0.05\end{array}$ 
$\begin{array}{llllll}19 & 14 & 13 & 10 & 0 & 0.05\end{array}$

$\begin{array}{llllll}20 & 12 & 9 & 10 & 0 & 0.05\end{array}$

$\begin{array}{llllll}21 & 11 & 12 & 10 & 1 & 0.05\end{array}$

$\begin{array}{llllll}22 & 12 & 13 & 10 & 0 & 0.05\end{array}$

$\begin{array}{llllll}23 & 13 & 20 & 10 & 1 & 0.05\end{array}$

$\begin{array}{llllll}24 & 19 & 14 & 10 & 1 & 0.05\end{array}$

$\begin{array}{llllll}25 & 20 & 19 & 10 & 1 & 0.05\end{array}$

$\begin{array}{llllll}26 & 19 & 18 & 10 & 1 & 0.05\end{array}$

$\begin{array}{llllll}27 & 15 & 18 & 10 & 0 & 0.05\end{array}$

$\begin{array}{llllll}28 & 17 & 16 & 10 & 0 & 0.05\end{array}$

$\begin{array}{llllll}29 & 18 & 17 & 10 & 1 & 0.05\end{array}$

$\begin{array}{llllll}30 & 18 & 22 & 10 & 1 & 0.05\end{array}$

$\begin{array}{llllll}31 & 23 & 22 & 10 & 1 & 0.05\end{array}$

$\begin{array}{llllll}32 & 22 & 21 & 10 & 1 & 0.05\end{array}$

Fluxo de Entrada do Produto 1

2

Solução Factível Inicial do Produto 1.

$\begin{array}{lllllllllllllllllllllllllllll}0 & 0.5 & 0.75 & 0.25 & 0 & 0 & 1 & 1 & 1.5 & 0.7 & 0.6 & 0 & 0.25 & 2 & 1.5 & 1 & 1 & 0 & 0.6 & 0.5 & 0 & 1 & 1.5 & 1 & 1.5 & 2 & 1 & 0\end{array}$

00.500

Fluxo de Entrada do Produto 2.

1.5

Solução Factível Inicial do Produto 2.

$\begin{array}{llllllllllllllllllllllllllll}1 & 2 & 0.5 & 0.6 & 0.75 & 0 & 1 & 1.5 & 1 & 2 & 0 & 0.5 & 1 & 0 & 0.5 & 0.75 & 0.8 & 0 & 0 & 1 & 2 & 1.5 & 0 & 0.5 & 0.75 & 1 & 1.5 & 1\end{array}$

$\begin{array}{lllll}2 & 0 & 0.5 & 1\end{array}$

Fluxo de Entrada do Produto 3.

1

Solução Factível Inicial do Produto 3.

$\begin{array}{llllllllllllllllllllllllllll}0.5 & 0 & 0 & 0.75 & 0.6 & 0 & 1 & 1.5 & 2 & 1.6 & 0 & 0.9 & 0.75 & 0.6 & 0 & 1 & 1.5 & 1 & 1 & 0 & 0.5 & 0.6 & 0.75 & 1 & 1 & 2 & 0 & 0\end{array}$ $\begin{array}{llllll}1.5 & 0 & 0.5 & 0\end{array}$ 
Fluxo de Entrada do Produto 4.

0.5

Solução Factível Inicial do Produto 4.

$\begin{array}{lllllllllllllllllllllllllllllll}1 & 0 & 0.5 & 0 & 0.75 & 0.8 & 0 & 1 & 0 & 0 & 2 & 1.6 & 0 & 0 & 0.5 & 0 & 1 & 2 & 1.5 & 0 & 0.5 & 0.6 & 0 & 1 & 1.5 & 1 & 1 & 0 & 0.5 & 0\end{array}$

0.52

Fluxo de Entrada do Produto 5.

1

Solução Factível Inicial do Produto 5.

$\begin{array}{llllllllllllllllllllllllllll}1.5 & 0 & 0.75 & 0 & 1 & 1.5 & 0.4 & 0.8 & 1 & 1.4 & 1 & 1.1 & 1 & 0 & 0.6 & 0.8 & 0.6 & 0.5 & 2 & 1 & 0 & 0 & 0.5 & 0.75 & 0.5 & 0 & 0.5\end{array}$ $\begin{array}{lllll}1 & 2 & 1 & 0 & 0.5\end{array}$

Fluxo de Entrada do Produto 6.

0.75

Solução Factível Inicial do Produto 6.

$\begin{array}{llllllllllllllllllllllllllllllll}1 & 1.5 & 0 & 0.6 & 0 & 0 & 1 & 1.5 & 2 & 1 & 1.5 & 0 & 0.5 & 0.75 & 0 & 0.5 & 0.8 & 0 & 0 & 1 & 1.1 & 1 & 1 & 2 & 0 & 0.5 & 0.75 & 0 & 0 & 1\end{array}$ 1.52 


\section{APÊNDICE II}

Exemplo de um Arquivo de Saída do Algoritmo Paralelo Implementado

Arquivo de Entrada: ./exemplos/prob3c.dat

Arquivo de Saída: prob3c.txt

Número de Nós: 23

Número de Arcos: 32

Número de Produtos: 6

Arcos Origem Destino Capacidade Base Atraso

$\begin{array}{llllll}1 & 2 & 1 & 10.000 & 1 & 0.050 \\ 2 & 4 & 2 & 10.000 & 1 & 0.050 \\ 3 & 3 & 2 & 10.000 & 1 & 0.050 \\ 4 & 2 & 5 & 10.000 & 1 & 0.050 \\ 5 & 6 & 5 & 10.000 & 1 & 0.050 \\ 6 & 5 & 10 & 10.000 & 0 & 0.050 \\ 7 & 5 & 8 & 10.000 & 1 & 0.050 \\ 8 & 8 & 7 & 10.000 & 1 & 0.050 \\ 9 & 9 & 8 & 10.000 & 1 & 0.050 \\ 10 & 7 & 6 & 10.000 & 0 & 0.050 \\ 11 & 6 & 1 & 10.000 & 0 & 0.050 \\ 12 & 10 & 4 & 10.000 & 0 & 0.050 \\ 13 & 9 & 10 & 10.000 & 1 & 0.050 \\ 14 & 10 & 11 & 10.000 & 1 & 0.050 \\ 15 & 14 & 9 & 10.000 & 1 & 0.050\end{array}$




$\begin{array}{llllll}16 & 8 & 15 & 10.000 & 0 & 0.050 \\ 17 & 16 & 15 & 10.000 & 1 & 0.050 \\ 18 & 15 & 14 & 10.000 & 1 & 0.050 \\ 19 & 14 & 13 & 10.000 & 0 & 0.050 \\ 20 & 12 & 9 & 10.000 & 0 & 0.050 \\ 21 & 11 & 12 & 10.000 & 1 & 0.050 \\ 22 & 12 & 13 & 10.000 & 0 & 0.050 \\ 23 & 13 & 20 & 10.000 & 1 & 0.050 \\ 24 & 19 & 14 & 10.000 & 1 & 0.050 \\ 25 & 20 & 19 & 10.000 & 1 & 0.050 \\ 26 & 19 & 18 & 10.000 & 1 & 0.050 \\ 27 & 15 & 18 & 10.000 & 0 & 0.050 \\ 28 & 17 & 16 & 10.000 & 0 & 0.050 \\ 29 & 18 & 17 & 10.000 & 1 & 0.050 \\ 30 & 18 & 22 & 10.000 & 1 & 0.050 \\ 31 & 23 & 22 & 10.000 & 1 & 0.050 \\ 32 & 22 & 21 & 10.000 & 1 & 0.050\end{array}$

Fluxo de Entrada do Produto 1: 2.000

Solução Factível Inicial do Produto 1:

0.0000 .5000 .7500 .2500 .0000 .0001 .0001 .0001 .5000 .7000 .6000 .0000 .2502 .0001 .500

1.0001 .0000 .0000 .6000 .5000 .0001 .0001 .5001 .0001 .5002 .0001 .0000 .0000 .0000 .500 0.0000 .000

Fluxo de Entrada do Produto 2: 1.500

Solução Factível Inicial do Produto 2:

1.0002 .0000 .5000 .6000 .7500 .0001 .0001 .5001 .0002 .0000 .0000 .5001 .0000 .0000 .500

0.7500 .8000 .0000 .0001 .0002 .0001 .5000 .0000 .5000 .7501 .0001 .5001 .0002 .0000 .000 0.5001 .000 
Fluxo de Entrada do Produto 3: 1.000

Solução Factível Inicial do Produto 3:

0.5000 .0000 .0000 .7500 .6000 .0001 .0001 .5002 .0001 .6000 .0000 .9000 .7500 .6000 .000 1.0001 .5001 .0001 .0000 .0000 .5000 .6000 .7501 .0001 .0002 .0000 .0000 .0001 .5000 .000 0.5000 .000

Fluxo de Entrada do Produto 4: 0.500

Solução Factível Inicial do Produto 4:

1.0000 .0000 .5000 .0000 .7500 .8000 .0001 .0000 .0000 .0002 .0001 .6000 .0000 .0000 .500 0.0001 .0002 .0001 .5000 .0000 .5000 .6000 .0001 .0001 .5001 .0001 .0000 .0000 .5000 .000 0.5002 .000

Fluxo de Entrada do Produto 5: 1.000

Solução Factível Inicial do Produto 5:

1.5000 .0000 .7500 .0001 .0001 .5000 .4000 .8001 .0001 .4001 .0001 .1001 .0000 .0000 .600 0.8000 .6000 .5002 .0001 .0000 .0000 .0000 .5000 .7500 .5000 .0000 .5001 .0002 .0001 .000 0.0000 .500

Fluxo de Entrada do Produto 6: 0.750

Solução Factível Inicial do Produto 6:

1.0001 .5000 .0000 .6000 .0000 .0001 .0001 .5002 .0001 .0001 .5000 .0000 .5000 .7500 .000 0.5000 .8000 .0000 .0001 .0001 .1001 .0001 .0002 .0000 .0000 .5000 .7500 .0000 .0001 .000 1.5002 .000

Função para a Solução Inicial: $F i=33.213898$

\section{APÓS 11 ITERAÇÕES}


Produto: 1

Solução ótima

Arcos Origem Destino Capacidade Base Atraso

$\begin{array}{llllll}1 & 2 & 1 & 4.825 & 1 & 0.050 \\ 2 & 4 & 2 & 6.600 & 1 & 0.050 \\ 3 & 3 & 2 & 8.250 & 1 & 0.050 \\ 4 & 2 & 5 & 8.325 & 0 & 0.050 \\ 5 & 6 & 5 & 9.625 & 0 & 0.050 \\ 6 & 5 & 10 & 8.200 & 0 & 0.050 \\ 7 & 5 & 8 & 9.100 & 1 & 0.050 \\ 8 & 8 & 7 & 6.600 & 1 & 0.050 \\ 9 & 9 & 8 & 5.881 & 1 & 0.050 \\ 10 & 7 & 6 & 6.900 & 1 & 0.050 \\ 11 & 6 & 1 & 5.675 & 0 & 0.050 \\ 12 & 10 & 4 & 6.000 & 1 & 0.050 \\ 13 & 9 & 10 & 6.944 & 1 & 0.050 \\ 14 & 10 & 11 & 9.244 & 1 & 0.050 \\ 15 & 14 & 9 & 8.900 & 1 & 0.050 \\ 16 & 8 & 15 & 8.431 & 1 & 0.050 \\ 17 & 16 & 15 & 6.600 & 1 & 0.050 \\ 18 & 15 & 14 & 8.045 & 0 & 0.050 \\ 19 & 14 & 13 & 7.406 & 0 & 0.050 \\ 20 & 12 & 9 & 8.575 & 1 & 0.050 \\ 21 & 11 & 12 & 6.494 & 0 & 0.050 \\ 22 & 12 & 13 & 5.319 & 1 & 0.050 \\ 23 & 13 & 20 & 8.675 & 0 & 0.050 \\ 24 & 19 & 14 & 5.612 & 0 & 0.050 \\ 25 & 20 & 19 & 7.175 & 1 & 0.050 \\ 26 & 19 & 18 & 5.563 & 1 & 0.050 \\ 27 & 15 & 18 & 7.487 & 1 & 0.050\end{array}$




$\begin{array}{llllll}28 & 17 & 16 & 9.300 & 0 & 0.050 \\ 29 & 18 & 17 & 5.300 & 1 & 0.050 \\ 30 & 18 & 22 & 8.000 & 1 & 0.050 \\ 31 & 23 & 22 & 7.000 & 1 & 0.050 \\ 32 & 22 & 21 & 4.500 & 1 & 0.050\end{array}$

Produto: 2

Solução 6tima

Arcos Origem Destino Capacidade Base Atraso

$\begin{array}{llllll}1 & 2 & 1 & 4.975 & 1 & 0.050 \\ 2 & 4 & 2 & 7.250 & 1 & 0.050 \\ 3 & 3 & 2 & 8.000 & 1 & 0.050 \\ 4 & 2 & 5 & 8.675 & 1 & 0.050 \\ 5 & 6 & 5 & 9.625 & 0 & 0.050 \\ 6 & 5 & 10 & 8.200 & 0 & 0.050 \\ 7 & 5 & 8 & 8.350 & 0 & 0.050 \\ 8 & 8 & 7 & 7.200 & 1 & 0.050 \\ 9 & 9 & 8 & 5.031 & 1 & 0.050 \\ 10 & 7 & 6 & 8.300 & 1 & 0.050 \\ 11 & 6 & 1 & 5.925 & 1 & 0.050 \\ 12 & 10 & 4 & 5.650 & 0 & 0.050 \\ 13 & 9 & 10 & 6.844 & 1 & 0.050 \\ 14 & 10 & 11 & 7.244 & 0 & 0.050 \\ 15 & 14 & 9 & 7.800 & 0 & 0.050 \\ 16 & 8 & 15 & 6.981 & 1 & 0.050 \\ 17 & 16 & 15 & 5.600 & 0 & 0.050 \\ 18 & 15 & 14 & 8.045 & 0 & 0.050 \\ 19 & 14 & 13 & 7.406 & 1 & 0.050 \\ 20 & 12 & 9 & 7.975 & 1 & 0.050 \\ 21 & 11 & 12 & 8.494 & 1 & 0.050 \\ 22 & 12 & 13 & 6.919 & 1 & 0.050\end{array}$




$$
\begin{array}{llllll}
23 & 13 & 20 & 8.875 & 1 & 0.050 \\
24 & 19 & 14 & 5.612 & 0 & 0.050 \\
25 & 20 & 19 & 8.125 & 1 & 0.050 \\
26 & 19 & 18 & 5.763 & 1 & 0.050 \\
27 & 15 & 18 & 5.987 & 0 & 0.050 \\
28 & 17 & 16 & 9.500 & 1 & 0.050 \\
29 & 18 & 17 & 6.500 & 1 & 0.050 \\
30 & 18 & 22 & 7.500 & 1 & 0.050 \\
31 & 23 & 22 & 7.500 & 1 & 0.050 \\
32 & 22 & 21 & 5.500 & 1 & 0.050
\end{array}
$$

Produto: 3

\section{Solução ótima}

$$
\begin{array}{cllllll}
\multicolumn{3}{c}{\text { Arcos }} & \multicolumn{6}{c}{\text { Origem }} & \text { Destino Capacidade Base Atraso } \\
1 & 2 & 1 & 4.725 & 1 & 0.050 \\
2 & 4 & 2 & 5.750 & 0 & 0.050 \\
3 & 3 & 2 & 7.500 & 1 & 0.050 \\
4 & 2 & 5 & 9.075 & 1 & 0.050 \\
5 & 6 & 5 & 9.625 & 0 & 0.050 \\
6 & 5 & 10 & 8.200 & 0 & 0.050 \\
7 & 5 & 8 & 8.750 & 1 & 0.050 \\
8 & 8 & 7 & 7.100 & 1 & 0.050 \\
9 & 9 & 8 & 6.075 & 1 & 0.050 \\
10 & 7 & 6 & 7.800 & 1 & 0.050 \\
11 & 6 & 1 & 5.675 & 0 & 0.050 \\
12 & 10 & 4 & 6.550 & 1 & 0.050 \\
13 & 9 & 10 & 7.250 & 1 & 0.050 \\
14 & 10 & 11 & 8.000 & 1 & 0.050 \\
15 & 14 & 9 & 7.800 & 0 & 0.050 \\
16 & 8 & 15 & 7.775 & 1 & 0.050 \\
17 & 16 & 15 & 7.100 & 1 & 0.050
\end{array}
$$




$\begin{array}{llllll}18 & 15 & 14 & 8.045 & 0 & 0.050 \\ 19 & 14 & 13 & 7.500 & 0 & 0.050 \\ 20 & 12 & 9 & 7.175 & 0 & 0.050 \\ 21 & 11 & 12 & 7.150 & 1 & 0.050 \\ 22 & 12 & 13 & 5.975 & 1 & 0.050 \\ 23 & 13 & 20 & 8.675 & 0 & 0.050 \\ 24 & 19 & 14 & 6.705 & 1 & 0.050 \\ 25 & 20 & 19 & 7.425 & 1 & 0.050 \\ 26 & 19 & 18 & 5.220 & 1 & 0.050 \\ 27 & 15 & 18 & 6.830 & 1 & 0.050 \\ 28 & 17 & 16 & 9.300 & 0 & 0.050 \\ 29 & 18 & 17 & 6.800 & 1 & 0.050 \\ 30 & 18 & 22 & 7.500 & 1 & 0.050 \\ 31 & 23 & 22 & 7.500 & 1 & 0.050 \\ 32 & 22 & 21 & 4.500 & 1 & 0.050\end{array}$

Produto: 4

Solução ótima

Arcos Origem Destino Capacidade Base Atraso

$\begin{array}{llllll}1 & 2 & 1 & 4.850 & 1 & 0.050 \\ 2 & 4 & 2 & 5.750 & 0 & 0.050 \\ 3 & 3 & 2 & 8.000 & 1 & 0.050 \\ 4 & 2 & 5 & 8.700 & 1 & 0.050 \\ 5 & 6 & 5 & 10.000 & 1 & 0.050 \\ 6 & 5 & 10 & 9.000 & 1 & 0.050 \\ 7 & 5 & 8 & 8.350 & 1 & 0.050 \\ 8 & 8 & 7 & 7.200 & 1 & 0.050 \\ 9 & 9 & 8 & 4.231 & 0 & 0.050 \\ 10 & 7 & 6 & 6.800 & 0 & 0.050 \\ 11 & 6 & 1 & 8.050 & 0 & 0.050 \\ 12 & 10 & 4 & 7.250 & 1 & 0.050\end{array}$




$\begin{array}{llllll}13 & 9 & 10 & 6.344 & 0 & 0.050 \\ 14 & 10 & 11 & 7.244 & 0 & 0.050 \\ 15 & 14 & 9 & 8.300 & 1 & 0.050 \\ 16 & 8 & 15 & 6.931 & 1 & 0.050 \\ 17 & 16 & 15 & 6.600 & 1 & 0.050 \\ 18 & 15 & 14 & 9.688 & 1 & 0.050 \\ 19 & 14 & 13 & 8.906 & 1 & 0.050 \\ 20 & 12 & 9 & 7.175 & 0 & 0.050 \\ 21 & 11 & 12 & 6.994 & 1 & 0.050 \\ 22 & 12 & 13 & 5.819 & 1 & 0.050 \\ 23 & 13 & 20 & 8.675 & 0 & 0.050 \\ 24 & 19 & 14 & 6.969 & 1 & 0.050 \\ 25 & 20 & 19 & 8.675 & 1 & 0.050 \\ 26 & 19 & 18 & 4.706 & 1 & 0.050 \\ 27 & 15 & 18 & 7.344 & 0 & 0.050 \\ 28 & 17 & 16 & 9.300 & 0 & 0.050 \\ 29 & 18 & 17 & 5.800 & 1 & 0.050 \\ 30 & 18 & 22 & 7.500 & 1 & 0.050 \\ 31 & 23 & 22 & 7.500 & 1 & 0.050 \\ 32 & 22 & 21 & 6.500 & 1 & 0.050\end{array}$

Produto: 5

Solução otima

Arcos Origem Destino Capacidade Base Atraso

$\begin{array}{llllll}1 & 2 & 1 & 5.525 & 1 & 0.050 \\ 2 & 4 & 2 & 5.750 & 0 & 0.050 \\ 3 & 3 & 2 & 8.250 & 1 & 0.050 \\ 4 & 2 & 5 & 8.525 & 1 & 0.050 \\ 5 & 6 & 5 & 9.625 & 0 & 0.050 \\ 6 & 5 & 10 & 9.200 & 1 & 0.050 \\ 7 & 5 & 8 & 8.450 & 1 & 0.050\end{array}$




$\begin{array}{llllll}8 & 8 & 7 & 6.200 & 0 & 0.050 \\ 9 & 9 & 8 & 4.231 & 0 & 0.050 \\ 10 & 7 & 6 & 7.400 & 1 & 0.050 \\ 11 & 6 & 1 & 6.875 & 1 & 0.050 \\ 12 & 10 & 4 & 6.750 & 1 & 0.050 \\ 13 & 9 & 10 & 7.844 & 1 & 0.050 \\ 14 & 10 & 11 & 7.244 & 0 & 0.050 \\ 15 & 14 & 9 & 8.400 & 1 & 0.050 \\ 16 & 8 & 15 & 7.231 & 1 & 0.050 \\ 17 & 16 & 15 & 5.700 & 1 & 0.050 \\ 18 & 15 & 14 & 8.045 & 0 & 0.050 \\ 19 & 14 & 13 & 8.406 & 1 & 0.050 \\ 20 & 12 & 9 & 7.675 & 1 & 0.050 \\ 21 & 11 & 12 & 6.494 & 1 & 0.050 \\ 22 & 12 & 13 & 5.719 & 0 & 0.050 \\ 23 & 13 & 20 & 8.675 & 0 & 0.050 \\ 24 & 19 & 14 & 5.862 & 1 & 0.050 \\ 25 & 20 & 19 & 7.175 & 1 & 0.050 \\ 26 & 19 & 18 & 4.063 & 0 & 0.050 \\ 27 & 15 & 18 & 5.987 & 0 & 0.050 \\ 28 & 17 & 16 & 9.800 & 1 & 0.050 \\ 29 & 18 & 17 & 6.800 & 1 & 0.050 \\ 30 & 18 & 22 & 8.500 & 1 & 0.050 \\ 31 & 23 & 22 & 7.000 & 1 & 0.050 \\ 32 & 22 & 21 & 5.000 & 1 & 0.050\end{array}$

Produto: 6

Solução ótima

Arcos Origem Destino Capacidade Base Atraso

$$
\begin{array}{llllll}
1 & 2 & 1 & 6.225 & 1 & 0.050 \\
2 & 4 & 2 & 7.650 & 1 & 0.050
\end{array}
$$




$\begin{array}{llllll}3 & 3 & 2 & 7.500 & 1 & 0.050 \\ 4 & 2 & 5 & 8.325 & 0 & 0.050 \\ 5 & 6 & 5 & 9.625 & 0 & 0.050 \\ 6 & 5 & 10 & 8.200 & 0 & 0.050 \\ 7 & 5 & 8 & 8.750 & 1 & 0.050 \\ 8 & 8 & 7 & 6.700 & 1 & 0.050 \\ 9 & 9 & 8 & 5.706 & 1 & 0.050 \\ 10 & 7 & 6 & 6.800 & 0 & 0.050 \\ 11 & 6 & 1 & 6.175 & 1 & 0.050 \\ 12 & 10 & 4 & 6.050 & 1 & 0.050 \\ 13 & 9 & 10 & 6.494 & 1 & 0.050 \\ 14 & 10 & 11 & 7.244 & 0 & 0.050 \\ 15 & 14 & 9 & 7.800 & 0 & 0.050 \\ 16 & 8 & 15 & 7.306 & 1 & 0.050 \\ 17 & 16 & 15 & 6.400 & 1 & 0.050 \\ 18 & 15 & 14 & 8.357 & 0 & 0.050 \\ 19 & 14 & 13 & 7.406 & 0 & 0.050 \\ 20 & 12 & 9 & 7.300 & 0 & 0.050 \\ 21 & 11 & 12 & 6.844 & 1 & 0.050 \\ 22 & 12 & 13 & 6.344 & 1 & 0.050 \\ 23 & 13 & 20 & 9.800 & 1 & 0.050 \\ 24 & 19 & 14 & 7.299 & 1 & 0.050 \\ 25 & 20 & 19 & 7.300 & 1 & 0.050 \\ 26 & 19 & 18 & 5.001 & 1 & 0.050 \\ 27 & 15 & 18 & 6.299 & 1 & 0.050 \\ 28 & 17 & 16 & 9.300 & 0 & 0.050 \\ 29 & 18 & 17 & 5.300 & 1 & 0.050 \\ 30 & 18 & 22 & 8.500 & 1 & 0.050 \\ 31 & 23 & 22 & 8.500 & 1 & 0.050 \\ 32 & 22 & 21 & 6.500 & 1 & 0.050\end{array}$


Fluxo de Entrada do Produto 1: 2.000

Solução Factível Final do Produto 1:

0.6000 .8500 .7500 .0000 .0000 .0000 .7500 .4001 .6500 .1000 .0000 .3500 .6002 .0001 .100 $1 . 5 0 0 \longdiv { 1 . 0 0 0 } 0 . 0 0 0 0 . 0 0 0 1 . 4 0 0 0 . 0 0 0 0 . 1 0 0 0 . 0 0 0 0 . 0 0 0 0 . 0 0 0 1 . 5 0 0 1 . 5 0 0 0 . 0 0 0 0 . 0 0 0 0 . 5 0 0$ 0.0000 .000

Fluxo de Entrada do Produto 2: 1.500

Solução Factível Final do Produto 2:

0.7501 .5000 .5000 .3500 .0000 .0000 .0001 .0000 .8001 .5000 .2500 .0000 .5000 .0000 .000 0.0500 .0000 .0000 .0000 .8002 .0001 .7000 .2000 .0000 .9501 .7000 .0000 .2001 .2000 .000 0.5001 .000

Fluxo de Entrada do Produto 3: 1.000

Solução Factível Final do Produto 3:

0.5000 .0000 .0000 .7500 .0000 .0000 .4000 .9001 .8441 .0000 .0000 .9000 .9060 .7560 .000 0.8441 .5000 .0000 .0940 .0000 .6560 .7560 .0001 .0940 .2501 .1560 .8440 .0001 .5000 .000 0.5000 .000

Fluxo de Entrada do Produto 4: 0.500

Solução Factível Final do Produto 4:

$0.6250 .0000 .5000 .3750 .3750 .8000 .0001 .0000 .0000 .0002 .375 \quad 1.6000 .0000 .0000 .500$ 0.0001 .0001 .6431 .5000 .0000 .5000 .6000 .0001 .3571 .5000 .6431 .3570 .0000 .5000 .000 0.5002 .000

Fluxo de Entrada do Produto 5: 1.000

Solução Factível Final do Produto 5:

$1.3000 .0000 .7500 .2000 .0001 .0000 .1000 .000-0.0000 .6001 .2001 .1001 .5000 .0000 .600$ 0.3000 .1000 .0001 .0000 .5000 .0000 .5000 .0000 .2500 .0000 .0000 .0000 .5001 .5001 .000 0.0000 .500 
Fluxo de Entrada do Produto 6: 0.750

Solução Factível Final do Produto 6:

2.0001 .9000 .0000 .0000 .0000 .0000 .4000 .5001 .4750 .0000 .5000 .4000 .1500 .0000 .000

0.3750 .8000 .3120 .0000 .1250 .3501 .1251 .1251 .6880 .1250 .9380 .3120 .0000 .0001 .000

1.5002 .000

Função para a Solução Final: Ff = 21.064026

Número de Iteraçōes: 12

Tempo de Execução Total: 0.02 Seg.

OBS: Este arquivo de saída é do programa executado no SP2 em um só processador. A única diferença entre os arquivos de saída, dos programas paralelo e sequiencial, é que no paralelo as soluçōes não saem em ordem (uma vez que os processos escravos possuem tempo de resposta diferenciados) e no sequiencial sim. 